\title{
ACTN2 missense variant causes proteopathy in human iPSC-derived cardiomyocytes
}

Antonia T. L. Zech ${ }^{1,2^{\star}}$, Maksymilian Prondzynski ${ }^{1,2,3^{*}}$, Sonia R. Singh ${ }^{1,2}$, Ellen Orthey ${ }^{1,2}$, Erda Alizoti ${ }^{1,2}$, Josefine Busch ${ }^{1,2}$, Alexandra Madsen ${ }^{1,2}$, Charlotta S. Behrens ${ }^{1,2}$, Giulia Mearini ${ }^{1,2}$, Marc D. Lemoine ${ }^{1,2,4}$, Elisabeth Krämer $^{1,2}$, Diogo Mosqueira ${ }^{5}$, Sanamjeet Virdi ${ }^{6}$, Daniela Indenbirken ${ }^{6}$, Maren Depke ${ }^{7}$, Manuela Gesell Salazar ${ }^{7}$, Uwe Völker ${ }^{7,8}$, Ingke Braren ${ }^{9}$, William T. Pu ${ }^{3,10}$, Thomas Eschenhagen ${ }^{1,2}$, Elke Hammer ${ }^{7,8}$, Saskia Schlossarek ${ }^{1,2}$, Lucie Carrier ${ }^{1,2^{*} \#}$

${ }^{1}$ Institute of Experimental Pharmacology and Toxicology, University Medical Center Hamburg-Eppendorf, Hamburg, Germany;

${ }^{2}$ DZHK (German Centre for Cardiovascular Research), partner site Hamburg/Kiel/Lübeck, Hamburg, Germany;

${ }^{3}$ Department of Cardiology, Boston Children's Hospital, Harvard Medical School, Boston, USA;

${ }^{4}$ Department of Cardiology, University Heart and Vascular Center, Hamburg, Germany;

${ }^{5}$ Biodiscovery Institute, University of Nottingham, Nottingham, United Kingdom;

${ }^{6}$ Heinrich-Pette-Institute, Leibniz Institute for Experimental Virology, Hamburg, Germany;

${ }^{7}$ Department for Functional Genomics, Interfaculty Institute for Genetics and Functional Genomics, University Medicine Greifswald, Greifswald, Germany;

${ }^{8}$ DZHK (German Centre for Cardiovascular Research), partner site Greifswald, Greifswald, Germany;

${ }^{9}$ Vector facility, University Medical Center Hamburg-Eppendorf, Hamburg, Germany; ${ }^{10}$ Harvard Stem Cell Institute, Cambridge, USA.

\section{Running title: Missense ACTN2 variant causes proteopathy}

${ }^{*}$ These authors contributed equally.

\#Corresponding author: Lucie Carrier, PhD, Institute of Experimental Pharmacology and Toxicology, University Medical Center Hamburg-Eppendorf, Hamburg, Germany, Martinistrasse 52, 20246 Hamburg, Germany, Phone: +49-40-7410-57208; Email: I.carrier@uke.de 


\section{Abstract}

Rationale: Genetic variants in ACTN2, encoding a-actinin 2 (ACTN2), are associated with several forms of (cardio)myopathy in the heterozygous state, and can cause progressive, severe cardiomyopathy in the homozygous state. We previously reported a heterozygous missense (c.740C>T) ACTN2 variant, associated with hypertrophic cardiomyopathy (HCM), which induced an electro-mechanical phenotype in human induced pluripotent stem cell-derived cardiomyocytes (hiPSC-CMs).

Objective: To evaluate the impact of heterozygosity and homozygosity of the c.740C > T ACTN2 variant on cardiomyocyte structure and function.

Methods and Results: Next to the previously established hiPSC line carrying the heterozygous ACTN2 variant (ACTN2het), we created a homozygous line (ACTN2hom) with CRISPR/Cas9. Differentiation into cardiomyocytes revealed myofibrillar disarray, increased cell area and volume, multinucleation, and ACTN2 aggregates in mutant hiPSC-CMs. Live cell imaging in hiPSC-CMs showed an inverse correlation between sarcomeric incorporation and aggregation of exogenously expressed mutant ACTN2. RNA-seq and proteomic analyses showed alteration of several canonical pathways involved in metabolism, oxidative and cellular stress, and proteostasis, including the ubiquitin-proteasome system (UPS) and autophagylysosomal pathway (ALP) in mutant hiPSC-CMs. Detailed evaluation of the UPS and ALP, including a high-content screening with a mWasabi-mTagRFP-hLC3 tandem construct, revealed a global activation of these systems in mutant hiPSC-CMs. The ACTN2 missense variant caused allele dose-dependent and -independent effects on several cardiomyocyte features. ACTN2hom exhibited markedly lower levels of sarcomere-associated proteins, and hypocontractility in engineered heart tissues, resembling a dilated cardiomyopathy phenotype.

Conclusion: This study showed allele dose-independent effects of the ACTN2 variant on multinucleation, ACTN2 aggregation, and UPS activation, and allele dosedependent effects of the variant on cellular hypertrophy, myofibrillar disarray, and ALP activation. Activation of the proteolytic systems is likely to cope with ACTN2 aggregation. Our data indicates proteopathy as an additional cellular feature caused by the c.740C>T ACTN2 variant, which may contribute to human ACTN2-associated inherited cardiomyopathy. 


\section{Introduction}

$\alpha$-Actinin-2 (ACTN2) is a component of the sarcomere of skeletal and cardiac myocytes, which forms anti-parallel homodimers that can anchor and crosslink actin thin filaments to the Z-disk (for reviews, see ${ }^{1,2}$ ). Additionally, ACTN2 is implicated in assembling large protein complexes for structural integrity, mechanotransduction and cell signaling (for reviews, see ${ }^{3-5}$ ).

Genetic variants in ACTN2 are associated in the heterozygous state with common inherited cardiac diseases, which are hypertrophic (HCM), dilated (DCM), and restrictive (RCM) cardiomyopathy., 6-9 Although considered as a rare disease gene, ${ }^{10}$ recent reports showed the association of homozygous ACTN2 variants with core myopathy, ${ }^{11}$ or progressive, severe $\mathrm{RCM}^{8}{ }^{8}$ In addition, it was shown that heterozygous ACTN2 variants have critical effects on structure and function of the cardiac muscle. ${ }^{12,13}$ We recently demonstrated that a heterozygous HCM missense ACTN2 variant induced an electro-mechanical phenotype in human induced pluripotent stem cell-derived cardiomyocytes (hiPSC-CMs). ${ }^{6}$ The molecular mechanisms by which missense ACTN2 variants lead to different forms of (cardio)myopathy is not fully understood. It is assumed that mutant transcripts are translated into mutant proteins, which are expected to have a dominant-negative effect on sarcomere structure and/or function. However, mutant proteins can also be misfolded and targeted towards the ubiquitin-proteasome-system (UPS) for degradation or can form aggregates, causing cellular proteopathy if not targeted towards the autophagy-lysosomal pathway (ALP). ${ }^{14-16}$ Protein aggregation was associated with a high risk of sudden cardiac death in HCM patients carrying a filamin C (FLNC) variant. ${ }^{17}$ Additionally, alterations of the UPS and ALP were observed in septal myectomies of HCM patients harboring MYBPC3 mutations. ${ }^{18,19}$ Furthermore, several modulators of protein quality control systems, including heat shock proteins, are more abundant in $\mathrm{HCM}$ than in non-failing heart samples. ${ }^{20,} 21$ Finally, gene transfer of mutant MYBPC3 in neonatal rat cardiomyocytes resulted in protein aggregates and UPS impairment. ${ }^{22,23}$ These studies provided evidence that alterations of proteolytic quality control systems are common in HCM.

In this study, we evaluated the impact of heterozygosity and homozygosity of the missense (c.740C>T; p.Thr247Met) ACTN2 variant on cellular structure and function in hiPSC-CMs, using a combination of different technologies, including 
immunofluorescence and live cell imaging, RNA-seq and mass-spectrometry (MS) analyses. Our data showed (1) allele dose-independent effects of the variant on multinucleation, ACTN2 aggregation, and UPS activation, (2) allele dose-dependent effects of the variant on hypertrophy, myofibrillar disarray, and ALP activation, and (3) a marked reduction of sarcomere-associated protein levels and force impairment in the homozygous state. Our data indicate proteopathy as an additional cellular feature caused by the missense ACTN2 variant, which may contribute to human ACTN2associated cardiomyopathy.

\section{Methods}

Data sets, analysis and study materials will be made available on request to other researchers for purposes of reproducing the results or replicating the procedures. The full description of materials and methods and the major resources tables are provided in the Supplement. All data of OMICs experiments have been made publicly available. The mass spectrometry (MS) data have been deposited to the ProteomeXchange Consortium via the PRIDE partner repository with the dataset identifier PCD029211. The RNA-seq data have been deposited to the European Nucleotide Archive (ENA) at EMBL-EBI under accession number PRJEB48371.

\section{Generation and culture of hiPSC-CMs in 2D and EHT formats}

Cultivation, CRISPR/Cas9 gene editing, and differentiation of hiPSC lines into CMs were as previously described. ${ }^{6}$ A detailed methodology is provided in the Supplement.

\section{Morphological analysis of 2D-cultured hiPSC-CMs}

Quantification of myofibrillar disarray and cell area was evaluated with Fiji (ImageJ) as described previously. ${ }^{6,24}$ Detailed information for ACTN2 protein aggregate analysis and hiPSC-CMs volume measurement is provided in the Supplement.

\section{Production and purification of adeno-associated virus vector particles}

The production and purification of adeno-associated virus serotype 6 (AAV6) vector particles carrying the mTagRFP-mWasabi-hLC3 tandem construct and the wild-type 
(WT)- or mutant (Mut)-ACTN2-HaloTag® was adapted from a recent publication. ${ }^{25} \mathrm{~A}$ detailed protocol is provided in the Supplement.

\section{Proteome analysis}

Sample preparation $(n=$ pool of 2-3 biological replicates per batch from 3 independent differentiation batches), protein digestion, and liquid chromatography-tandem MS were performed as described previously. ${ }^{25,} 26$ Detailed information is provided in the Supplement.

\section{High-content imaging of autophagy-lysosomal pathway in hiPSC-CMs}

A high-content screen for ALP activity was performed in 2D-cultured hiPSC-CMs transduced with an AAV6 encoding the mTagRFP-mWasabi-hLC3 tandem construct under the control of human TNNT2 promoter. Chemical properties of the tandem construct were utilized to visualize mWasabi quenching in the acidic environment of autolysosomes (ALs). In this assay, green puncta correspond to autophagosomes (APs), red puncta to APs plus ALs, and the difference between red and green puncta (=red minus green puncta) to ALs. After 30 days of culture, hiPSC-CMs were fixed, stained with a cardiac troponin T antibody (TNNT2, 1:500; ab45932) and with Hoechst 33342 for nuclei staining ( $1 \mathrm{\mu g} / \mathrm{mL}$; Thermo Fisher Scientific, Waltham, MA, USA), and imaged with the Operetta high-content imaging system (PerkinElmer, Nottingham, UK). Subsequent image analysis was performed with the Harmony high-content imaging analysis software (PerkinElmer, Nottingham, UK) by identifying TNNT2+ cells and quantifying green and red puncta (number and intensity). A detailed method is described in the Supplement.

\section{Statistics}

Group data are presented as mean \pm SEM. GraphPad Prism 9 (GraphPad Software, San Diego, CA, USA) was used for data analysis. Curves were fitted to data points from individual experiments. All data were compared using nested t-tests when appropriate, for more than two groups one-way ANOVA followed by Dunett's or Tukey's post-test, and for more than two groups plus treatment two-way ANOVA followed by Tukey's post-test if not indicated differently. Chi-square analysis was performed for multinucleation and integration/aggregation analysis, whereby each data set was compared to ACTN2ic using "compare observed distribution with 
expected" and the Wilson/Brown method. A mixed-effects analysis plus Sidak's posttest was performed when pooled batches of two cell lines were analyzed over a timeline. For not normally distributed datasets, the Mann-Whitney test was used when two groups were compared, and the Kruskal-Wallis test followed by Dunn's post-test when three groups were compared. A $P$-value $<0.05$ was considered as statistically significant.

\section{Results}

\section{ACTN2het and ACTN2hom 2D-cultured hiPSC-CMs display hypertrophy, myofibrillar disarray, multinucleation, and protein aggregation}

The patient-specific cell line ACTN2het and its isogenic control (ACTN2ic) were thoroughly characterized in an earlier study. ${ }^{6}$ ACTN2hom line was derived from ACTN2het hiPSCs using CRISPR/Cas9 gene editing (Figure S1A). The three hiPSC lines presented a normal karyotype (Figure S1B), and were therefore differentiated to hiPSC-CMs according to our disease modeling protocol (Figure S1C). ${ }^{6}$ HiPSC-CMs were produced with high purity (on average $>90 \%$ TNNT2+) and quantity (Figure S2).

All hiPSC-CM lines were evaluated for ACTN2 abundance and localization, myofibrillar disarray, cellular hypertrophy and multinucleation. Immunofluorescence analysis revealed a cross-striated pattern of TNNT2 in all hiPSC-CM lines, indicating proper formation of sarcomeres (Figure 1A). However, ACTN2 was less organized and formed aggregates in both mutant lines when compared to ACTN2ic hiPSC-CMs. Quantification revealed a higher index of myofibrillar disarray and more ACTN2 aggregates in mutant hiPSC-CMs (Figure 1B, 1C). Further, cell area and volume were higher in both ACTN2het and ACTN2hom than in ACTN2ic hiPSC-CMs (Figure 1D, $1 \mathrm{E})$. Finally, the percentage of multinucleated hiPSC-CMs (>1 nucleus) was higher in mutant ACTN2 than in ACTN2ic. Mononucleated-to-multinucleated ratio was 80:20 in ACTN2ic hiPSC-CMs, supporting previous estimation obtained in human hearts, ${ }^{27}$ whereas it was lower in both ACTN2het (40:60), as reported in other HCM hiPSC$\mathrm{CMs}^{28}$ and in ACTN2hom (53:47; Figure 1F). These data revealed several HCM features in mutant ACTN2 hiPSC-CMs, in an allele dose-dependent (myofibrillar disarray and cell volume) or dose-independent (multinucleation, cell area and ACTN2 aggregates) manner. Immunoblotting showed that ACTN2 protein level did not differ 
between ACTN2het and ACTN2ic and was markedly lower in ACTN2hom hiPSC-CMs (Figure S3A, S3B).

\section{Exogenous mutant ACTN2 shows lower Z-disk integration and higher ACTN2 aggregate formation than exogenous wild-type ACTN2 in hiPSC-CMs}

To determine if mutant ACTN2 is responsible for the observed sarcomere alterations, the impact of exogenous WT and Mut ACTN2 on sarcomere structure was evaluated in living, 2D-cultured hiPSC-CMs. Therefore, ACTN2ic, ACTN2het, and ACTN2hom hiPSC-CMs were transduced with AAV6 encoding either the WT (c.740C) or Mut (c.740T) ACTN2 fused to a HaloTag ${ }^{\circledR}$ and seeded in 96-well plates. After 7 days of culture, live-cell imaging experiments were performed by staining ACTN2-HaloTag protein using TMR-ligand in combination with Hoechst. Exogenous WT- and MutACTN2 exhibited a distinct striation pattern in $\sim 80 \%$ and $\sim 20 \%$ of hiPSC-CMs in all groups, respectively (Figure 2A-2C; Movies 1, 2). Quantification of acquired live cell images for ACTN2 aggregates revealed larger aggregates in all cell lines transduced with Mut-ACTN2 than with WT-ACTN2 (Figure 2D).

We then performed immunofluorescence analysis of hiPSC-CMs transduced with WT- or Mut-ACTN2 and stained with antibodies directed against the HaloTag® for exogenous ACTN2, and ACTN2 for both endogenous and exogenous ACTN2 (= total ACTN2). Exogenous WT-ACTN2 was co-stained with total ACTN2 in hiPSC-CMs of the three groups, confirming Z-disk integration (Figure S4A). In contrast, exogenous Mut-ACTN2 was less abundant, exhibited co-localization with total ACTN2 in some parts, and formed aggregates predominantly around the nucleus in all hiPSC-CM lines (Figure S4B).

\section{ACTN2het and ACTN2hom hiPSC-CMs exhibit common and divergent alterations of canonical pathways}

To understand underlying molecular changes caused by the ACTN2 mutation, MS was performed in 2D-cultured hiPSC-CMs. Three biological replicates of each iPSC-CM line were pooled, and 3 batches of differentiation were analyzed. Volcano plots depict 98 (33 higher, 65 lower) and 481 (250 higher, 231 lower) dysregulated proteins in ACTN2het and ACTN2hom vs. ACTN2ic, respectively (Figure 3A, 3B). In addition, the Venn diagram indicates that 49 are dysregulated in both ACTN2het and ACTN2hom (Figure 3C). Ingenuity Pathway Analysis (IPA) revealed similarities and differences in 
dysregulated canonical pathways, diseases, and biological functions between ACTN2het and ACTN2hom when compared to ACTN2ic (Figure 3D, 3E; Data Set I, III). ACTN2het and ACTN2hom shared common pathways, such as mitochondrial dysfunction and disorder, hereditary myopathy, and dysregulation of mRNA stability and translation. ACTN2het specifically exhibited dysregulation of proteins involved in metabolism, oxidative and cellular stress response, whereas ACTN2hom showed specific dysregulation of pathways involved in sarcomere function and proteostasis, such as the UPS and ALP. Since both sarcomere function and proteostasis pathways were highly dysregulated in ACTN2hom, we performed a deeper analysis of proteomic data. The protein levels of ACTN2, several other sarcomere-associated proteins (e.g. ACTC1, MYBPC3, MYL2, MYH7, TNNC1, TNNI3) and desmosomal proteins (JUP, PKP2) were markedly lower in ACTN2hom hiPSC-CMs (Figure 3F; Tables S1, S2). Some of these proteins (FLNC, MYOZ2, NEBL, SYNPO2, SYNPO2L, TTN) are known to interact directly with ACTN2. ${ }^{29-31}$ Interestingly, FHL1 and FHL2, located at the Zband of the sarcomere, ${ }^{32,33}$ were more abundant in both ACTN2het and ACTN2hom, whereas the levels of SYNPO2 and SYNPOL were in the opposite direction. Conversely, several proteins associated with the UPS and/or ALP (e.g. BAG3, GBA, HSPA1A, PSMA3, PSMA6, PSMB5, PSME2, TRIM54, UBA1, UBE2O, UBQLN2) were more abundant in ACTN2hom, but not ACTN2het, except CTSC, which was higher in both mutant hiPSC-CMs (Figure 3G; Tables S3, S4).

We then performed RNA-seq on 3 biological replicates of each iPSC-CM line that were pooled, and we compared 3 cardiac differentiation batches. Volcano plots and Venn diagram of RNA-seq data showed 1005 (445 higher, 560 lower) and 344 (164 higher, 180 lower) dysregulated mRNAs in ACTN2het and ACTN2hom vs. ACTN2ic, respectively (Figure S5A, S5B). Out of them, 36 were dysregulated in both ACTN2het and ACTN2hom (Figure S5C). IPA analysis revealed common and several different dysregulated canonical pathways, diseases, and biological functions in ACTN2het and ACTN2hom when compared to ACTN2ic (Figure S5D, S5E; Data Set II, IV). Both ACTN2het and ACTN2hom revealed dysregulation in signaling of actin cytoskeleton and cardiac hypertrophy. ACTN2het specifically exhibited dysregulated genes, encoding proteins involved in cardiac hypertrophy, cardiomyopathy, heart contraction, Long-QT syndrome and sudden cardiac death, supporting our previous findings. ${ }^{6}$ ACTN2hom showed specific dysregulation of genes, encoding proteins involved in metabolism, hypoxia, oxidative and cellular stress, autophagy, and cellular 
remodeling. RNA-seq did not reveal differential expression of genes encoding sarcomere-associated proteins, except MYH6 upregulation, in ACTN2hom when compared to ACTN2ic, whereas many of these genes, including ACTN2, were upregulated in ACTN2het hiPSC-CMs (Figure S5F; Tables S1, S2). These data were confirmed by RNA count analysis using the nanoString nCounter® Elements technology (Figure S3C). RNA-seq also revealed dysregulation of several genes, encoding proteins involved in the UPS and ALP in both ACTN2het and ACTN2hom hiPSC-CMs (Figure S5F, S5G; Tables S3, S4).

Taken together, Omics analysis supported experimental findings for structural sarcomere abnormalities in mutant hiPSC-CMs and suggested alterations in pathways such as cellular stress response, cell survival/apoptosis or protein homeostasis, which directly point towards proteopathy as an important disease feature.

\section{Mutant ACTN2 hiPSC-CMs exhibit higher activities of the ubiquitin-proteasome system and autophagy-lysosomal pathway}

Higher abundance of several UPS- and/or ALP-associated proteins in ACTN2hom hiPSC-CMs and presence of ACTN2 aggregates in both mutant ACTN2 hiPSC-CMs suggested an altered proteostasis. Therefore, the activity of both systems was evaluated in 2D-cultured hiPSC-CMs. To evaluate the UPS, cells were treated either with vehicle (0.05\% DMSO) or the UPS inhibitor epoxomicin (250 nM; Figure 4A-4D). In basal DMSO condition, the levels of (poly)ubiquitinated proteins and of their shuttle protein for autophagy-mediated degradation SQSTM1 did not differ between cell lines, whereas the ACTN2 level was lower in ACTN2hom than ACTN2ic, reproducing our findings (Figure 3F; Figure S3A, S3B). Epoxomicin treatment induced a marked accumulation of (poly)ubiquitinated proteins and SQSTM1 in all hiPSC-CMs (Figure $4 \mathrm{~A}-4 \mathrm{C})$, validating the efficacy of the treatment. In contrast, epoxomicin did not increase the level of ACTN2 in any cell line, indicating that ACTN2 was not degraded by the UPS in this experimental condition (Figure 4A, 4D). On the other hand, the chymotrypsin-like activity of the proteasome was markedly higher in both ACTN2het and ACTN2hom than in ACTN2ic hiPSC-CMs (Figure 4E), suggesting UPS activation.

To evaluate the ALP, the autophagic flux was measured in hiPSC-CMs after treatment with either DMSO (0.05\%; vehicle) or bafilomycin A1 (50 nM; late-stage ALP inhibitor; Figure 4F, 4G). The level of microtubule-associated protein 1 light chain 3bII (LC3-II) did not differ between genotypes in basal conditions. Treatment with 
bafilomycin A1 markedly increased LC3-Il levels in all groups (Figure 4G). The difference in LC3-II level between bafilomycin-treated and DMSO-treated samples, which represents the autophagic flux, increased in an allele dose-dependent manner (difference in fold change, ACTN2ic: 2.60, ACTN2het: 2.72, ACTN2hom: 3.36). On the other hand, bafilomycin A1 did not increase ACTN2 levels (Figure 4H), implying that ACTN2 is not degraded by the ALP. To support the autophagic flux data, we performed a high-content screen in all hiPSC-CMs lines transduced with an AAV6 encoding mWasabi-mTagRFP-hLC3 under the control of the TNNT2 promoter. After 30 days of culture, hiPSC-CMs were fixed and immunostained for TNNT2 and Hoechst to ensure imaging of (solely) cardiomyocytes (>80\% TNNT2+; Figure S6). The signal intensity of red puncta, and to a lower extent of the green puncta, was reduced in mutant ACTN2 hiPSC-CMs (Figure S7, S8A, S8B). The number of green and red puncta was quantified in hiPSC-CMs using an unbiased and statistically powerful method, whereby the number of puncta was normalized to the number of cardiomyocytes per well. The number of red puncta per hiPSC-CM did not differ between lines, whereas the number of green puncta per hiPSC-CM was markedly lower in mutant ACTN2 lines (Figure S8C, S8D). The utilization of the LC3-tandem-construct allows determining APs and ALs, since the green fluorescence (mWasabi) is susceptible to low $\mathrm{pH}$ and hence quenched within ALs. Therefore, green puncta correspond to APs, red puncta to APs plus ALs, and the difference between red and green puncta (=red minus green puncta) to ALs. ACTN2ic hiPSC-CMs exhibited a similar number of APs and ALs per hiPSC-CM (Figure 4I), suggesting a steady-state autophagic flux. In contrast, the AP number per hiPSC-CM was markedly, and to the same extent, lower in both ACTN2het and ACTN2hom than in ACTN2ic hiPSC-CMs, whereas the AL number per hiPSC-CM was higher in an allele dose-dependent manner in mutant lines (Figure 4I). The combination of low AP number and high AL number supports the view of an activation of autophagy, particularly at the step of fusion of APs with lysosomes to form autolysosomes in mutant hiPSC-CMs.

Taken together, these data showed higher activities of both protein degradation systems in 2D-cultured mutant ACTN2 hiPSC-CMs, most likely to eliminate protein aggregates causing proteopathy. 


\section{ACTN2hom hiPSC-CMs exhibit faster kinetics and hypocontractility in EHTs}

The low abundance of several sarcomere-associated proteins in ACTN2hom hiPSCCMs (Figure $3 \mathrm{E}$ ) suggested an impairment of contractile function. We therefore assessed force amplitude and kinetics of the ACTN2hom in 3D EHTs after 30 days (Figure 5A, 5B). Unpaced ACTN2hom EHTs developed significantly lower force starting from day 9 onwards than ACTN2ic EHTs (Figure S9A). Beating frequency was significantly higher in ACTN2hom than in ACTN2ic EHTs (50 vs. 28 beats per minute from day 21 on, respectively: Figure S9B). To compare functional parameters independent of variable baseline frequencies, EHTs were subjected to electrical pacing at $1 \mathrm{~Hz}$ (Movies 3, 4). Contraction traces of EHTs showed markedly lower force in ACTN2hom than ACTN2ic EHTs (Figure 5C, 5D). Normalized averaged force exhibited $19 \%$ shorter time to peak (TTP -80\%; Figure 5E, 5F) and 25\% shorter relaxation time (RT 80\%; Figure 5E, 5G) in ACTN2hom EHTs. Similar results were obtained at 1.5 and $2 \mathrm{~Hz}$ (data not shown). Overall, ACTN2hom EHTs presented a significantly lower force and faster kinetics, which can be explained by the marked deficiency of sarcomere-associated proteins detected in 2D-cultured hiPSC-CMs, which was also found by MS in EHTs (Table S5).

\section{Discussion}

This study investigated the allele dose-dependent cellular and functional consequences of an ACTN2 missense variant (c.740C>T; p.Thr247Met) in hiPSCCMs, revealing hallmarks of HCM, ACTN2 aggregation, and activation of protein degradation pathways. Shared HCM phenotypes between heterozygous and homozygous ACTN2 mutants comprised myofibrillar disarray, hypertrophy and multinucleation, ${ }^{6,8,24,28,34}$ ACTN2 aggregation, ${ }^{12}$ and dysregulated pathways involved in mRNA stability and translation, mitochondrial function, and signaling of actin cytoskeleton and cardiac hypertrophy. In addition, divergent disease mechanisms were underlined such as the opposite abundance of the ACTN2-interacting partners SYNPO2 and SYNPO2L, and a specific low abundance of several sarcomereassociated proteins in ACTN2hom EHTs. This study showed (i) allele doseindependent effects of the ACTN2 variant on multinucleation, ACTN2 aggregation, and UPS activation, (ii) allele dose-dependent effects of the variant on cellular hypertrophy, 
myofibrillar disarray, and ALP activation, and (iii) a marked reduction of sarcomereassociated protein levels and force impairment in ACTN2hom, suggesting reduced sarcomerogenesis or sarcomere homeostasis. Overall, these results indicate proteopathy as an additional cellular feature caused by the ACTN2 variant.

We reproduced previous disease modeling findings in 2D-cultured ACTN2het hiPSC-CMs, such as hypertrophy and myofibrillar disarray. ${ }^{6}$ Specific dysregulation of pathways involved in metabolism, oxidative phosphorylation, and cellular stress response in ACTN2het hiPSC-CMs, ${ }^{35}$ combined with previously reported hypercontractility and abnormal relaxation in EHTs, ${ }^{6}$ validates this model as a typical HCM human cellular model. In contrast, ACTN2hom hiPSC-CMs exhibited dysregulation of pathways involved in sarcomere function, cellular remodeling and proteostasis, and ACTN2hom EHTs exhibited hypocontractility and faster kinetics, resembling a DCM phenotype. ${ }^{36-39}$ This is in line with the low abundance of several sarcomeric proteins, including ACTN2 in ACTN2hom hiPSC-CMs, leading to a poorly developed sarcomere and possibly to a more immature cardiomyocyte state. In addition, SYNPO2 and SYNPO2L, which contribute to early assembly and stabilization of the Z-disk via interaction with filamin and $\alpha$-actinin, ${ }^{29,} 36$ were also less abundant, supporting disruption of the ACTN2 interactome and deficient sarcomere development in ACTN2hom hiPSC-CMs. The reduced Z-disk integration of exogenous Mut ACTN2 combined with myofibrillar disarray in all hiPSC-CMs by live cell imaging supports the susceptibility of mutant ACTN2 to aggregate. The inverse correlation between sarcomere incorporation and aggregation of exogenously expressed mutant ACTN2 suggests that non-incorporated mutant proteins form aggregates and contribute to the low level of ACTN2 protein in ACTN2hom hiPSC-CMs. Previous analysis of the dynamic behavior of two ACTN2 missense variants (p.Ala119Thr and p.Gly111Val), which are also located in the calponin-homology domain, revealed similar phenotypes. $^{12}$ Both mutants exhibited reduced binding affinities to F-actin by biochemical assays and alterations of Z-disk localization and dynamic behavior after gene transfer of mEos2-tagged ACTN2 in adult cardiomyocytes. Taken together, these data are in agreement with previous descriptions of protein aggregation in heart sections of both human $\mathrm{HCM}$ patients ${ }^{40}$ and a mouse model of $\mathrm{HCM},{ }^{41}$ after gene transfer of HCM-causing mutant MYBPC3 in cardiomyocytes, ${ }^{22,} 23$ and in human and mouse models of desmin-related (cardio)myopathy. ${ }^{42}$ 
Functional deficits found in ACTN2hom EHTs are in line with a recent disease modeling study that investigated the p.Arg14del variant in phospholamban (PLN). ${ }^{38}$ The authors showed activation of the unfolded protein response as a compensatory, protective mechanism in the setting of PLN-caused hypocontractility in hiPSC-CMs and EHTs. These findings are further supported by the evidence of PLN protein aggregates in a p.Arg14del mouse model. ${ }^{43}$ Interestingly, PLN aggregates and altered protein homeostasis pathways were observed before the onset of functional deficits. The higher levels of several proteins involved in proteostasis such as the UPS and ALP in mutant ACTN2 hiPSC-CMs found in this study are in agreement with previous findings in HCM septal myectomies. ${ }^{20}$ This was associated with a higher chymotrypsinlike activity of the proteasome and global activation of the ALP in mutant ACTN2 hiPSC-CMs. Even though others have shown that WT ACTN2 is degraded by the UPS, ${ }^{44}$ the low ACTN2 protein level detected by Western blot and proteomic analysis in the homozygous mutant line was neither degraded by the UPS nor by the ALP. This suggests that the global activation of both the UPS and ALP are rather compensatory, protective mechanisms for ACTN2 aggregation. ${ }^{39}$ The low abundance of ACTN2 and of several other sarcomeric proteins likely reflects a reduced mRNA translation and protein incorporation into myofilament to maintain the overall stoichiometry of the sarcomere. ${ }^{45}$ This might explain the poor and reduced formation of sarcomeres in ACTN2hom hiPSC-CMs. Alteration of Z-disk protein turnover combined with subsequent activation of autophagy has been recently reported in hiPSC-CMs carrying heterozygous FLNC variants (p.Gly1674X; p.Val1668_Gly1674del) resulting either in haploinsufficiency or misfolded protein. ${ }^{46}$ These data emphasized the disease-causing role of proteotoxicity in FLNC-related cardiomyopathies and presumed its therapeutic potential.

To date, there is only one preprint investigating a homozygous truncating ACTN2 variant (p.GIn860Stop) associated with $\mathrm{RCM}$ in mutant carriers. ${ }^{8}$ Corresponding hiPSC-CMs displayed hypertrophy, impaired contractility, and myofibrillar disarray. In contrast to our findings, the authors detected higher levels of ACTN2 mRNA without altered levels of ACTN2 protein. However, because of the Cterminal truncation, the authors suggested loss of protein-protein interaction as the main cause for disease development. This implies a differing mode of action for truncating and missense ACTN2 variants, further depending on affected functional domains. Nevertheless, these findings are in line with the diminished contractile 
function in ACTN2hom EHTs, as the patient affected by the homozygous truncating ACTN2 variant (p.GIn860Stop) developed RCM and heart failure (HF) at the age of $23 .^{8}$ The heterozygous carriers of the here investigated missense variant developed HCM without HF. ${ }^{6}$ However, based on the severity of cardiomyopathy phenotypes found in this study combined with the recent evidence that ACTN2 is linked to HF, ${ }^{47}$ it can be supposed that a patient harboring the homozygous ACTN2 variant would develop DCM or RCM leading to HF.

In conclusion, this study revealed an additional cellular pathology for the p.Thr247Met ACTN2 variant, leading to proteopathy. Our data indicates the (compensatory) activation of the proteolytic machinery in mutant ACTN2 hiPSC-CMs, likely to 'cope' with protein aggregation. Therefore, we believe that in this specific case, $\mathrm{HCM}$ is caused by a combination of different pathomechanisms induced by the same variant, which might also be applicable to other mutations in sarcomere genes that cause HCM, especially if associated with protein aggregates. ${ }^{39,43}$ The order and impact of each suggested pathomechanism on cardiomyopathy development and disease progression remains unclear and has to be elucidated in future studies. Nevertheless, altered protein function for missense variants, as well as their consequences on proteolytic systems should be taken into consideration for further development of new therapeutics in HCM.

\section{Study Limitations}

When working with hiPSCs it is important to consider possible limitations of the model such as unstable genome integrity, storage of hiPSC lines, immaturity and reproducibility when using hiPSC-CMs (for reviews, see ${ }^{34,48,49}$ ). To comply with best cell culture practices we applied regular karyotyping, genotyping, and established master cell banks ${ }^{50}$ of each hiPSC line, resulting in the validation of previous disease modeling data obtained in the ACTN2het line, ${ }^{6}$ and the description of a novel disease feature in both mutant ACTN2 lines. Another limitation is that we cannot fully claim that ACTN2 aggregate formation is detrimental, contributing to disease progression, or rather beneficial, to avoid sarcomere incorporation of the mutant protein. Further experiments are needed to answer this question. 


\section{Acknowledgements}

The authors gratefully acknowledge Birgit Klampe, Sandra Laufer and Thomas Schulze (Pharmacology, Hamburg) for participating in the production of hiPSC-CMs, Niels Pietsch and Malte Loos for supporting in the hiPSC-CMs treatment and fixation, the FACS and Microscopy Imaging Facility core facilities (Hamburg). Additionally, we thank Anja Wiechert for support in sample preparation and Stephan Michalik for providing the in-house $\mathrm{R}$ pipeline for the quantitative analysis of proteomics data.

\section{Sources of Funding}

This work was supported fully or in part by the German Centre for Cardiovascular Research (DZHK) to MP, MDL, EH, UV, and LC, German Ministry of Research Education (BMBF) to MP, MDL, EH, UV, and LC, Deutsche Herzstiftung (F/51/17) to SaS, Helmut und Charlotte Kassau Stiftung to LC, European Research Council Advanced Grant (IndivuHeart) to TE, Research Promotion Fund of the Faculty of Medicine (Hamburg) to ATLZ, MP and MDL ("Clinician Scientist Program" and "Project funding for young scientists"), Leducq Foundation (20CVD01) to LC, National Centre for the Replacement, Refinement, and Reduction of Animals in Research (NC3Rs: NC/S001808/1) to DM, and Pro Exzellenzia 4.0 to SRS.

\section{Disclosures}

AM is now an employee and shareholder of AstraZeneca2GM is now an employee at DiNAQOR. TE and LC are members of DiNAQOR Scientific Advisory Board and have shares in DiNAQOR. The remaining authors declare no competing interests.

\section{Author contributions}

Conceptualization and analysis: ATLZ, MP, LC; Methodology: CRISPR/Cas9: MP; Cloning and virus production: ATLZ, SRS, IB; Cardiac differentiation: ATLZ, MP, AM; Cell culture, transduction and treatments: ATLZ, MP, JB, CSB, AM, GM; EHT generation, maintenance and force measurement: AM; Immunofluorescence and livecell imaging of 2D hiPSC-CMs: ATLZ, MP, JB; Proteomics/bioinformatics: EH, MD, MGS, UV, MP; RNA isolation and gene expression analysis: MP, MDL, EK; RNA sequencing: DI, SV; Omics analysis: ATLZ, MP, SC, SV; Western blots: SRS, EO, EA, SaS; High-content imaging of 2D cultured hiPSC-CM: DM; Original draft: ATLZ, MP 
bioRxiv preprint doi: https://doi.org/10.1101/2021.10.28.466251; this version posted October 28, 2021. The copyright holder for this preprint (which was not certified by peer review) is the author/funder, who has granted bioRxiv a license to display the preprint in perpetuity. It is made available under aCC-BY-NC-ND 4.0 International license.

and LC; Review and editing: ATLZ, MP, SRS, AL, ML, MD, DM, UV, WTP, TE, EH, SaS, LC. All authors reviewed the manuscript and approved the submitted version.

\section{Supplemental Materials}

Expanded Materials and Methods

Supplemental Figures and Tables

Figures S1-S9

Tables S1-S8

Movies 1-4

Data Sets I-IV 


\section{References}

1. Sjoblom B, Salmazo A, Djinovic-Carugo K. Alpha-actinin structure and regulation. Cell Mol Life Sci. 2008;65:2688-2701

2. Gautel M, Djinovic-Carugo K. The sarcomeric cytoskeleton: From molecules to motion. J Exp Biol. 2016;219:135-145

3. Djinovic-Carugo K, Gautel M, Ylanne J, Young P. The spectrin repeat: A structural platform for cytoskeletal protein assemblies. FEBS Lett. 2002;513:119-123

4. Broderick MJ, Winder SJ. Spectrin, alpha-actinin, and dystrophin. Adv Protein Chem. 2005;70:203-246

5. Doll S, Dressen M, Geyer PE, Itzhak DN, Braun C, Doppler SA, Meier F, Deutsch MA, Lahm H, Lange $\mathrm{R}$, et al. Region and cell-type resolved quantitative proteomic map of the human heart. Nat Commun. 2017;8:1469

6. Prondzynski M, Lemoine MD, Zech AT, Horvath A, Di Mauro V, Koivumaki JT, Kresin N, Busch J, Krause T, Kramer E, et al. Disease modeling of a mutation in alpha-actinin 2 guides clinical therapy in hypertrophic cardiomyopathy. EMBO Mol Med. 2019;11:e11115

7. Mohapatra B, Jimenez S, Lin JH, Bowles KR, Coveler KJ, Marx JG, Chrisco MA, Murphy RT, Lurie PR, Schwartz RJ, et al. Mutations in the muscle lim protein and alpha-actinin-2 genes in dilated cardiomyopathy and endocardial fibroelastosis. Mol Genet Metab. 2003;80:207-215

8. Lindholm ME, Jimenez-Morales D, Zhu H, Seo K, Amar D, Zhao C, Raja A, Madhvani R, Espenel C, Sutton S, et al. Mono- and bi-allelic protein truncating variants in alpha-actinin 2 cause cardiomyopathy through distinct mechanisms. . bioRxiv 2020. Preprint.

9. Fan LL, Huang H, Jin JY, Li JJ, Chen YQ, Xiang R. Whole-exome sequencing identifies a novel mutation (p.L320r) of alpha-actinin 2 in a chinese family with dilated cardiomyopathy and ventricular tachycardia. Cytogenet Genome Res. 2019;157:148-152

10. Walsh R, Thomson KL, Ware JS, Funke BH, Woodley J, McGuire KJ, Mazzarotto F, Blair E, Seller A, Taylor JC, et al. Reassessment of mendelian gene pathogenicity using 7,855 cardiomyopathy cases and 60,706 reference samples. Genet Med. 2017;19:192-203 
11. Inoue M, Noguchi S, Sonehara K, Nakamura-Shindo K, Taniguchi A, Kajikawa $\mathrm{H}$, Nakamura $\mathrm{H}$, Ishikawa $\mathrm{K}$, Ogawa $\mathrm{M}$, Hayashi $\mathrm{S}$, et al. A recurrent homozygous actn2 variant associated with core myopathy. Acta Neuropathol. 2021;142:785-788

12. Haywood NJ, Wolny M, Rogers B, Trinh CH, Shuping Y, Edwards TA, Peckham M. Hypertrophic cardiomyopathy mutations in the calponin-homology domain of actn2 affect actin binding and cardiomyocyte z-disc incorporation. Biochem J. 2016;473:2485-2493

13. Maron BJ, Maron MS. Hypertrophic cardiomyopathy. Lancet. 2013;381:242255

14. Sandri M, Robbins J. Proteotoxicity: An underappreciated pathology in cardiac disease. J Mol Cell Cardiol. 2014;71:3-10

15. Zech ATL, Singh SR, Schlossarek S, Carrier L. Autophagy in cardiomyopathies. Biochim Biophys Acta Mol Cell Res. 2020;1867:118432

16. Kocaturk NM, Gozuacik D. Crosstalk between mammalian autophagy and the ubiquitin-proteasome system. Front Cell Dev Biol. 2018;6:128

17. Valdes-Mas R, Gutierrez-Fernandez A, Gomez J, Coto E, Astudillo A, Puente DA, Reguero JR, Alvarez V, Moris C, Leon D, et al. Mutations in filamin c cause a new form of familial hypertrophic cardiomyopathy. Nat Commun. 2014;5:5326

18. Thottakara T, Friedrich FW, Reischmann S, Braumann S, Schlossarek S, Kramer E, Juhr D, Schluter H, van der Velden J, Munch J, et al. The e3 ubiquitin ligase asb2beta is downregulated in a mouse model of hypertrophic cardiomyopathy and targets desmin for proteasomal degradation. $\mathrm{J} \mathrm{Mol} \mathrm{Cell}$ Cardiol. 2015;87:214-224

19. Singh SR, Zech ATL, Geertz B, Reischmann-Dusener S, Osinska H, Prondzynski M, Kramer E, Meng Q, Redwood C, van der Velden J, et al. Activation of autophagy ameliorates cardiomyopathy in mybpc3-targeted knockin mice. Circ Heart Fail. 2017;10

20. Dorsch LM, Schuldt M, dos Remedios CG, Schinkel AFL, de Jong PL, Michels M, Kuster DWD, Brundel B, van der Velden J. Protein quality control activation and microtubule remodeling in hypertrophic cardiomyopathy. Cells. 2019;8

21. Schuldt M, Pei J, Harakalova M, Dorsch LM, Schlossarek S, Mokry M, Knol JC, Pham TV, Schelfhorst T, Piersma SR, et al. Proteomic and functional studies 
reveal detyrosinated tubulin as treatment target in sarcomere mutation-induced hypertrophic cardiomyopathy. Circ Heart Fail. 2021;14:e007022

22. Sarikas A, Carrier L, Schenke C, Doll D, Flavigny J, Lindenberg KS, Eschenhagen T, Zolk O. Impairment of the ubiquitin-proteasome system by truncated cardiac myosin binding protein c mutants. Cardiovasc Res. 2005;66:33-44

23. Bahrudin U, Morikawa K, Takeuchi A, Kurata Y, Miake J, Mizuta E, Adachi K, Higaki K, Yamamoto Y, Shirayoshi Y, et al. Impairment of ubiquitin-proteasome system by e334k cmybpc modifies channel proteins, leading to electrophysiological dysfunction. J Mol Biol. 2011;413:857-878

24. Prondzynski M, Kramer E, Laufer SD, Shibamiya A, Pless O, Flenner F, Muller OJ, Munch J, Redwood C, Hansen A, et al. Evaluation of mybpc3 trans-splicing and gene replacement as therapeutic options in human ipsc-derived cardiomyocytes. Mol Ther Nucleic Acids. 2017;7:475-486

25. Palma Medina LM, Becker AK, Michalik S, Yedavally H, Raineri EJM, Hildebrandt P, Gesell Salazar M, Surmann K, Pfortner H, Mekonnen SA, et al. Metabolic cross-talk between human bronchial epithelial cells and internalized staphylococcus aureus as a driver for infection. Mol Cell Proteomics. 2019;18:892-908

26. Seidl MD, Stein J, Hamer S, Pluteanu F, Scholz B, Wardelmann E, Huge A, Witten A, Stoll M, Hammer E, et al. Characterization of the genetic program linked to the development of atrial fibrillation in crem-ibdeltac- $x$ mice. Circ Arrhythm Electrophysiol. 2017;10

27. Derks W, Bergmann O. Polyploidy in cardiomyocytes: Roadblock to heart regeneration? Circ Res. 2020;126:552-565

28. Mosqueira D, Mannhardt I, Bhagwan JR, Lis-Slimak K, Katili P, Scott E, Hassan M, Prondzynski M, Harmer SC, Tinker A, et al. Crispr/cas9 editing in human pluripotent stem cell-cardiomyocytes highlights arrhythmias, hypocontractility, and energy depletion as potential therapeutic targets for hypertrophic cardiomyopathy. Eur Heart J. 2018;39:3879-3892

29. Ladha FAT, K., Pettinato AM, Legere N, Cohn R, Romano R, Meredith E, Chen YS, Hinson JT. Identifying cardiac actinin interactomes reveals sarcomere crosstalk with rna-binding proteins. bioRxiv 2020.03.18.994004. Preprint. 
30. Wan C, Borgeson B, Phanse S, Tu F, Drew K, Clark G, Xiong X, Kagan O, Kwan J, Bezginov A, et al. Panorama of ancient metazoan macromolecular complexes. Nature. 2015;525:339-344

31. Linnemann A, van der Ven PF, Vakeel P, Albinus B, Simonis D, Bendas G, Schenk JA, Micheel B, Kley RA, Furst DO. The sarcomeric z-disc component myopodin is a multiadapter protein that interacts with filamin and alpha-actinin. Eur J Cell Biol. 2010;89:681-692

32. Friedrich FW, Wilding BR, Reischmann S, Crocini C, Lang P, Charron P, Muller OJ, McGrath MJ, Vollert I, Hansen A, et al. Evidence for fhl1 as a novel disease gene for isolated hypertrophic cardiomyopathy. Hum Mol Genet. 2012;21:32373254

33. Friedrich FW, Reischmann S, Schwalm A, Unger A, Ramanujam D, Munch J, Muller OJ, Hengstenberg C, Galve E, Charron P, et al. Fhl2 expression and variants in hypertrophic cardiomyopathy. Basic Res Cardiol. 2014;109:451

34. Eschenhagen T, Carrier L. Cardiomyopathy phenotypes in human-induced pluripotent stem cell-derived cardiomyocytes-a systematic review. Pflugers Arch. 2019;471:755-768

35. Sequeira V, Bertero E, Maack C. Energetic drain driving hypertrophic cardiomyopathy. FEBS Lett. 2019;593:1616-1626

36. Hinson JT, Chopra A, Nafissi N, Polacheck WJ, Benson CC, Swist S, Gorham J, Yang L, Schafer S, Sheng CC, et al. Heart disease. Titin mutations in ips cells define sarcomere insufficiency as a cause of dilated cardiomyopathy. Science. 2015;349:982-986

37. Cuello F, Knaust AE, Saleem U, Loos M, Raabe J, Mosqueira D, Laufer S, Schweizer $M$, van der Kraak $P$, Flenner $F$, et al. Impairment of the er/mitochondria compartment in human cardiomyocytes with pln p.Arg14del mutation. EMBO Mol Med. 2021;13:e13074

38. Feyen DAM, Perea-Gil I, Maas RGC, Harakalova M, Gavidia AA, Arthur Ataam J, Wu TH, Vink A, Pei J, Vadgama N, et al. Unfolded protein response as a compensatory mechanism and potential therapeutic target in pln r14del cardiomyopathy. Circulation. 2021;144:382-392

39. Davis J, Davis LC, Correll RN, Makarewich CA, Schwanekamp JA, MoussaviHarami F, Wang D, York AJ, Wu H, Houser SR, et al. A tension-based model 
distinguishes hypertrophic versus dilated cardiomyopathy. Cell. 2016;165:1147-1159

40. Sanbe A, Osinska H, Saffitz JE, Glabe CG, Kayed R, Maloyan A, Robbins J. Desmin-related cardiomyopathy in transgenic mice: A cardiac amyloidosis. Proc Natl Acad Sci U S A. 2004;101:10132-10136

41. Schlossarek S, Schuermann F, Geertz B, Mearini G, Eschenhagen T, Carrier L. Adrenergic stress reveals septal hypertrophy and proteasome impairment in heterozygous mybpc3-targeted knock-in mice. J Muscle Res Cell Motil. 2012;33:5-15

42. Singh SR, Kadioglu H, Patel K, Carrier L, Agnetti G. Is desmin propensity to aggregate part of its protective function? Cells. 2020;9

43. Eijgenraam TR, Boogerd CJ, Stege NM, Oliveira Nunes Teixeira V, Dokter MM, Schmidt LE, Yin X, Theofilatos K, Mayr M, van der Meer P, et al. Protein aggregation is an early manifestation of phospholamban p.(arg14del)-related cardiomyopathy: Development of pln-r14del-related cardiomyopathy. Circ Heart Fail. 2021:CIRCHEARTFAILURE121008532

44. Spaich S, Will RD, Just S, Kuhn C, Frank D, Berger IM, Wiemann S, Korn B, Koegl M, Backs J, et al. F-box and leucine-rich repeat protein 22 is a cardiacenriched f-box protein that regulates sarcomeric protein turnover and is essential for maintenance of contractile function in vivo. Circ Res. 2012;111:1504-1516

45. Lewis YE, Moskovitz A, Mutlak M, Heineke J, Caspi LH, Kehat I. Localization of transcripts, translation, and degradation for spatiotemporal sarcomere maintenance. J Mol Cell Cardiol. 2018;116:16-28

46. Agarwal R, Paulo JA, Toepfer CN, Ewoldt JK, Sundaram S, Chopra A, Zhang Q, Gorham J, DePalma SR, Chen CS, et al. Filamin c cardiomyopathy variants cause protein and lysosome accumulation. Circ Res. 2021;129:751-766

47. Arvanitis M, Tampakakis E, Zhang Y, Wang W, Auton A, andMe Research T, Dutta D, Glavaris S, Keramati A, Chatterjee N, et al. Genome-wide association and multi-omic analyses reveal actn2 as a gene linked to heart failure. Nat Commun. 2020;11:1122

48. Brandao KO, Tabel VA, Atsma DE, Mummery CL, Davis RP. Human pluripotent stem cell models of cardiac disease: From mechanisms to therapies. Dis Model Mech. 2017;10:1039-1059 
49. Puri MC, Nagy A. Concise review: Embryonic stem cells versus induced pluripotent stem cells: The game is on. Stem Cells. 2012;30:10-14

50. Shibamiya A, Schulze E, Krauss D, Augustin C, Reinsch M, Schulze ML, Steuck S, Mearini G, Mannhardt I, Schulze T, et al. Cell banking of hipscs: A practical guide to cryopreservation and quality control in basic research. Curr Protoc Stem Cell Biol. 2020;55:e127

51. Breckwoldt K, Letuffe-Breniere D, Mannhardt I, Schulze T, Ulmer B, Werner T, Benzin A, Klampe B, Reinsch MC, Laufer S, et al. Differentiation of cardiomyocytes and generation of human engineered heart tissue. Nat Protoc. 2017;12:1177-1197

52. Mosqueira D, Lis-Slimak K, Denning C. High-throughput phenotyping toolkit for characterizing cellular models of hypertrophic cardiomyopathy in vitro. Methods Protoc. 2019;2

53. Patro R, Duggal G, Love MI, Irizarry RA, Kingsford C. Salmon provides fast and bias-aware quantification of transcript expression. Nat Methods. 2017;14:417419

54. Soneson C, Love MI, Robinson MD. Differential analyses for rna-seq: Transcript-level estimates improve gene-level inferences. F1000Res. 2015;4:1521

55. Love MI, Huber W, Anders S. Moderated estimation of fold change and dispersion for rna-seq data with deseq2. Genome Biol. 2014;15:550

56. Strimmer K. Fdrtool: A versatile $r$ package for estimating local and tail areabased false discovery rates. Bioinformatics. 2008;24:1461-1462

57. Singh SR, Meyer-Jens M, Alizoti E, Bacon WC, Davis G, Osinska H, Gulick J, Reischmann-Dusener S, Orthey E, McLendon PM, et al. A high-throughput screening identifies znf418 as a novel regulator of the ubiquitin-proteasome system and autophagy-lysosomal pathway. Autophagy. 2020:1-16

58. Vignier N, Schlossarek S, Fraysse B, Mearini G, Kramer E, Pointu H, Mougenot N, Guiard J, Reimer R, Hohenberg H, et al. Nonsense-mediated mrna decay and ubiquitin-proteasome system regulate cardiac myosin-binding protein $\mathrm{C}$ mutant levels in cardiomyopathic mice. Circ Res. 2009;105:239-248

59. Schlossarek S, Englmann DR, Sultan KR, Sauer M, Eschenhagen T, Carrier L. Defective proteolytic systems in Mybpc3-targeted mice with cardiac hypertrophy. Basic Res Cardiol. 2012;107:1-13 
60. Wenzel K, Kramer E, Geertz B, Carrier L, Felix SB, Konemann S, Schlossarek S. A transgenic mouse model of eccentric left ventricular hypertrophy with preserved ejection fraction exhibits alterations in the autophagy-lysosomal pathway. Front Physiol. 2021;12:614878

61. Suomi T, Elo LL. Enhanced differential expression statistics for dataindependent acquisition proteomics. Sci Rep. 2017;7:5869

62. Phipson B, Lee S, Majewski IJ, Alexander WS, Smyth GK. Robust hyperparameter estimation protects against hypervariable genes and improves power to detect differential expression. Ann App/ Stat. 2016;10:946-963

63. Benjamini $Y$, Hochberg $Y$. Controlling the false discovery rate: A practical and powerful approach to multiple testing. J R Statist Soc. 1995;57:289-300

64. Zhou C, Zhong W, Zhou J, Sheng F, Fang Z, Wei Y, Chen Y, Deng X, Xia B, Lin J. Monitoring autophagic flux by an improved tandem fluorescent-tagged lc3 (mtagrfp-mwasabi-lc3) reveals that high-dose rapamycin impairs autophagic flux in cancer cells. Autophagy. 2012;8:1215-1226

65. Wasilko DJ, Lee SE, Stutzman-Engwall KJ, Reitz BA, Emmons TL, Mathis KJ, Bienkowski MJ, Tomasselli AG, Fischer HD. The titerless infected-cells preservation and scale-up (tips) method for large-scale production of nosensitive human soluble guanylate cyclase (sgc) from insect cells infected with recombinant baculovirus. Protein Expr Purif. 2009;65:122-132 
A

过
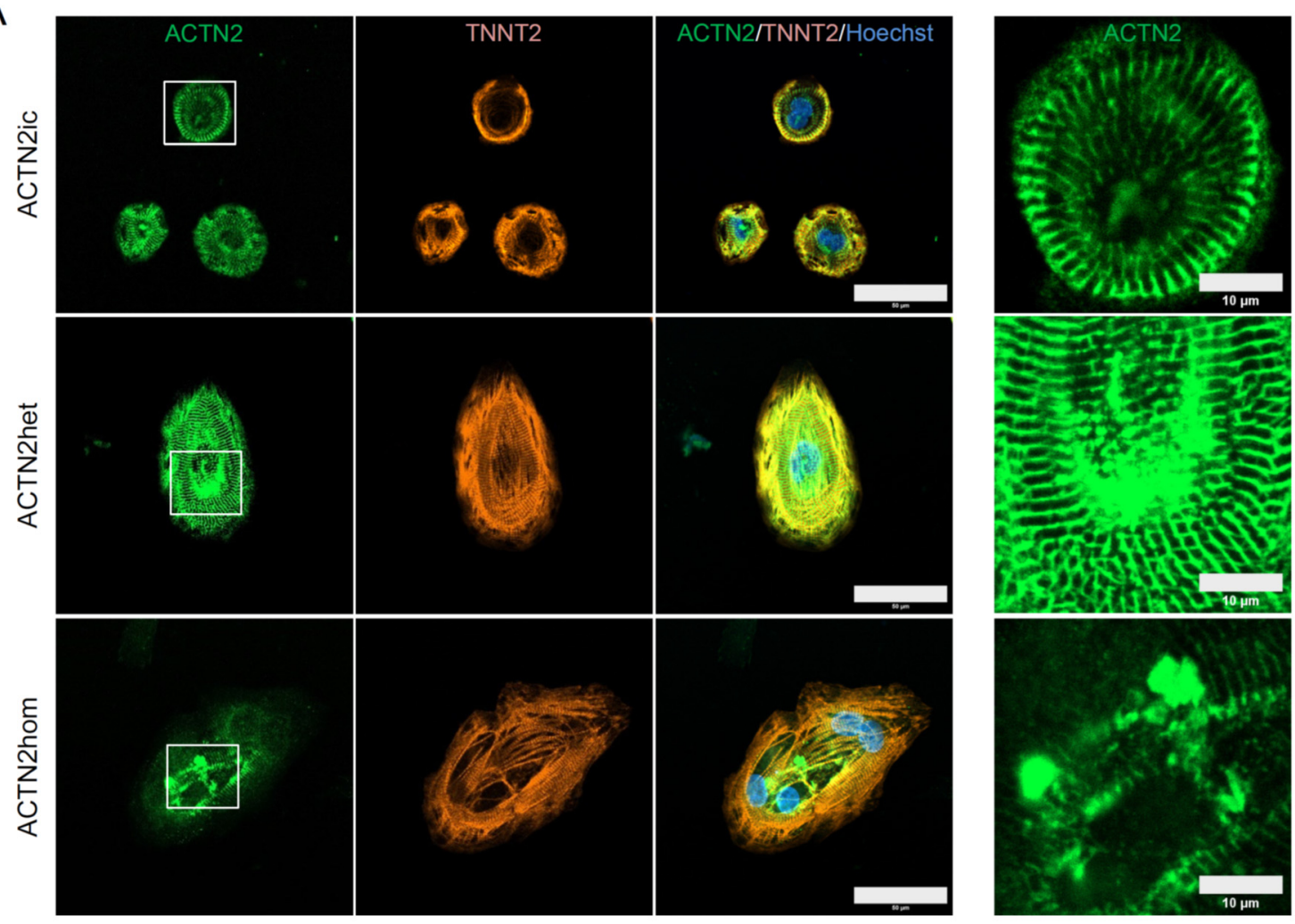

B

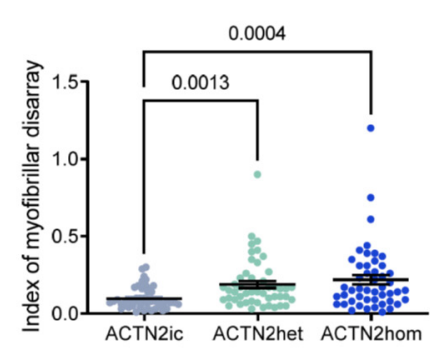

$\mathrm{E}$

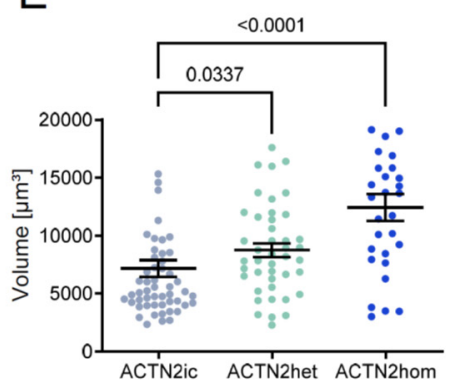

C

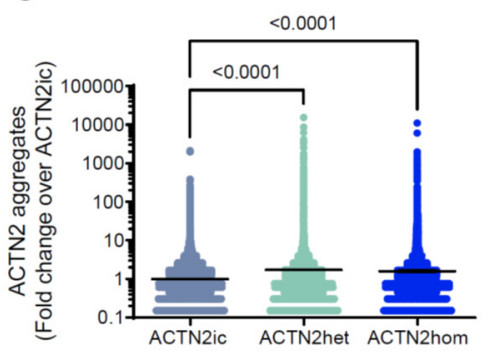

$\mathrm{F}$

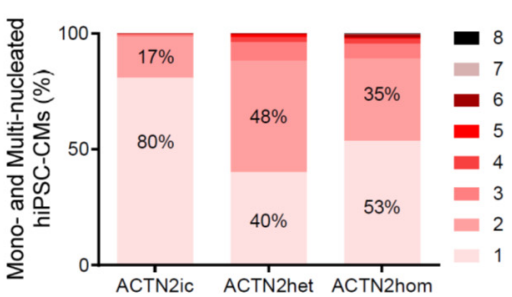

$\mathrm{D}$

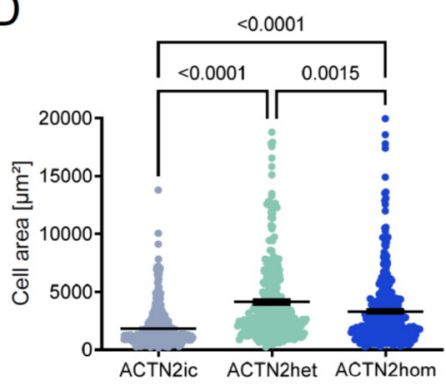

Figure 1. Disease modeling in 30-day-old, 2D-cultured hiPSC-CMs. (A) Representative immunofluorescence images of hiPSC-CMs (scale bar $=50 \mu \mathrm{m}$ ), including a higher magnification on the right (scale bar $=10 \mu \mathrm{m}$ ). After 30 days, hiPSCCMs were fixed, and stained with antibodies against ACTN2 and TNNT2, and with Hoechst for nuclei. (B) Blinded analysis of myofibrillar disarray using high-resolution pictures (ACTN2ic: N/d = 16/3, ACTN2het: N/d = 16/3, ACTN2hom: N/d = 16/3). (C) Quantification of ACTN2 aggregates in hiPSC-CMs, analyzed with Fiji software (ACTN2ic: $\mathrm{N} / \mathrm{d}=14 / 3$, ACTN2het: N/d $=15 / 3$, ACTN2hom: N/d = 15/3). 
Quantification of cell area analyzed with Fiji software (ACTN2ic: N/n/d $=548 / 3 / 3$, ACTN2het: N/n/d = 288/3/3, ACTN2hom: N/n/d 319/3/3). (E) Quantification of cell volume analyzed with Imaris software (ACTN2ic: N/n/d =54/3/3, ACTN2het: N/n/d = 43/3/3, ACTN2hom: N/n/d = 29/3/3). (F) Quantification of nuclei per hiPSC-CM analyzed with Fiji software (ACTN2ic: N/n/d = 548/3/3, ACTN2het: N/n/d = 288/3/3, ACTN2hom: $\mathrm{N} / \mathrm{n} / \mathrm{d}=319 / 3 / 3$; Chi-square $=280.1, P<0.0001)$. Data are expressed as mean \pm SEM (panels B-E) or in percentage (panel F), with $P$-values obtained with the Kruskal-Wallis plus Dunn's post-test (panels B-E) or two-tailed Chi-square test (panel F). Abbreviations: TNNT2, cardiac troponin $\mathrm{T} ; \mathrm{N} / \mathrm{n} / \mathrm{d}$, number of cells/wells/differentiations. 


\section{A}

A AAV6-ACTN2-WT-HaloTag AAV6-ACTN2-Mut-HaloTag

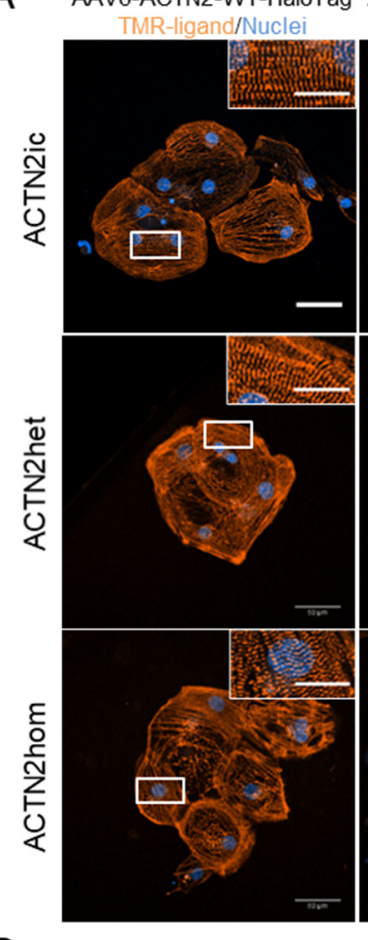

Non-transduced

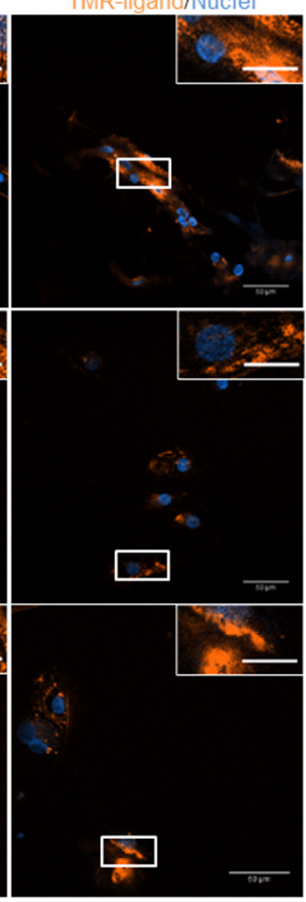

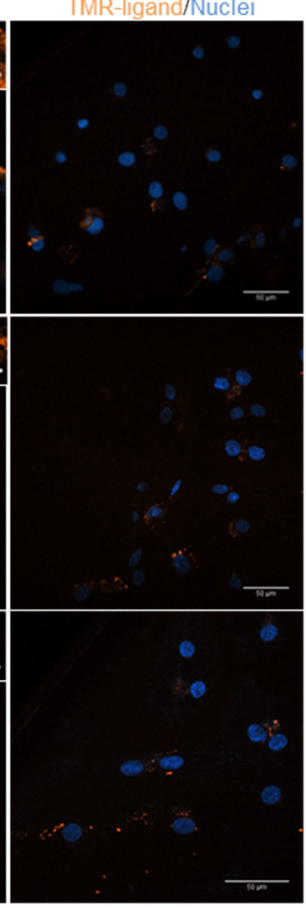

B

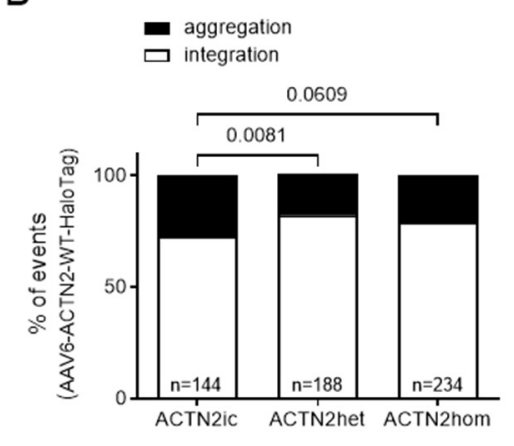

C

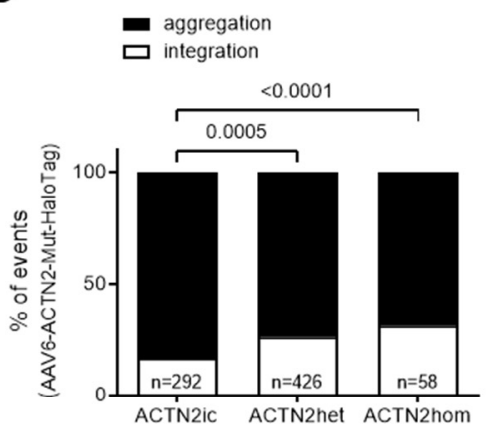

D

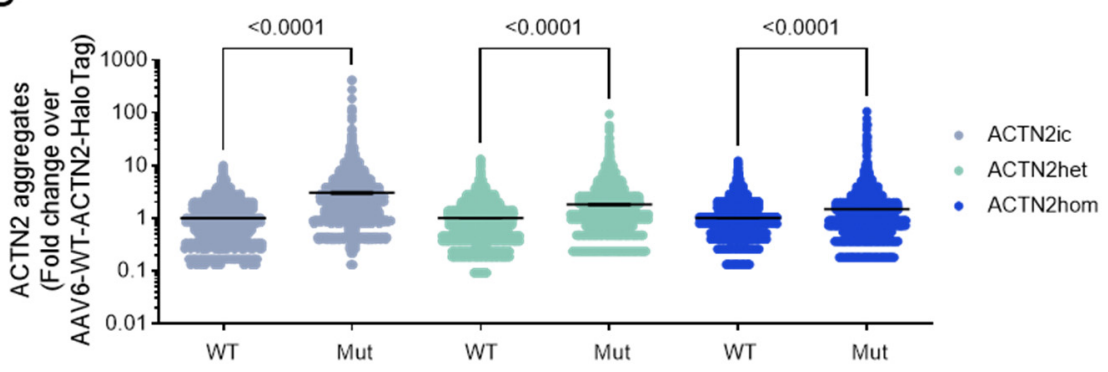

Figure 2. Live cell imaging and immunofluorescence analysis in 2D-cultured hiPSC-CMs. (A) Representative images of hiPSC-CMs transduced with an AAV6 carrying the ACTN2-WT-HaloTag® or ACTN2-Mut-HaloTag ${ }^{\circledR}$ construct and seeded in 96-well plates (2,500-5,000 cells/well). After 7 days, live cell imaging was performed by adding TMR-ligand to stain ACTN2-HaloTag® protein and Hoechst for nuclei staining. Images were taken with a Zeiss LSM 800 microscope (Scale bars $=50 \mu \mathrm{m}$; zoom $=20 \mu \mathrm{m}$ ). (B) Blinded quantification of sarcomere integration or aggregation of exogenous WT ACTN2 in hiPSC-CMs (ACTN2ic: N/n/d = 144/3/1, ACTN2het: N/n/d = 188/3/1, ACTN2hom: $\mathrm{N} / \mathrm{n} / \mathrm{d}=234 / 3 / 1)$. (C) Blinded quantification of sarcomere integration or aggregation of exogenous Mut ACTN2 in hiPSC-CMs (ACTN2ic: N/n/d = 292/3/1; ACTN2het: N/n/d= 426/3/1, ACTN2hom: N/n/d = 58/3/1). (D) Quantification of ACTN2 aggregates in hiPSC-CM lines. Analysis was performed with Fiji software (ACTN2ic-WT: N/d = 8/1, ACTN2ic-Mut: N/d = 26/1, ACTN2het-WT: N/d = 10/1, ACTN2het-Mut: N/d = 31/1, ACTN2hom-WT: N/d = 9/1, ACTN2hom-Mut: (N/d = 12/1). Data are expressed as mean \pm SEM (panel D) or in percentage (panel $B, C$ ), with $P$ values obtained vs. ACTN2ic with one-tailed Chi-square test (panel B,C) or MannWhitney test (panel D). Abbreviations: AAV6, adeno-associated virus serotype 6; Mut, mutant; WT, wild-type; N/n/d, number of cells/wells/differentiations. 
bioRxiv preprint doi: https://doi.org/10.1101/2021.10.28.466251; this version posted October 28, 2021. The copyright holder for this preprint (which was not certified by peer review) is the author/funder, who has granted bioRxiv a license to display the preprint in perpetuity. It is made available under aCC-BY-NC-ND 4.0 International license.

A

ACTN2het vs. ACTN2ic

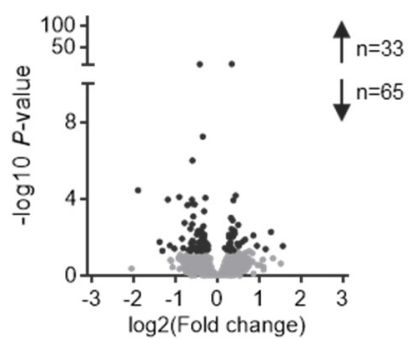

B

ACTN2hom vs. ACTN2ic

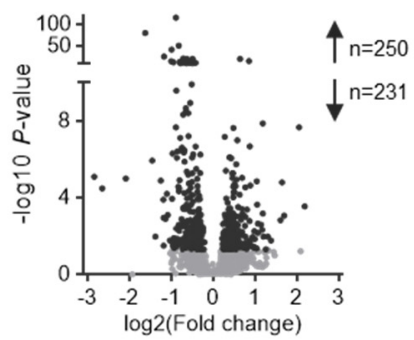

C ACTN2het vs. ACTN2ic ACTN2hom vs. ACTN2ic

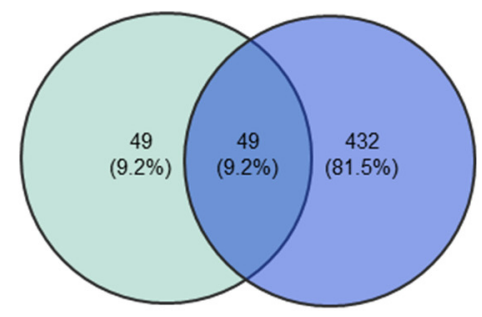

D

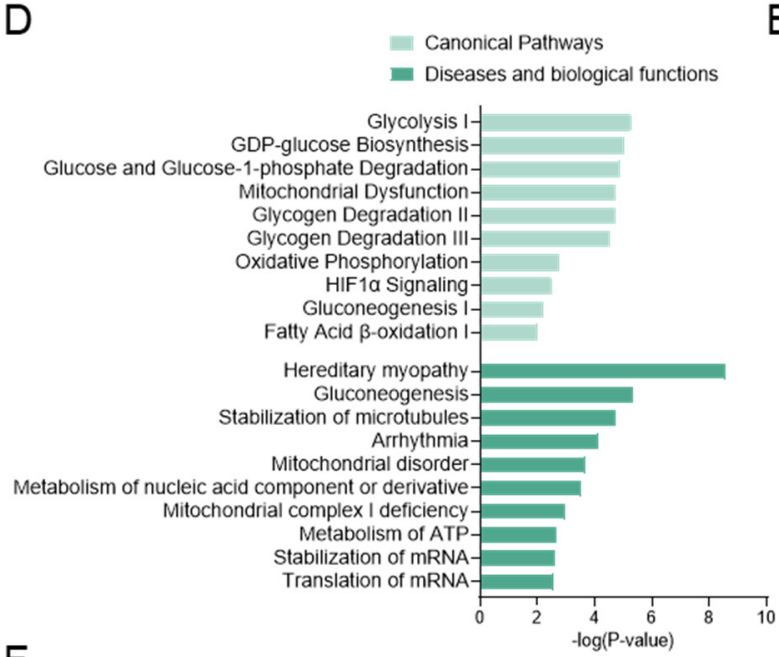

F

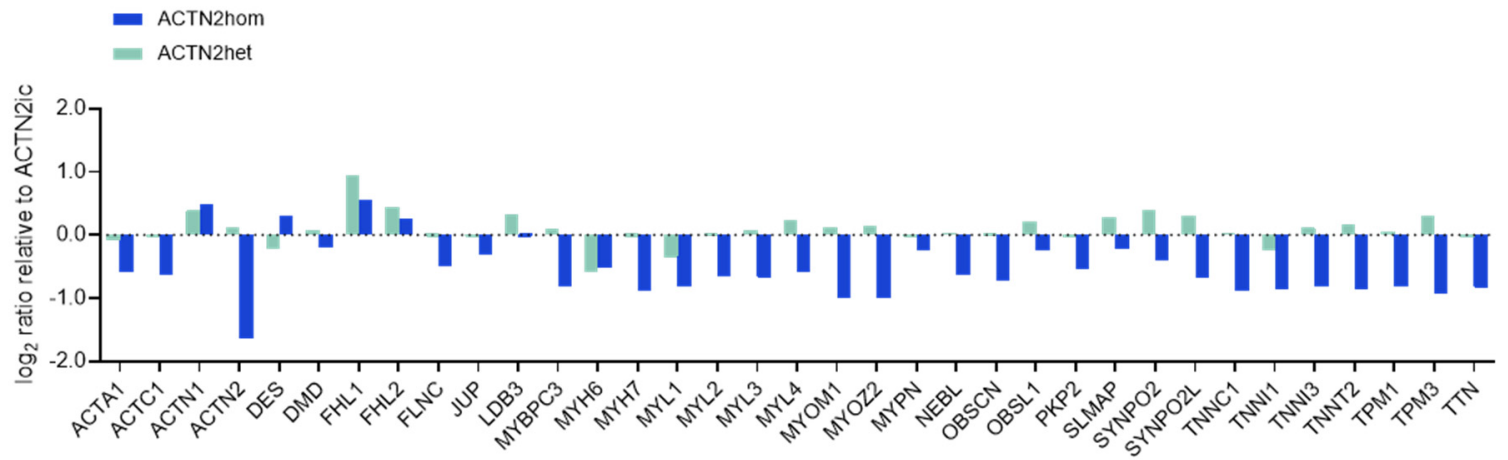

G

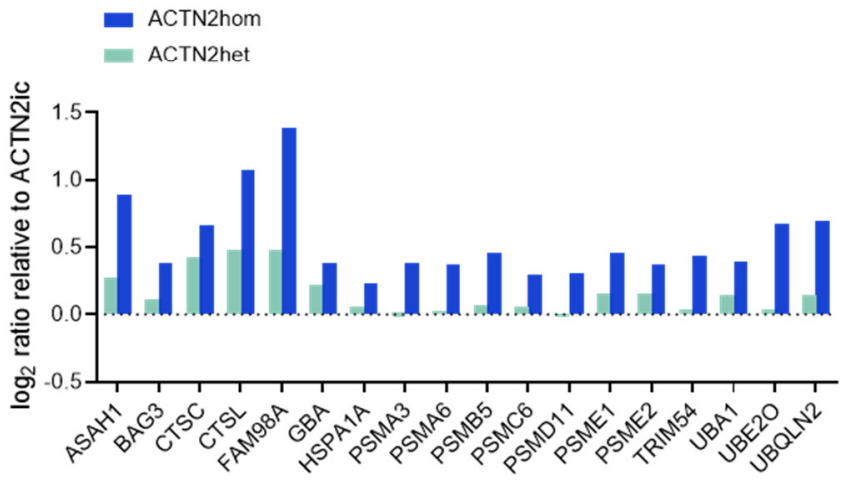

Figure 3. Mass spectrometry analysis of 30-day-old, 2D-cultured hiPSC-CMs. Alterations in protein levels between ACTN2het vs. ACTN2ic and ACTN2hom vs. ACTN2ic hiPSC-CMs are displayed in (A,B) Volcano plots that show -log10 of $P$-value vs. magnitude of change (log2 ratio) whereby light grey dots indicate $P>0.05$ and dark 
grey dots $P<0.05$, and in (C) a Venn diagram that also depicts the number of proteins that are dysregulated in both ACTN2het and ACTN2hom ACTN2ic hiPSC-CMs $(P<$ 0.05). Selected hits of significantly dysregulated canonical pathways and biological functions in 2D-cultured ACTN2het vs. ACTN2ic (D) and ACTN2hom vs. ACTN2ic (E) hiPSC-CMs based on MS analysis using Ingenuity Pathway Analysis (IPA). Unsupervised IPA was performed for significantly altered proteins (Fisher's exact test; $P<0.05)$. (F) Log2 ratio of sarcomere-associated protein levels in ACTN2het and ACTN2hom hiPSC-CMs. (G) Log2 ratio of levels of proteins involved in protein degradation pathways in ACTN2het and ACTN2hom hiPSC-CMs. 

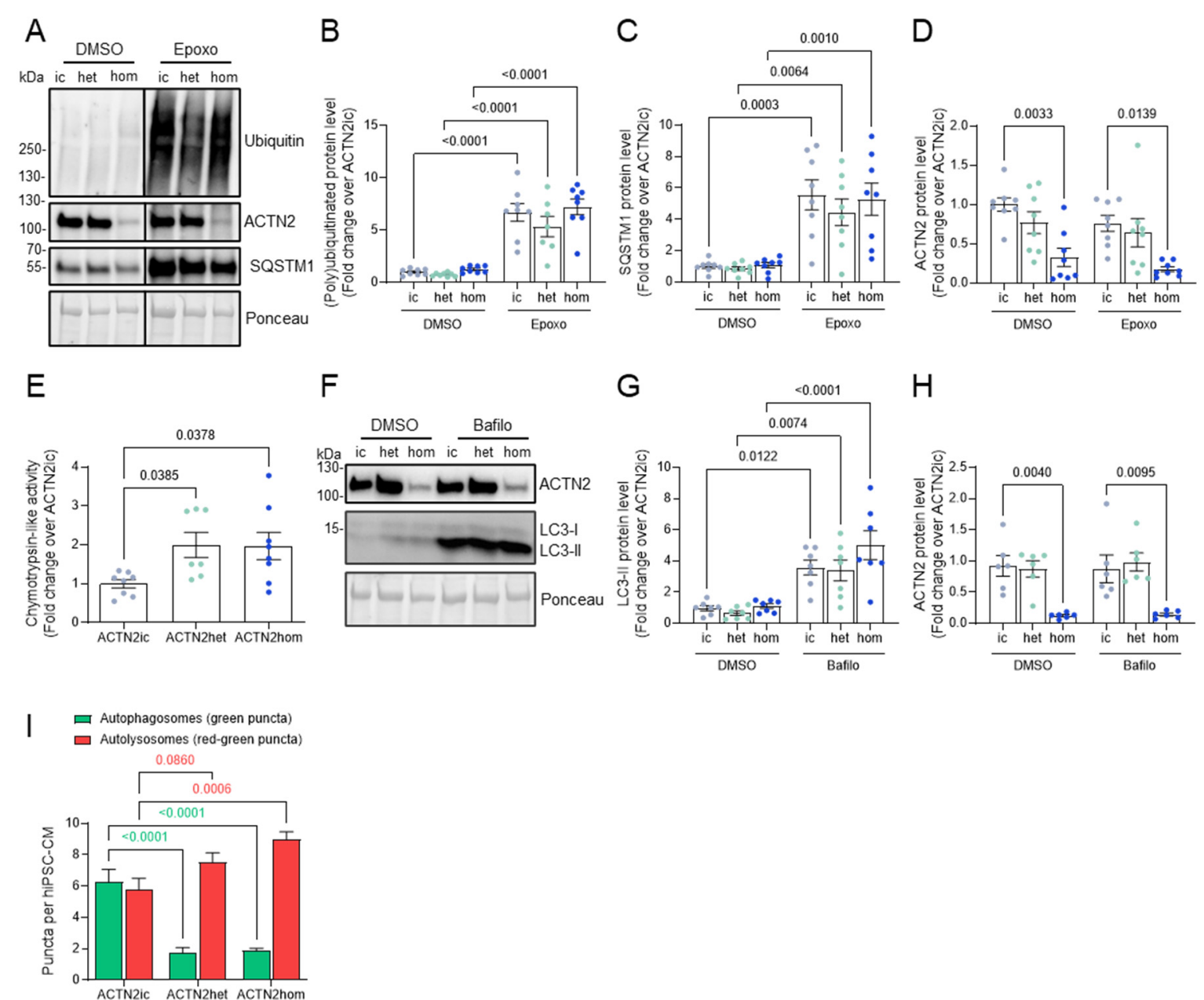

Figure 4. Evaluation of the proteolytic systems in 30-day-old, 2D-cultured hiPSCCMs. Representative Western blots and Ponceau (A), and quantification, normalized to Ponceau, of the levels of (B) (poly)ubiquitinated proteins, (C) SQSTM1, (D) ACTN2 in hiPSC-CMs treated with DMSO $(0.05 \%)$ or epoxomicin (Epoxo; $250 \mathrm{nM})$ for $16.5 \mathrm{~h}$ at $37^{\circ} \mathrm{C}$ (ACTN2ic: $\mathrm{N} / \mathrm{n}=7-8 / 3$, ACTN2het: $\mathrm{N} / \mathrm{n}=7-8 / 3$, ACTN2hom: $\left.\mathrm{N} / \mathrm{n}=7-8 / 3\right)$. (E) Chymotrypsin-like activity of the proteasome in hiPSC-CMs (ACTN2ic: $N / n=8 / 3$, ACTN2het: $\mathrm{N} / \mathrm{n}=7 / 3$, ACTN2hom: $\mathrm{N} / \mathrm{n}=8 / 3$ ). (F) Representative Western blots, Ponceau, and quantification of protein levels of (G) LC3-II and (H) ACTN2 of hiPSCCMs treated with DMSO (0.05\%) or bafilomycin A1 (Bafilo; $50 \mathrm{nM}$ ) for $3 \mathrm{~h}$ at $37^{\circ} \mathrm{C}$ (ACTN2ic: $N / n=6-7 / 3$, ACTN2het: N/n = 6-7/3, ACTN2hom: N/n = 6-7/3). (I) Highcontent screen of hiPSC-CMs transduced with an AAV6-mWasabi-mTagRFP-hLC3 tandem construct $(\mathrm{MOI} 10,000)$ and seeded in 96 -well plates (2,500 cells/well). The ALP activity was indirectly measured by determining the amount of autophagosomes (green puncta) and autolysosomes (red minus green puncta) whereby the number of puncta is related to the hiPSC-CM number per well (ACTN2ic: $n=9$, ACTN2het: $n=$ 9 , ACTN2hom: $\mathrm{n}=9$ ). Data are expressed as mean \pm SEM, with $P$-values obtained with two-way ANOVA and Tukey's post-test (panels B-D, G, H, I), or with one-way ANOVA and Dunnett's post-test (panel E). Abbreviations: ALP, autophagy-lysosomal pathway; het, ACTN2het; hom, ACTN2hom; ic, ACTN2ic; N/n, number of wells/differentiations. 
A

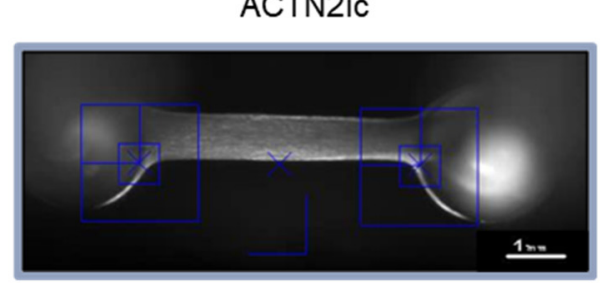

B

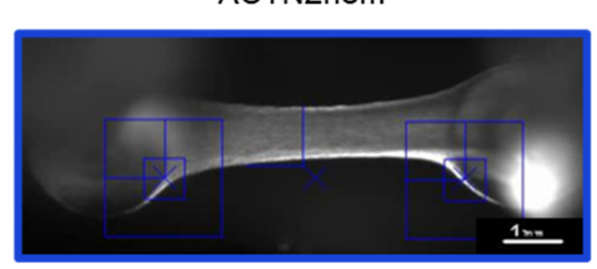

C

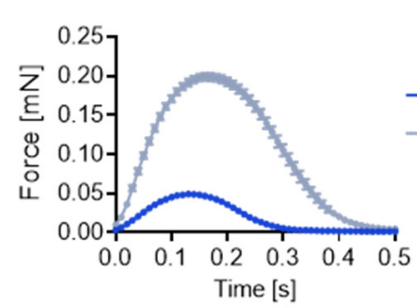

$E$

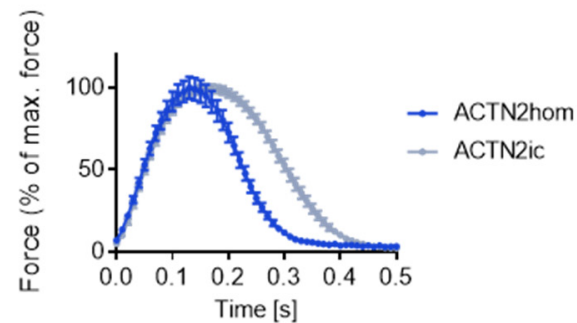

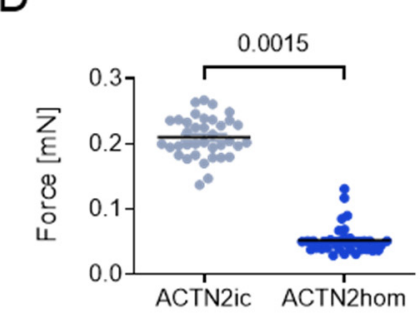

$\mathrm{F}$

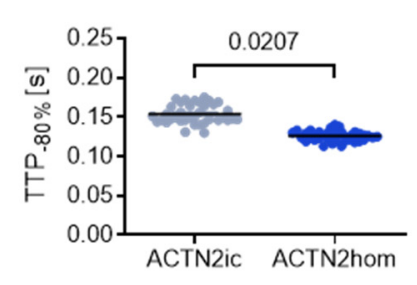

G

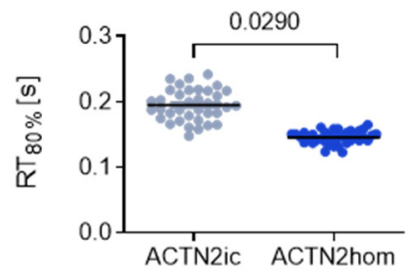

Figure 5. Force measurements in 3D-cultured hiPSC-engineered heart tissues. Representative images of (A) ACTN2ic and (B) ACTN2hom EHTs cultured for 30 days (scale bar $=1 \mathrm{~mm}$ ). (C) Average force, (D) force, $(\mathbf{E})$ normalized force, $(\mathbf{F})$ time to peak $-80 \%$ (TTP-80\%), and (G) relaxation time to baseline $80 \%$ (RT80\%) were measured under paced conditions at $1 \mathrm{~Hz}$ in $1.8 \mathrm{mM} \mathrm{Ca}^{2+}$ Tyrode's solution at $37^{\circ} \mathrm{C}$ (ACTN2ic: $\mathrm{N} / \mathrm{d}=37 / 3$, ACTN2hom: $\mathrm{N} / \mathrm{d}=37 / 3$ ); data are expressed as mean $\pm \mathrm{SEM}$, with $P$ values vs. ACTN2ic obtained with the nested t-test. Abbreviations: EHTs, engineered heart tissues; $\mathrm{N} / \mathrm{d}$, number of EHTs/differentiations. 


\section{Supplement}

\section{Expanded Materials and Methods}

\section{Generation and culture of hiPSC-derived cardiomyocytes (hiPSC-CMs) in 2D and EHT formats}

The HCM patient carrying the ACTN2 (c.740C>T; dbSNP ID: rs755492182) mutation was recruited in the outpatient HCM clinic at the University Heart Center Hamburg and provided written informed consent for genetic analysis and the use of skin fibroblasts. ${ }^{6}$ All procedures were in accordance with the Code of Ethics of the World Medical Association (Declaration of Helsinki). The study was reviewed and approved by the Ethical Committee of the Ärztekammer Hamburg (PV3501). Fibroblasts were reprogrammed as described previously. ${ }^{6,24}$ Generation of the homozygous mutant cell line (ACTN2hom) was performed with CRISPR/Cas9 gene tools in ACTN2het hiPSC using the same approach that was previously published to generate the ACTN2 isogenic control (ACTN2ic). ${ }^{6}$ This clone was analyzed for the same offtargets as published previously. Additionally, PCR fragments of cells containing the modified ACTN2 locus were subcloned using the CloneJET PCR Cloning Kit (Thermo Scientific, Vilnius, Lithuania) for discrimination of allele-specific genotypes. Finally, all used cell lines were genotyped by PCR for the ACTN2 locus and karyotyped by G-banding as reported previously. ${ }^{6}$ To amplify specific DNA fragments, PCR was conducted according to standard protocols using PrimeSTAR® HS DNA Polymerase (Takara, Kusatsu, Japan) and AmpliTaq® Gold DNA polymerase (Thermo Fisher Scientific, Vilnius, Lithuania) following manufacturer's instructions.

Cardiomyocyte (CM) differentiation from hiPSCs was performed following a three-step protocol with generation of embryoid bodies (EBs) in spinner flasks and cardiac differentiation efficiency was determined by flow cytometry as described previously. ${ }^{51}$ After dissociation with collagenase 2 (200 units/mL, LS004176, Worthington, Lakewood, NJ) hiPSC-CMs were plated on Geltrex-coated (1:100, Gibco, Grand Island, NY) 96-well or 12-well plates at a density of 2,500 - 5,000 cells/well or 440,000 cells/well, respectively. HiPSC-CMs were maintained in culture for 7 days in 96-well plates ( $\mu$ clear®, Greiner Bio-One, Frickenhausen, Germany) 
when used for live cell imaging and for 30 days for immunofluorescent analysis, as well as 12-well plates, which were used for molecular analysis, at $37{ }^{\circ} \mathrm{C}$ in $7 \% \mathrm{CO}_{2}$ and atmospheric $\mathrm{O}_{2}(21 \%)$ prior to further analysis. Furthermore, single cell suspensions of hiPSC-CMs were subjected to the 3D format of EHTs, which were generated in a 24 -well format $(800,000$ hiPSC-CM/EHT) in a fibrin matrix, maintained in culture and analyzed from day 26 on as described previously. ${ }^{6}$

\section{Immunofluorescence staining of hiPSC-CMs}

HiPSC-CMs were cultured for 30 days in 96-well plates ( $\mu$ clear $®$, Greiner Bio-One, Frickenhausen, Germany) and subsequently prepared for immunofluorescence analysis as described previously. ${ }^{6}$ The following primary antibodies were used: ACTN2 - A7811 (1:800), Sigma-Aldrich, St.Louis, MO; cardiac troponin T (TNNT2) ab8295 (1:200) or ab45932 (1:500), Abcam, Cambridge, UK; HaloTag - G9281 (1:400), Promega, Madison, WI. The following secondary antibodies were used: antimouse Alexa Fluor® 488 antibody - LT A11029 (1:800), Life Technologies, Eugene, OR; anti-rabbit Alexa Fluor® 546 antibody - LT A11035 (1:800), Life Technologies, Eugene, OR; anti-rabbit Alexa Fluor ${ }^{\circledR} 647$ - LT A11031 (1:800), Life Technologies, Eugene, OR. Nuclei staining was obtained with Hoechst $33342(1 \mu \mathrm{g} / \mathrm{mL}$; Thermo Fisher Scientific, Waltham, MA). The Wheat Germ Agglutinin (WGA) Alexa Fluor ${ }^{\circledR}$ 633 conjugate (W21404, 1:50, Thermo Fisher Scientific, Waltham, MA) was used to perform the volume measurement of hiPSC-CMs. Images were obtained by confocal microscopy using a Zeiss LSM 800 confocal microscope with a 40x-oil immersion objective.

\section{Morphological analysis of 2D-cultured hiPSC-CMs}

Analysis of ACTN2 protein aggregates was performed using ImageJ. Therefore, immunofluorescence images were imported to ImageJ and subjected to the "find Maxima" tool adjusting the signal threshold to 254 and 1 in fixed hiPSC-CMs and live-cell imaging experiments, respectively. The automatically generated image was then analyzed with the "find particles" tool, and areas of ACTN2 aggregates were automatically determined by ImageJ. Finally, ACTN2 areas were normalized to a control line or condition to express differences in areas as fold changes.

The volume measurement of hiPSC-CMs was performed using Imaris 7.6.1. software. Z-stack images were imported to Imaris and a surface was added. After 
choosing default parameters, the relevant channel (WGA) was selected. Next, a smooth surface was selected (surface area detail level of $0.312 \mu \mathrm{m}$ ), and the threshold was set with the absolute intensity. Subsequently, the volume $\left(\mu \mathrm{m}^{3}\right)$ of the generated surface was calculated.

\section{Live cell imaging of 2D-cultured hiPSC-CMs}

After cardiac differentiation, hiPSC-CMs were transduced for $1 \mathrm{~h}$ in suspension at 37 ${ }^{\circ} \mathrm{C}$ with an adeno-associated virus serotype 6 (AAV6) carrying either the wild-type (WT; ACTN2-WT-HaloTag®) or the mutant (Mut; ACTN2-Mut-HaloTag®) construct under the control of the human TNNT2 promoter at a MOI of $10,000 .{ }^{24}$ Ultimately, transduced hiPSC-CMs were seeded in Geltrex-coated (1:100; Gibco, Grand Island, NY) 96-well plates at a density of 2,500 - 5,000 cells per well. Live-cell imaging experiments were performed after 7 days in culture by adding TMR-ligand to the medium (0.1 mM; G8251, Promega, Madison, WI) for $30 \mathrm{~min}$, specifically staining ACTN2-HaloTag® protein, followed by washing twice with culture medium and 10 min of Hoechst 33342 incubation $(1 \mu \mathrm{g} / \mathrm{mL}$; H3570, Thermo Fisher Scientific, Waltham, MA), which was diluted in culture medium, followed by a final washing step. Images of hiPSC-CMs were acquired by confocal microscopy using a Zeiss LSM 800 confocal microscope, whereby only beating hiPSC-CMs were included to ensure cell viability. Quantification of integration events was carried out in a blinded fashion and expressed as percentage of transduced hiPSC-CMs.

\section{High-content imaging of 2D cultured hiPSC-CMs}

HiPSC-CMs were either gently thawed or dissociated at day 17 into single cells using collagenase $\mathrm{II}^{51}$ and transduced with an AAV6-TNNT2-mTagRFP-mWasabihLC3 (human LC3) tandem construct (MOI 10,000) for $1 \mathrm{~h}$ at $37^{\circ} \mathrm{C}$, while inverting the tube every $10 \mathrm{~min}$, including a non-transduced control. HiPSC-CMs were seeded at a density of 2,500 cells in 96-well plates. After 30 days of culture, hiPSC-CMs were washed twice with PBS and fixed with Roti-Histofix (Roth, Karlsruhe, Germany) for 20 min at $4{ }^{\circ} \mathrm{C}$. After three additional washing steps with PBS, hiPSC-CMs were stained with a TNNT2 antibody (1:500; ab45932) and with Hoechst 33342 (1 $\mu \mathrm{g} / \mathrm{mL}$; Thermo Fisher Scientific, Waltham, MA), as previously described.6, 28 Automated image acquisition was performed in the Operetta high-content imaging system (Perkin Elmer), by capturing mWasabi signal (green), mTagRFP signal (red) and 
counterstained nuclei (Hoechst) and TNNT2 (far-red), at 20x magnification. Since mWasabi is quenched in the acidic autolysosomes, green puncta were considered as autophagosomes. Assuming the red puncta to represent autophagosomes plus lysosomes, we then quantified the red puncta minus green puncta as autolysosomes in hiPSC-CMs. This was done by Harmony high-content imaging analysis software, by repurposing previously developed algorithms for determination of cardiomyocyterelevant markers. ${ }^{52}$ In brief, hiPSC-CMs were identified by displaying positive TNNT2 signal and quantification of green and red puncta (number and intensity) was done in the whole cell area using Harmony in-built functions.

\section{RNA isolation and gene expression analysis}

Total RNA was extracted from 2D-cultured hiPSC-CMs using TRIzol@ Reagent (Life Technologies) following the manufacturer's protocol. For expression analysis with the nanoString nCounter ${ }^{\circledR}$ Elements technology a total amount of 50 ng RNA was hybridized with a customized nanoString Gene Expression CodeSet (Table VI in the Data Supplement) and analyzed using the $\mathrm{nCounter} \circledast$ Sprint Profiler (nanoString). The mRNA levels were determined with the nSolver ${ }^{\mathrm{TM}}$ Data Analysis Software including background subtraction using negative controls and normalization to housekeeping genes (ABCF1, CLTC, GAPDH, TUBB; Table VI in the Data Supplement) and expressed as fold change over ACTN2ic for the respective groups. For RNA sequencing analysis, samples derived from 2-3 independent differentiations were analyzed for each comparison. Therefore, total RNA was extracted from individual 2D cell pellet or EHT (2-3 biological replicates per differentiation) and after concentration measurement, equal amounts of RNA from 2-3 hiPSC-CMs in 2Dcultured or EHT format of each biological replicate (differentiation) were pooled and prepared as previously reported. ${ }^{6}$

For RNA-seq analysis, gene abundance were quantified using salmon (v0.12.0), ${ }^{53}$ and human gene annotations from gencode (version 33) for GRCh38 genome assembly were imported using $\mathrm{R}$ package tximport. ${ }^{54}$ Counts normalization and differential gene expression analysis was performed using DESeq2 package. ${ }^{55}$ Null variance of Wald test statistic output by DESeq2 was re-estimated using $R$ package fdrtool ${ }^{56}$ to calculate $P$-values (and adjusted using Benjamini-Hochburg method) for the final list of differentially expressed genes. FDR (BH-adjusted $P$ value) $<0.1$ and $\log 2$ fold change $<X$ was used as criteria for the final $D E$ gene list. 


\section{Protein isolation}

The isolation of proteins from 2D-cultured hiPSC-CMs is based on a recent publication, ${ }^{57}$ with adjusted volumes as follow. For the isolation of protein from untreated 2D-cultured hiPSC-CMs, $50 \mu \mathrm{L}$ water with protease inhibitor cocktail was added to obtain the cytosolic fraction and $75 \mu \mathrm{L}$ SDS-buffer for the collection of the membrane-enriched fraction. For the isolation of protein from treated 2D-cultured hiPSC-CMs, $100 \mu \mathrm{L}$ SDS-buffer was added, the samples homogenized and spun down for $15 \mathrm{~min}$ at $14000 \mathrm{rpm}$ at RT. The supernatant was kept has total crude protein lysate.

\section{Western blot analysis}

Western blot analysis was performed according to previous publications, ${ }^{57,} 58$ with slight adaptations. For analysis of 30-day-old, 2D-cultured hiPSC-CMs, total crude protein lysates were evaluated by mixing $7.5 \mu \mathrm{g}$ of protein with $6 \mathrm{x}$ Laemmli buffer and subsequent separations on 4-15\% Mini-PROTEAN Precast Gels (Bio-Rad, Hercules, CA) or $10 \% / 12 \%$ self-casted acrylamide/bisacrylamide (29:1) gels. After electrophoresis, proteins were transferred to nitrocellulose or PVDF membranes and stained with the following antibodies: ACTN2 - A7811(1:10,000), Sigma-Aldrich, St. Louis, MO; TNNT2 - ab8295 (1:5000), Abcam, Cambridge, UK; GAPDH - 5 G4 (1:5000), HyTest, Turku, Finland; LC3B - 2775 (1:1000), Cell Signaling Technology, Danvers, MA; SQSTM1 - P0067 (1:2000), Sigma-Aldrich, St. Louis, MO; ubiquitin FK2 clone, BML-PW8810 (1:10,000), Enzo Life Sciences, Farmingdale, NY. Signals were detected using the SuperSignal West Dura Extended Duration Substrate (Thermo Fisher Scientific, Rockford, IL), acquired with the ChemiDoc Touch Imaging System (Bio-Rad, Hercules, CA) and quantified with the Image Lab software (BioRad, Hercules, CA).

\section{Measurement of chymotrypsin-like activity of the proteasome}

The measurement of the chymotrypsin-like activity of the proteasome was based on previous publications ${ }^{59,60}$ and was slightly adapted for the evaluation in the cytosolic fraction of untreated 30-day-old, 2D-cultured hiPSC-CMs. To determine the activity of the $20 \mathrm{~S}$ proteasome, $10 \mu \mathrm{g}$ of protein were used for the measurement which was 
performed in the absence of ATP and with a final concentration of $60 \mu \mathrm{M}$ of the synthetic fluorogenic substrate Suc-LLVY-AMC (Enzo Life Sciences, BML-P802).

\section{Proteome analysis}

Generation of protein samples: Samples derived from 3 independent differentiations were analyzed for each comparison. Initially, protein was extracted from individual 2D cell pellet or EHT (2-3 biological replicates per differentiation) by five cycles of freezing (liquid nitrogen) and thawing $\left(30^{\circ} \mathrm{C}, 1,400 \mathrm{rpm}\right)$ in $8 \mathrm{M}$ urea/2 $\mathrm{M}$ thiourea. Cell debris and insoluble material was separated by centrifugation $(20,000 \times \mathrm{g}, 1 \mathrm{~h}$ at $4{ }^{\circ} \mathrm{C}$ ). After determination of protein content with a Bradford assay (Biorad, Munich, Germany), equal protein amounts from 2-3 hiPSC-CMs in 2D culture or EHT format of each biological replicate (differentiation) were pooled and subjected to proteolytic digestion.

Sample preparation: $4 \mu \mathrm{g}$ of total protein from each sample were reduced $(2.5 \mathrm{mM}$ DTT ultrapure, Invitrogen, for $15 \mathrm{~min}$ at $37^{\circ} \mathrm{C}$ ) and alkylated (10 mM iodacetamide, Sigma Aldrich, for $30 \mathrm{~min}$ at $37^{\circ} \mathrm{C}$ ). Proteolysis was performed using LysC (1:100 for $3 \mathrm{~h}$ at $37^{\circ} \mathrm{C}$ ), followed by tryptic digestion overnight at $37^{\circ} \mathrm{C}$ (both from Promega, Madison, WI, USA). The tryptic digestion was stopped by adding acetic acid (final concentration 1\%) followed by desalting using ZipTip- $\mu$ C18 tips (Merck Millipore, Darmstadt, Germany). Eluted peptides were concentrated by evaporation under vacuum and subsequently resolved in $0.1 \%$ acetic acid, $2 \%$ acetonitrile (ACN) containing HRM/iRT peptides (Biognosys, Zurich, Switzerland) according to manufacturer's recommendation.

Mass Spectrometry Measurements: Mass spectrometric (MS) data was recorded on a QExactive HFx mass spectrometer (Thermo Electron, Bremen, Germany). Before MS data acquisition tryptic peptides were separated by reverse phase chromatography (Accucore ${ }^{\mathrm{TM}}$ 150-C18, $25 \mathrm{~cm} \times 75 \mu \mathrm{m}, 2.6 \mu \mathrm{m} \mathrm{C} 18,150 \AA$ ) using an Ultimate 3000 nano-LC system (Thermo Scientific, Waltham, MA, USA) at a constant temperature of $40^{\circ} \mathrm{C}$ and a flow rate of $300 \mathrm{~nL} / \mathrm{min}$.

To design a spectral library, MS/MS peptides were separated by 2 or $3 \mathrm{~h}-$ linear gradients with increasing acetonitrile concentration from 5 to $25 \%$ in $0.1 \%$ 
acetic acid, and data were recorded in data dependent mode (DDA). The MS scans were carried out in a $\mathrm{m} / \mathrm{z}$ range of 350 to $1650 \mathrm{~m} / \mathrm{z}$. Data were acquired with a resolution of 60,000 and an AGC target of $3 \times 10^{6}$ at maximal injection times of 45 ms. The top 12 most abundant isotope patterns with charge $\geq 2$ from the survey scan were selected for fragmentation by high energy collisional dissociation (HCD) with a maximal injection time of $22 \mathrm{~ms}$, an isolation window of $1.3 \mathrm{~m} / \mathrm{z}$, and a normalized collision energy of $27.5 \mathrm{eV}$. Dynamic exclusion was set to $45 \mathrm{~s}$. The MS/MS scans had a resolution of 15,000 and an AGC target of $1 \times 10^{5}$.

The acquisition of MS data for relative quantitation was performed in data independent mode (DIA) after peptide pre-fractionation using a 120 min-linear gradient from $5 \%$ to $25 \%$ acetonitrile in $0.1 \%$ acetic acid. Briefly, the data was acquired in the $\mathrm{m} / \mathrm{z}$ range from 350 to $1200 \mathrm{~m} / \mathrm{z}$, the resolution for MS was 120,000 and for MS/MS 30,000. The AGC target was $3 \times 10^{6}$ for $M S$ and MS/MS. The number of DIA isolation windows was 70 of $11 \mathrm{~m} / \mathrm{z}$ with $1 \mathrm{~m} / \mathrm{z}$ overlap. For further details to the instrumental setup and the parameters for LC-MS/MS analysis in DDA and DIA mode see Table VII and Table VIII in the Data Supplement.

Data analysis: Proteins were identified using Spectronaut ${ }^{\mathrm{TM}}$ Pulsar 13.4 software (Biognosys $A G$ ) against a spectral library generated from data-dependent acquisition measurements of individual and pooled samples of the study. The spectral library construction by Spectronaut was based on a database search using a human protein database (Uniprot vs 03_2019, 20404 entries) extended by sequences of bovine fibrinogen subunits $A, B$, and $C$. Because of the use of horse serum as medium supplement, sequences of 10 proteins reproducibly identified by proteotypic peptides were added to the database. The target-decoy search was performed with a parent mass error of $\pm 20 \mathrm{ppm}$, fragment mass error of $0.01 \mathrm{Da}$, and allowing full-tryptic peptides (trypsin/P cleavage rule) with a minimal peptide length of 6 amino acids and up to two internal cleavage sites. The search included carbamidomethylation at cysteine as fixed modification and oxidation at methionine and acetylation at protein $\mathrm{N}$-termini as variable modifications. The generation of the ion library in Spectronaut $^{\mathrm{TM}} \mathrm{v} 13.4 .190802 .43655$ resulted in a constructed library consisting of 335,310 fragments, 30,756 peptides and 3,376 protein groups.

The Spectronaut DIA-MS analysis was carried out as described previously ${ }^{25}$ with project specific modifications. Briefly, the following parameter settings were 
applied: dynamic MS1 and MS2 mass tolerance, dynamic XIC RT extraction window, automatic calibration, dynamic decoy strategy (library size factor $=0.1$, minimum limit $=5000$ ), protein $Q$-value cutoff of 0.01 , precursor $Q$-value cutoff of 0.001 . The search included variable and static modifications as described above for spectral library construction. A local cross run normalization was performed using complete profiles with a $Q$-value $<0.001$. The MS2 peak area was quantified and reported. Missing values were parsed using an iRT profiling strategy with carry-over of exact peak boundaries (minimum $Q$-value row selection $=0.001$ ). Only non-identified precursors were parsed with a $Q$-value $>0.0001$. Ion values were parsed when at least $20 \%$ of the samples contained high quality measured values. Peptides were assigned to protein groups and protein inference was resolved by the automatic workflow implemented in Spectronaut. Only proteins with at least two identified peptides were considered for further analyses.

Data has been median normalized on ion level before statistical analysis was carried out on peptide level after exclusion of peptides with oxidized methionine using the algorithm ROPECA. ${ }^{61}$ Binary differences have been identified by application of a moderate t-test. ${ }^{62}$ Multiple test correction was performed according to Benjamini and Hochberg. ${ }^{63}$ Variance within the data set was visualized by principal component analyses and differences in the protein pattern by Volcano plots.

\section{Production and purification of adeno-associated virus vector particle}

To generate the AAV transfer plasmid pFBGR-TNNT2-GFP, a PCR was performed (primer pair: 5'-GAG CGG CCG CAC GCG TCT CAG TCC ATT AGG AGC CAG TAG C-3' and 5'-GGG CGA ATT GGG TAC CTT ACT TGT ACA GCT CGT CCA TGC CG-3') and inserted into linearized pFBGR-GFP using the In-Fusion HD Cloning Kit (639648, Takara Bio Europe SAS, Kusatsu, Japan) according to the manufacturer's instructions.

The basis of the here applied mTagRFP-mWasabi-hLC3 tandem construct was kindly provided by $\mathrm{Dr} \mathrm{Zhou},{ }^{64}$ and we modified and subcloned it in our lab. $\underline{56}$ Therefore, the vector pBudCE4.1-CMV (Invitrogen, Carlsbad, CA) was digested with BamHI and HindlII. Touchdown PCR was performed using AmpliTaqGold (Thermo Fisher Scientific, Vilnius, Lithuania) and plasmid pcDNA3.1-mTagRFP-mWasabihLC3 as template with the following primer pair: 5'-TTC GAC AAG CTT ACC ATG 
AGC GAG CTG ATT AAG GAG AAC ATG CAC ATG A-3' and 5'-TTC GAC GGA TCC TTA CAC TGA CAA TTT CAT CCC GAA CGT CTC CTG GGA GG-3'. Ligation of the PCR product and the digested vector pBudCE4.1-CMV was performed using T4 Ligase according to manufacturer's instructions (Thermo Fisher Scientific, Vilnius, Lithuania). Subsequently, heat transformation using competent $E$. coli bacteria was performed. In short, bacteria were thawed on ice, 50 ng of DNA (ligation approach) was added, the tube once flicked and incubated for 30 min on ice. The heat shock was performed at $42{ }^{\circ} \mathrm{C}$ for $45 \mathrm{sec}$, followed by a 5 -min incubation on ice. After the addition of $200 \mu \mathrm{L}$ S.O.C. medium, the approach was incubated for $1 \mathrm{~h}$ at $37{ }^{\circ} \mathrm{C}$ gently shaking, before being plated on ampicillin agar plates. DNA of selected clones was isolated according to manufacturer's instructions (NucleoSpin Plasmid Mini kit, Macherey-Nagel, Düren, Germany) and evaluated by restriction digest and sequencing.

To express the mTagRFP-mWasabi-hLC3 tandem construct under control of the TNNT2 promoter with an ampicillin resistance and the ß-Globin IgG intron for higher transcription efficiency, the pGG2-TNNT2-insert plasmid was digested with BamHI and Nhel. Touchdown PCR was performed using AmpliTaqGold and plasmid pBudCE4.1-CMV-mTagRFP-mWasabi-hLC3 as template with the primer pair: 5'TTC GAC GGA TCC TTA CAC TGA CAA TTT CAT CCC GAA CGT CTC CTG GGA GG-3' and 5'-TTC GAC GCT AGC GCC ACC ATG AGC GAG CTG ATT AAG G-3'. Ligation of the PCR product and the digested pGG2-TNNT2-insert plasmid, heat transformation using competent $E$. coli bacteria and evaluation of selected clones by restriction digest and sequencing was performed as described above. For virus production, the pGG2-TNNT2-mTagRFP-mWasabi-hLC3 was inserted into pFBGRTNNT2 by In-Fusion cloning according to manufacturer's instructions. mTagRFPmWasabi-hLC3 was amplified from pGG2-TNNT2-mTagRFP-mWasabi-hLC3 using PrimeStar GXL Polymerase (Takara Bio Europe SAS, Kusatsu, Japan) using 5'-AAC ATC GAT TGA ATT CAC CAT GAG CGA GCT GAT TAA GG-3' and 5'-TAT AGG GCG AAT TGG GTA CCT TAC ACT GAC AAT TTC ATC CCG A-3'. pFBGR-UltraTNNT2-GFP was cut with EcoRI and $\mathrm{Kpnl}$ and both fragments were inserted simultaneously generating the AAV transfer plasmid pFBGR-Ultra-TNNT2mTagRFP-mWasabi-hLC3.

For live-cell imaging experiments, WT or Mut ACTN2 and HaloTag were assembled and inserted into pFBGR under control of a TNNT2 promoter by In- 
Fusion cloning. Two fragments were generated by PCR using PrimeStar GXL Polymerase (Takara Bio Europe SAS, Kusatsu, Japan): ACTN2 was amplified from plasmids either containing the WT or Mut sequence (c.740C>T; p.Thr247Met) that were kindly provided by Mathias Gautel using 5'-AAC ATC GAT TGA ATT CAC CAT GAA CCA GAT AGA GCC CGG-3' and 5'-GCT CGA GGA CAG ATCG CTC TCC CCG TAG AG-3'. HaloTag was amplified from the vector pFC14K-HaloTag®-CMVFlexi® (G9651, Promega, Madison, WI) using 5'-GAT CTG TCC TCG AGC GAG GAT CTG TAC TTT CAG AGC GAT AAC G-3' and 5'-GGG CGA ATT GGG TAC CTT AAC CGG AAA TCT CCA GAG TAG ACA GC-3'. pFBGR-Ultra-TNNT2-GFP was digested with EcoRI and Kpnl and both fragments were inserted simultaneously generating the AAV transfer plasmid pFBGR-Ultra-TNNT2-ACTN2-WT/Mut-HaloTag. Final AAV transfer plasmids were confirmed by restriction digestion and sequencing. Recombinant baculovirus DNA carrying AAV genomic components was verified by PCR using TNNT2/T7 promoter specific primers.

AAV were produced according to the "titerless infected-cells preservation and scale-up (TIPS)" also known as baculovirus-infected insect cells (BIIC). ${ }^{65}$ Sf9 cells were transfected with recombinant baculovirus DNA derived from pFBGR-UltraTNNT2-mTagRFP-mWasabi-hLC3 or pFBGR-Ultra-TNNT2-ACTN2-WT/MutHaloTag and pSR646-Ultra mCherry using TransIT®-Insect Transfection Reagent (MoBITec, Goettingen, Germany) according to the manufacturer's instructions. After 3 days, Sf9 cells (Novagen, Darmstadt, Germany) were collected, and 2E+07 fresh Sf9 cells were infected with this primary stock. On the next day, vital fluorescing TriEx Sf9 Cells (Novagen, Darmstadt, Germany) were collected and frozen at 2E+06 cells BIIC stocks in InsectXpress medium (Biozym Scientific GmbH, Verviers, Belgium)/10\% DMSO. For AAV production, 2E+08 fresh Sf9 cells were cultivated in InsectXpress Medium at a density of 2E+06 cells $/ \mathrm{ml}$. $\sim 2 \mathrm{E}+06$ Sf9 BIIC stocks containing the expression cassette TNNT2-mTagRFP-mWasabi-hLC3 or TNNT2ACTN2-WT/Mut-HaloTag and $\sim 2 E+06$ Sf9 BIIC stocks containing the desired AAV packaging elements were added. AVV lysis buffer $(50 \mathrm{mM}$ Tris base, $100 \mathrm{M} \mathrm{NaCl}, 5$ $\mathrm{mM} \mathrm{MgCl} 2, \mathrm{pH} 8.5$ ) was used for harvest. To remove cell debris, centrifugation for 20 min at $12,000 \times \mathrm{g}$ was performed, and vector containing lysates were purified using lodixanol (OptiPrep, PROGEN Biotechnik, Heidelberg, Germany) step gradients. $40 \%$ lodixanol layers were harvested, and iodixanol was removed by ultrafiltration 
bioRxiv preprint doi: https://doi.org/10.1101/2021.10.28.466251; this version posted October 28, 2021. The copyright holder for this preprint (which was not certified by peer review) is the author/funder, who has granted bioRxiv a license to display the preprint in perpetuity. It is made available under aCC-BY-NC-ND 4.0 International license.

(Amicon Ultra-4, PLQK Ultracel-PL Membran, 50 kDa, MerckMillipore, Darmstadt, Germany). 


\section{Supplemental Figures and Tables}

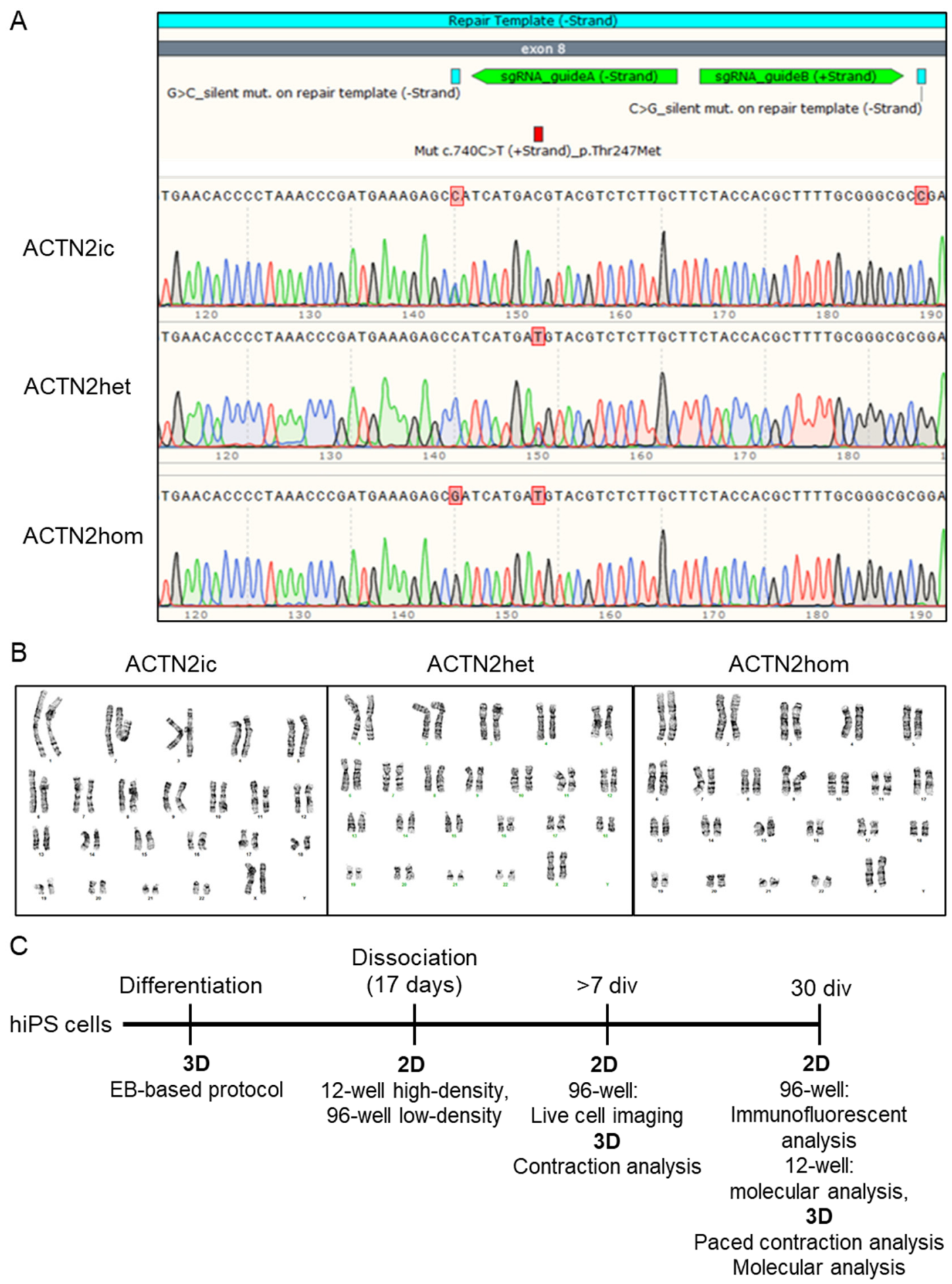

Figure S1. Generation of the homozygous ACTN2hom mutant cell line. (A) Representative Sanger sequencing results of the affected ACTN2 locus in the ACTN2ic, ACTN2het, and ACTN2hom human induced pluripotent stem cell-derived CMs (hiPSC-CMs). Depicted are the mutation on position g.54,208 (c.740C>T), the repair template from g.54,148-54,270 (-strand), the according silent mutations encoded on the repair template on position g.54,200 (G>C; -strand) and g.54,245 (C>G; -strand; rep. template, repair template), and sgRNAs A and B. (B) G-banding 
bioRxiv preprint doi: https://doi.org/10.1101/2021.10.28.466251; this version posted October 28, 2021. The copyright holder for this preprint (which was not certified by peer review) is the author/funder, who has granted bioRxiv a license to display the preprint in perpetuity. It is made available under aCC-BY-NC-ND 4.0 International license.

results are depicted by representative karyograms of the investigated human iPSC ACTN2ic (passage 55), ACTN2het (passage 11) and ACTN2hom (passage 68) line. (C) Disease modeling approach for the production of hiPSC-CMs, models and experimental procedures that were used for this study. Abbreviations: div, days in vitro; EB, embryoid body. 
A

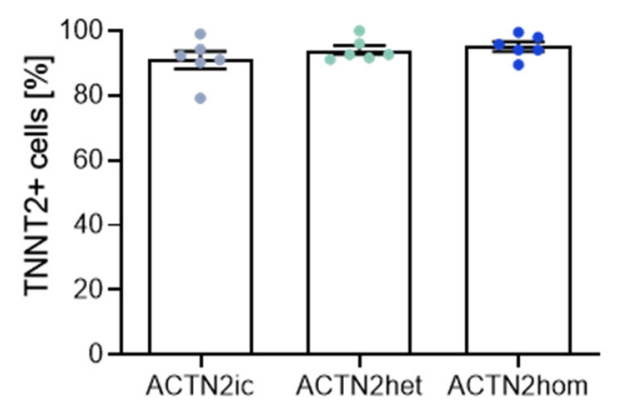

B

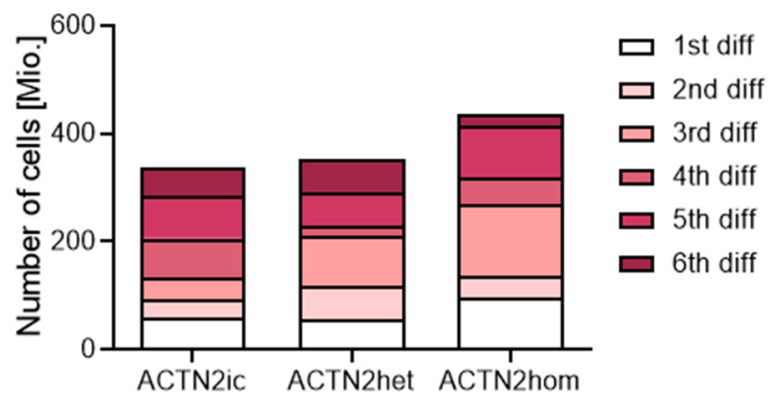

Figure S2: Validation of efficiency of cardiac differentiation. (A) Percentage of TNNT2+ cells in ACTN2ic, ACTN2het, and ACTN2hom hiPSC-CMs was determined by flow cytometry to validate the quality of cardiac differentiation ( $n=$ number of differentiations; ACTN2ic $(n=6)$; ACTN2het $(n=6)$; ACTN2hom $(n=6))$. (B) Cardiomyocyte yield of six single differentiation runs was evaluated in ACTN2ic, ACTN2het, and ACTN2hom hiPSC-CMs. 
A

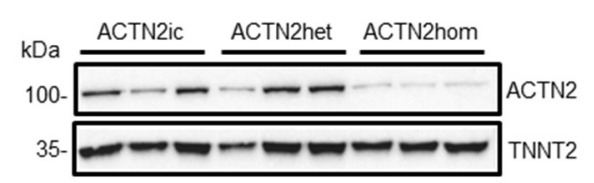

B

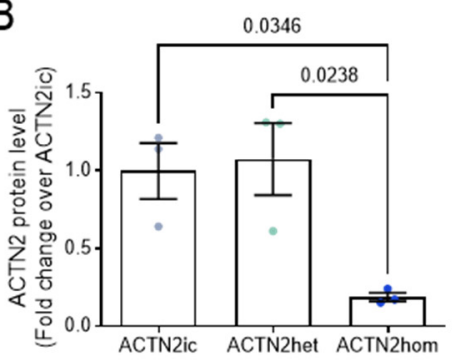

C

$$
\begin{aligned}
& \text { ACTN2-associated Sarcomere assembly Thin filament-associated Thick filament-associated }
\end{aligned}
$$

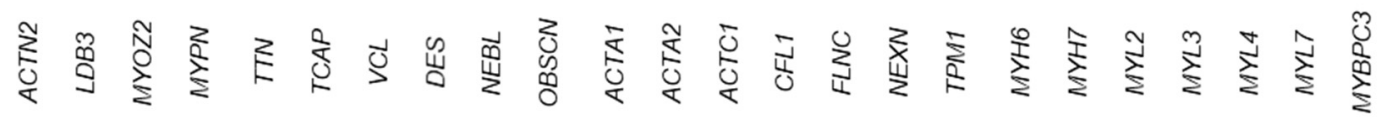

\begin{tabular}{|l|l|l|l|l|l|l|l|l|l|l|l|l|l|l|l|l|l|l|l|l|l|l|l|l|} 
ACTN2ic & 1.0 & 1.0 & 1.0 & 1.0 & 1.0 & 1.0 & 1.0 & 1.0 & 1.0 & 1.0 & 1.0 & 1.0 & 1.0 & 1.0 & 1.0 & 1.0 & 1.0 & 1.0 & 1.0 & 1.0 & 1.0 & 1.0 & 1.0 & 1.0 \\
\hline
\end{tabular}

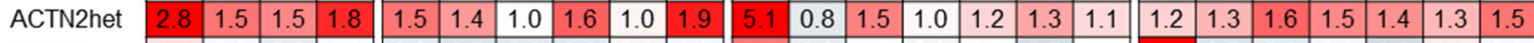

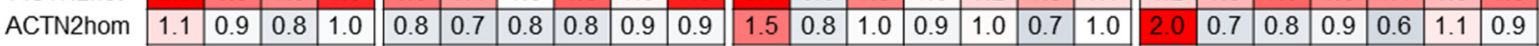

Figure S3. Protein and gene expression analysis of 30-day-old, 2D-cultured hiPSC-CMs. Representative Western blot (A), performed on SDS-fraction of pooled samples of hiPSC-CMs stained with antibodies against ACTN2 and TNNT2 and (B) corresponding quantification of ACTN2 normalized to TNNT2 is shown (ACTN2ic: $\mathrm{N} / \mathrm{d}=3 / 1$, ACTN2het: $\mathrm{N} / \mathrm{d}=3 / 1$, ACTN2hom: N/d = 3/1); Data are expressed as mean \pm SEM, with $P$-values obtained by one-way ANOVA and Tukey's post-test. (C) Gene expression analysis was performed with the nanoString nCounter $\circledast$ Elements technology. HiPSC-CMs were normalized to housekeeping genes ABCF1, CLTC, GAPDH, TUBB and related to ACTN2ic (ACTN2ic N/n=18/3, ACTN2het: N/n=15/3, ACTN2hom: $N / n=17 / 3)$. Abbreviations: TNNT2, cardiac troponin T; kDa, kilodalton; $\mathrm{N} / \mathrm{n} / \mathrm{d}$, number of (pooled) cells/wells/differentiations. 
A

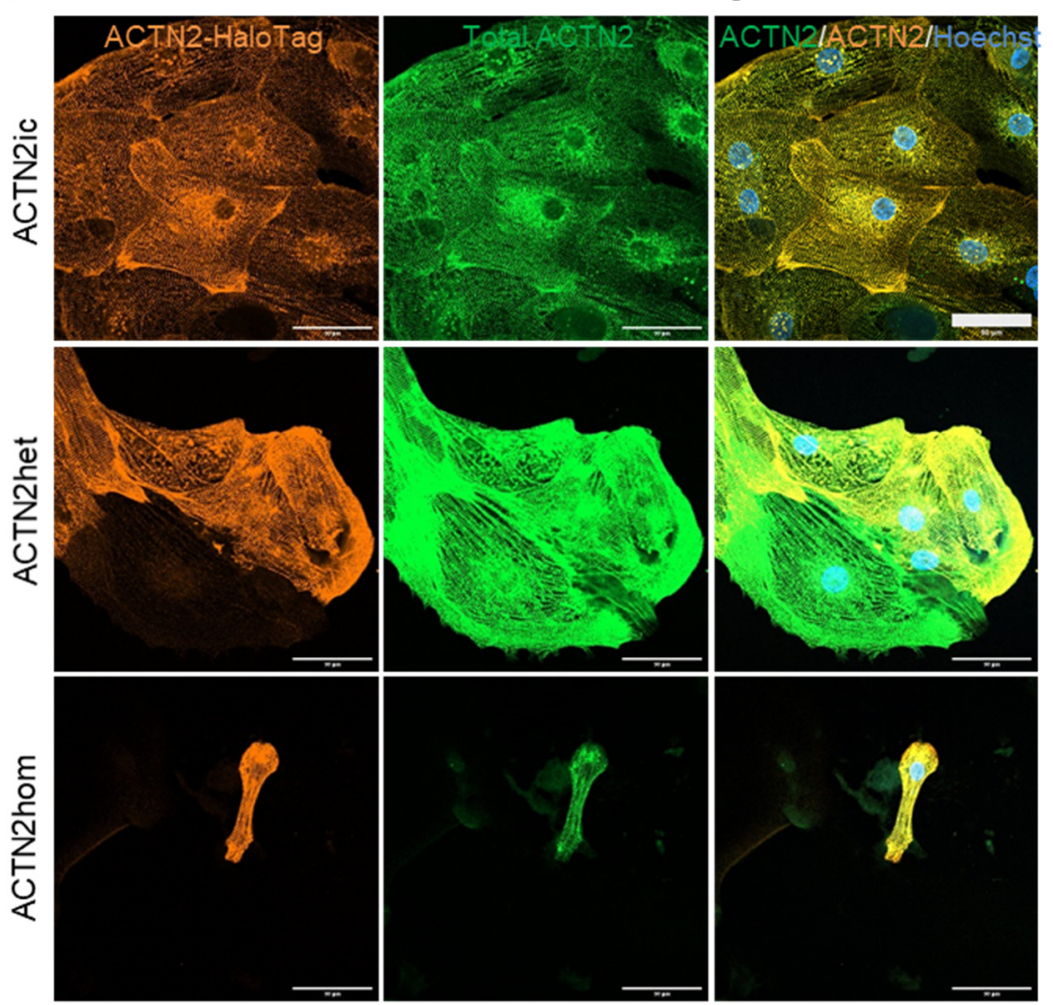

B

AAV6-ACTN2-Mut-HaloTag

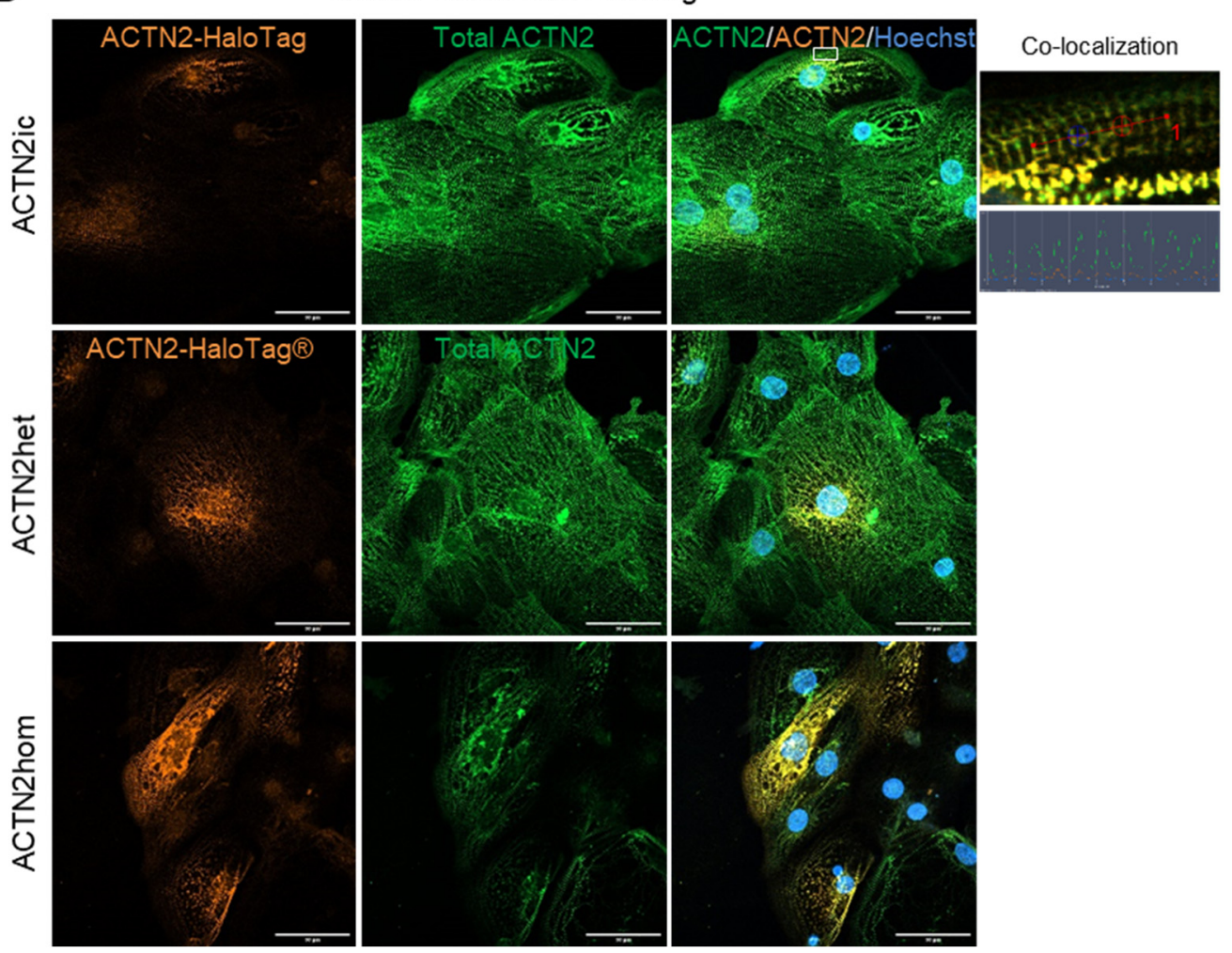

Figure S4. Immunofluorescence analysis of 30-day-old, 2D-cultured hiPSCCMs. Representative images of fixed ACTN2ic, ACTN2het- and ACTN2hom-hiPSCCMs transduced with an AAV6 either carrying the ACTN2-WT-HaloTag® (A) or ACTN2-Mut-HaloTag® (B). HiPSC-CMs were fixed after 30 days of culture and 
bioRxiv preprint doi: https://doi.org/10.1101/2021.10.28.466251; this version posted October 28, 2021. The copyright holder for this preprint (which was not certified by peer review) is the author/funder, who has granted bioRxiv a license to display the preprint in perpetuity. It is made available under aCC-BY-NC-ND 4.0 International license.

subsequently stained with an antibody against the HaloTag®, ACTN2 and Hoechst for nuclei staining (scale bar $=50 \mu \mathrm{m}$ ). Images were taken with a Zeiss LSM 800 microscope. Abbreviations: AAV6, adeno-associated virus serotype 6; Mut, mutant; WT, wild-type; N/n/d, number of cells/wells/differentiations. 
bioRxiv preprint doi: https://doi.org/10.1101/2021.10.28.466251; this version posted October 28, 2021. The copyright holder for this preprint (which was not certified by peer review) is the author/funder, who has granted bioRxiv a license to display the preprint in perpetuity. It is made available under aCC-BY-NC-ND 4.0 International license.

A

ACTN2het vs. ACTN2ic

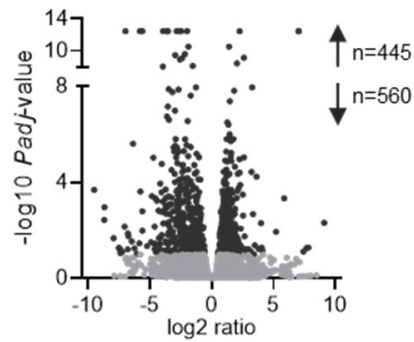

D

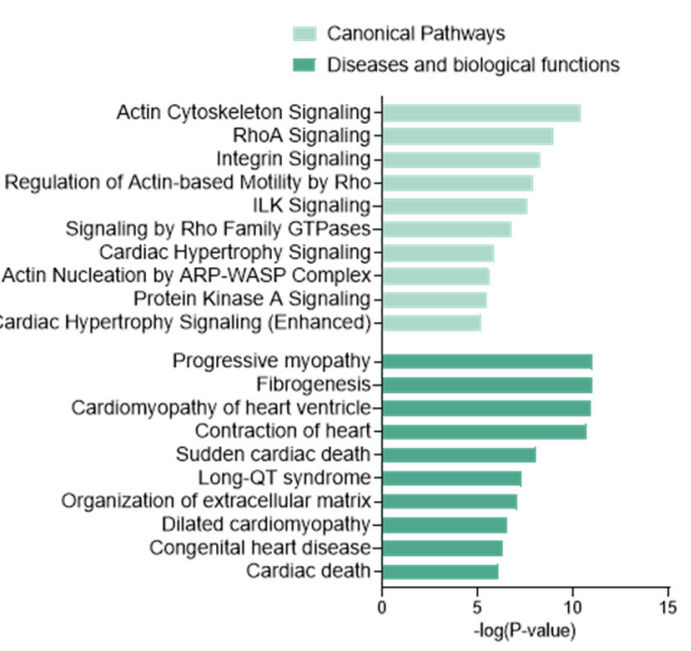

F

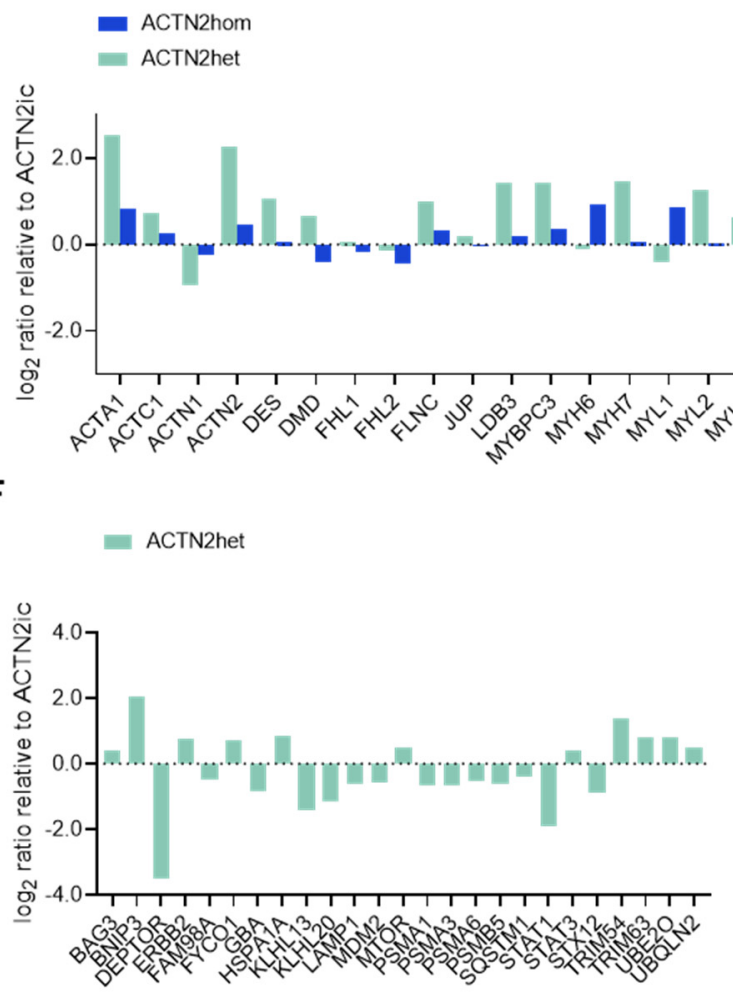

E
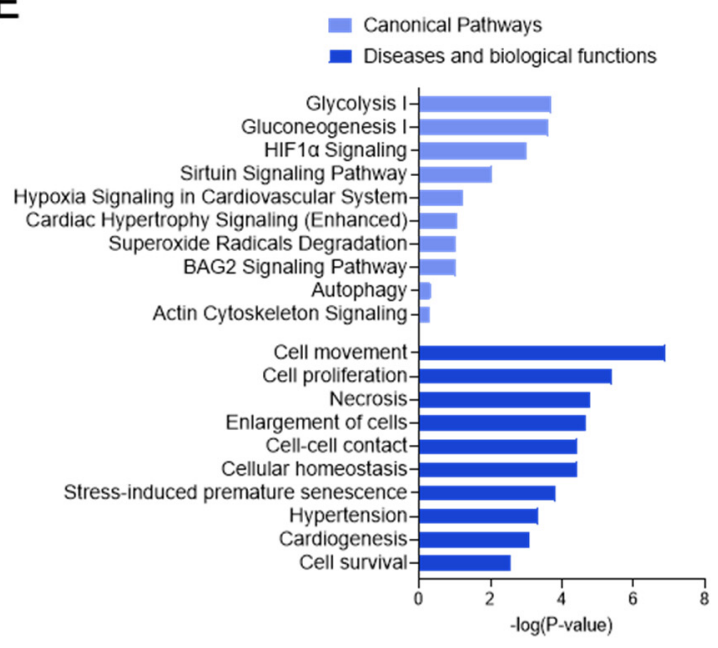

luconeogenesis HIF1a Signaling ACTN2het vs. ACTN2ic ACTN2hom vs. ACTN2ic

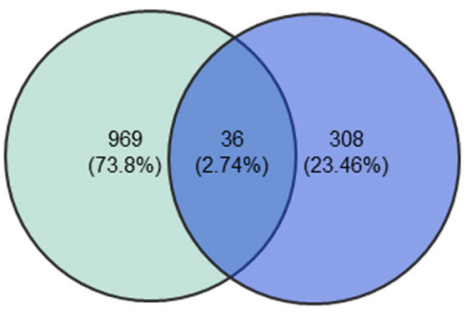

Hypoxia Signaling sertrophy Signaling (Enhanced)-_BAG2 Signaling Pathwayeleton SignalingCell proliferation Necrosisargement of cellsular homeostasisHypertensionCell survival- $\log (\mathrm{P}$-value $)$

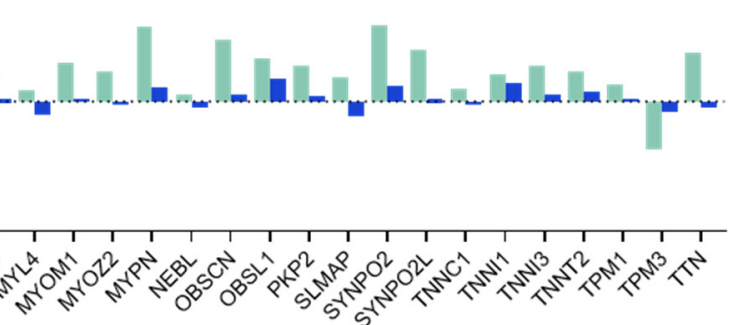

G

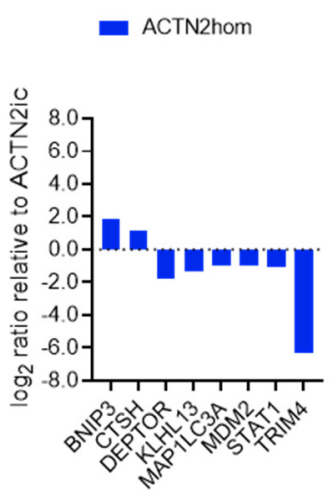

Figure S5. RNA-seq analysis of 30-day-old, 2D-cultured hiPSC-CMs. Alterations in gene expression levels between ACTN2het vs. ACTN2ic and ACTN2hom vs. ACTN2ic hiPSC-CMs are displayed in (A,B) Volcano plots that show -log10 of Padjvalue vs. magnitude of change (log2 ratio) whereby light grey dots indicate FDR > 
0.1 and dark grey dots FDR $<0.1$, and in $(\mathbf{C})$ a Venn diagram that also depicts the number of genes that are dysregulated in both ACTN2het and ACTN2hom ACTN2ic hiPSC-CMs (FDR < 0.1). Selected hits of significantly dysregulated canonical pathways and biological functions in 2D-cultured ACTN2het vs. ACTN2ic (D) and ACTN2hom vs. ACTN2ic (E) hiPSC-CMs based on RNA-seq analysis using Ingenuity Pathway Analysis (IPA). Unsupervised IPA was performed for significantly altered genes (Fisher's exact test; FDR < 0.1). (E) Log2 ratio of altered sarcomereassociated gene expression level in ACTN2het and ACTN2hom hiPSC-CMs $(P<$ 0.05). Log2 ratio of altered gene expression level in genes encoding proteins of the UPS and ALP in ACTN2het (F) and ACTN2hom (G) vs. ACTN2ic hiPSC-CMs $(P<$ 0.05). 


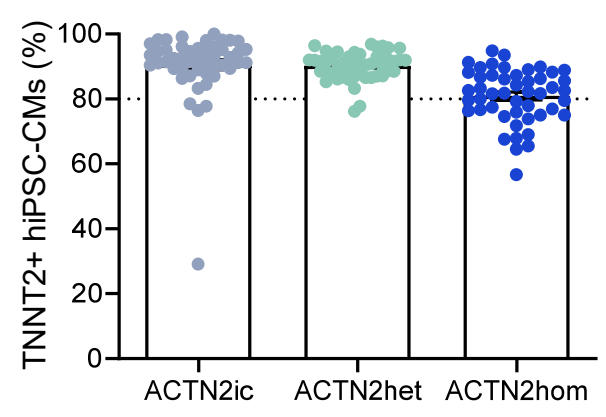

Figure S6. Evaluation of the purity in AAV6-mWasabi-mTagRFP-hLC3 tandem construct transduced hiPSC-CMs. Percentage of TNNT2+ hiPSC-CMs is shown as a marker of cardiomyocyte purity in ACTN2ic, ACTN2het, and ACTN2hom hiPSCCMs $(n=$ wells/CMs per well: ACTN2ic $(n=48)$; ACTN2het $(n=48)$; ACTN2hom $(n$ $=48)$ ). Data are expressed as mean \pm SEM. 


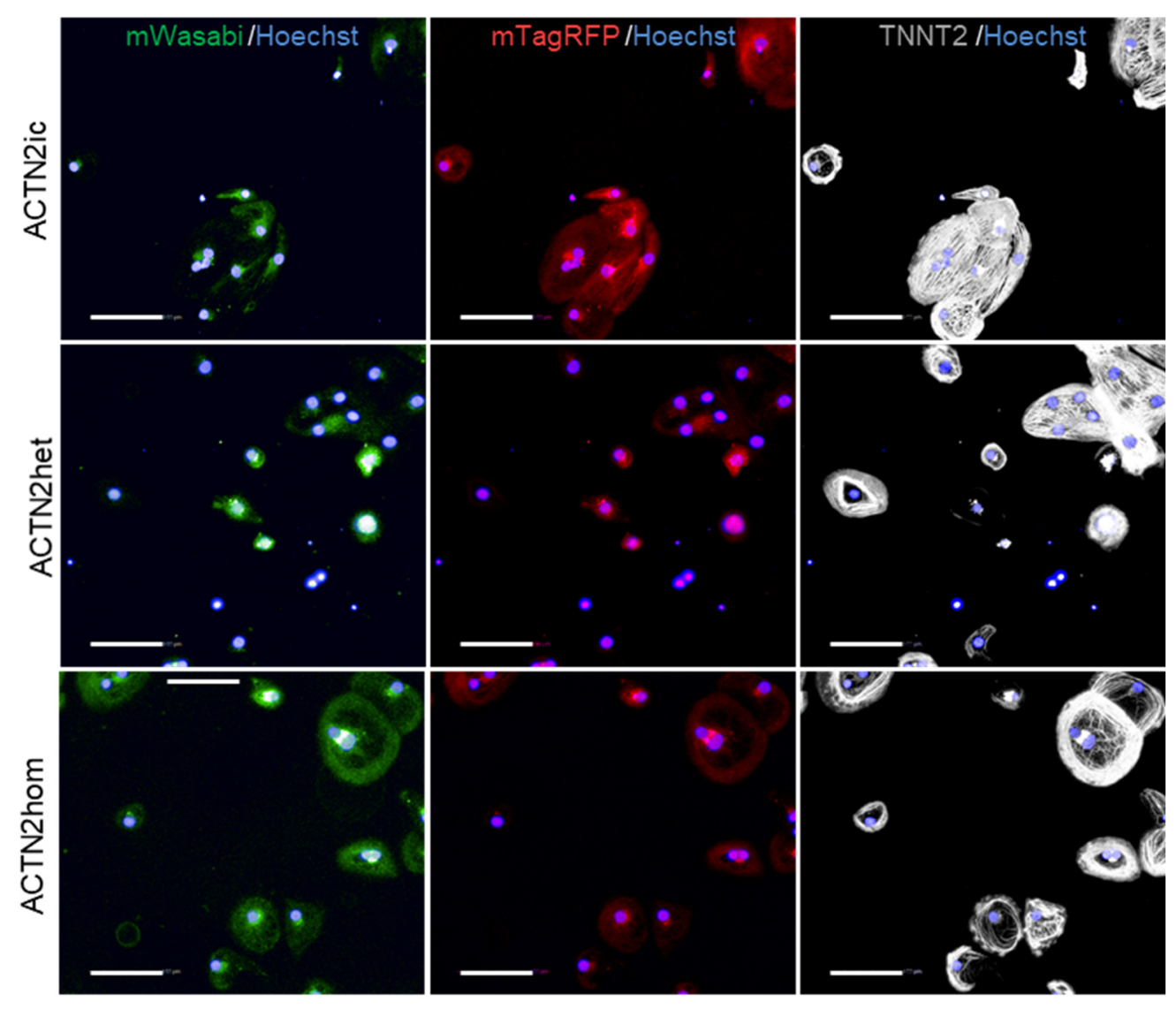

Figure S7. Representative images of the high-content screening performed in 2D-cultured hiPSC-CMs. Depicted are representative images of AAV6-mWasabimTagRFP-hLC3-transduced ACTN2ic, ACTN2het, and ACTN2hom hiPSC-CMs on day 30 of culture. Subsequently, the hiPSC-CMs were fixed and stained with a TNNT2 (cardiac troponin T) antibody and Hoechst for nuclei staining. Representative images were taken with the Operetta high-content imaging system at 20x magnification (PerkinElmer; Scale bar $=100 \mu \mathrm{m}$ ). 
A

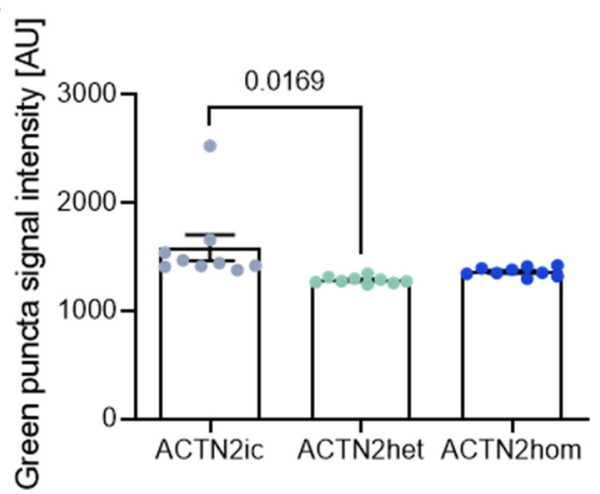

C

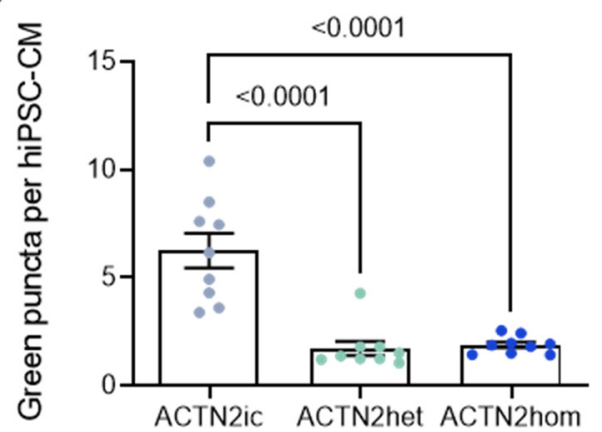

B
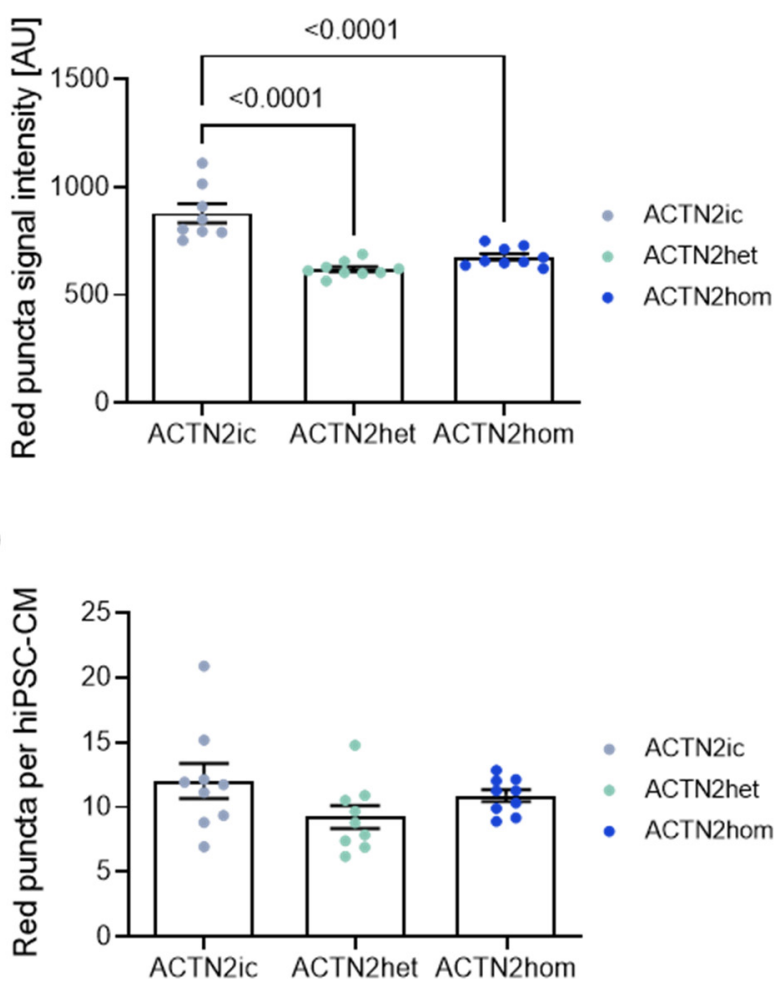

Figure S8. Examination of the high-content ALP screening in transduced hiPSC-CMs. Quantification of the green $(A)$ and red $(B)$ puncta intensity in mWasabi_mTagRFP_hLC3-transduced ACTN2ic, ACTN2het, and ACTN2hom hiPSC-CMs ( $n=$ mean intensity per well: ACTN2ic $(n=8-9)$; ACTN2het $(n=9)$; ACTN2hom $(n=9))$. Number of green (C) and red (D) puncta in mWasabi_mTagRFP_hLC3-transduced ACTN2ic, ACTN2het, and ACTN2hom hiPSC-CMs ( $n=$ wells/treatment per CMs per well: ACTN2ic $(n=9)$; ACTN2het $(n=$ $9)$; ACTN2hom $(n=9)$ ). Data are expressed as mean \pm SEM, and $P$-values were obtained with one-way ANOVA and Tukey's post-test. 
A

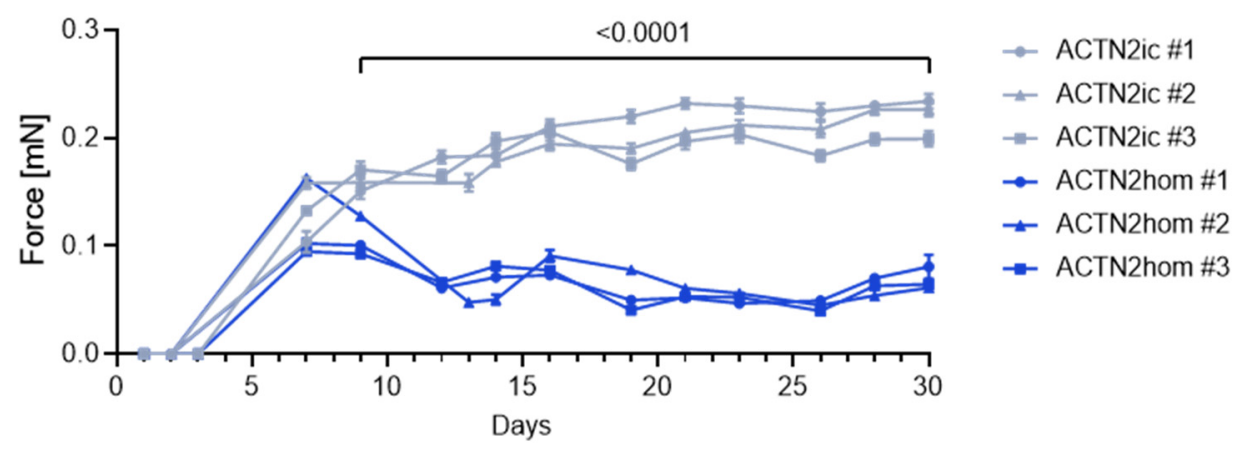

B

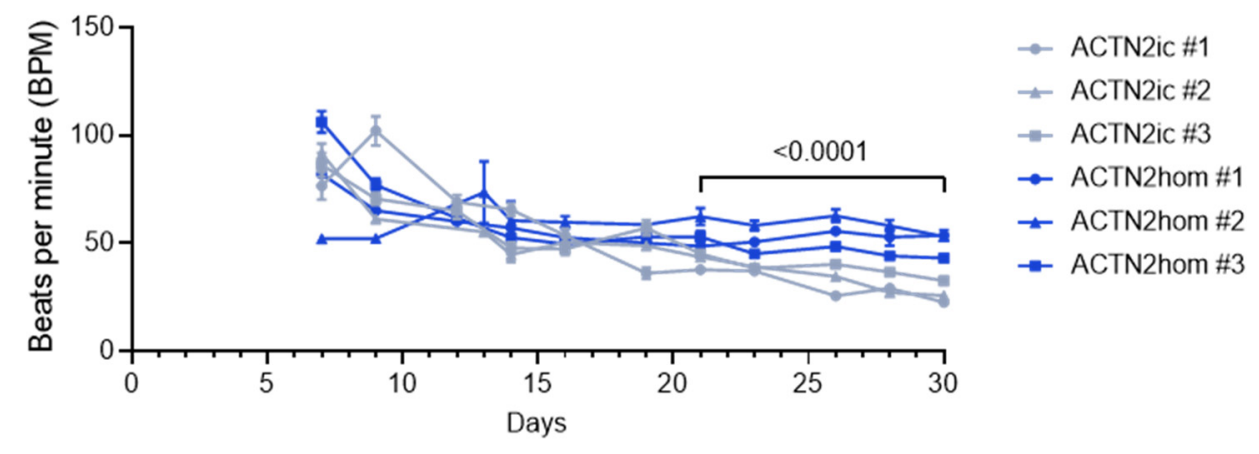

Figure S9. Functional measurements of 3D-cultured hiPSC-CMs in engineered heart tissue (EHT) format. (A) Force and (B) beats per minute were measured under unpaced conditions in EHT culture medium or in $1.8 \mathrm{mM} \mathrm{Ca}^{2+}$ Tyrode's solution at $37{ }^{\circ} \mathrm{C}$ (ACTN2ic: $\mathrm{N} / \mathrm{d}=27-44 / 3$, ACTN2hom: $\mathrm{N} / \mathrm{d}=32-44 / 3$ ). Data are expressed as mean \pm SEM, with $P$-values obtained with a mixed-effects analysis plus Sidak's post-test performed on pooled batches. $\mathrm{N} / \mathrm{d}$, number of EHTs/differentiations. 
Table S1. RNA-seq and mass-spectrometry analyses of sarcomere-associated proteins in 2D-cultured ACTN2het vs. ACTN2ic hiPSC-CMs.

\begin{tabular}{|c|c|c|c|c|c|c|c|c|c|c|c|c|}
\hline $\begin{array}{l}\text { Cell } \\
\text { line }\end{array}$ & Group & RNA & $\begin{array}{l}\text { Log2 } \\
\text { ratio }\end{array}$ & FC & $P$-value & $\begin{array}{c}\text { Adjusted } \\
P \text {-value }\end{array}$ & Group & Protein & $\begin{array}{l}\text { Log2 } \\
\text { ratio }\end{array}$ & FC & $P$-value & $\begin{array}{c}\text { Adjusted } \\
P \text {-value }\end{array}$ \\
\hline \multirow{19}{*}{ 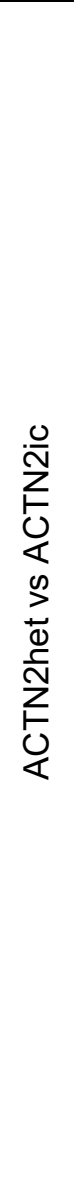 } & \multirow{19}{*}{ 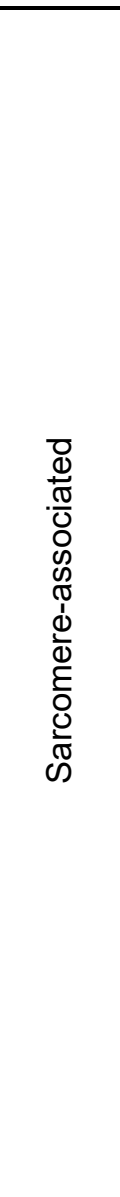 } & ACTA1 & 2.52 & 5.73 & $5.53 \mathrm{E}-13$ & $3.26 \mathrm{E}-04$ & \multirow{19}{*}{ 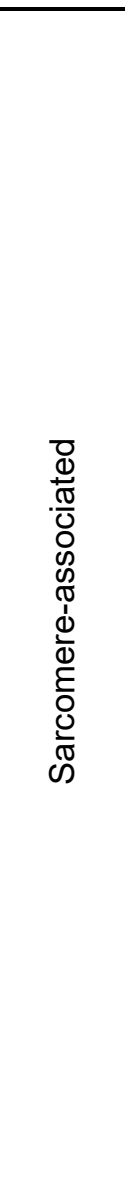 } & ACTA1 & -0.08 & 0.94 & $9.22 \mathrm{E}-01$ & $1.00 \mathrm{E}+00$ \\
\hline & & ACTC1 & 0.73 & 1.66 & $9.77 \mathrm{E}-06$ & $7.99 \mathrm{E}-02$ & & ACTC1 & -0.03 & 0.98 & $9.77 \mathrm{E}-01$ & $1.00 E+00$ \\
\hline & & ACTN1 & -0.95 & 0.52 & $6.53 \mathrm{E}-05$ & $1.41 \mathrm{E}-01$ & & ACTN1 & 0.39 & 1.31 & 1.12E-04 & 2.69E-02 \\
\hline & & ACTN2 & 2.25 & 4.77 & 7.12E-46 & $3.33 E-13$ & & ACTN2 & 0.12 & 1.09 & 8.10E-01 & $1.00 \mathrm{E}+00$ \\
\hline & & $D E S$ & 1.06 & 2.08 & 9.51E-05 & $1.56 \mathrm{E}-01$ & & DES & -0.22 & 0.86 & $9.74 \mathrm{E}-01$ & $1.00 \mathrm{E}+00$ \\
\hline & & $D M D$ & 0.66 & 1.58 & $3.02 \mathrm{E}-08$ & 1.33E-02 & & DMD & 0.08 & 1.06 & $1.00 \mathrm{E}+00$ & $1.00 \mathrm{E}+00$ \\
\hline & & FHL1 & -0.01 & 0.99 & 9.56E-01 & 9.99E-01 & & FHL1 & 0.95 & 1.93 & $2.71 \mathrm{E}-02$ & $1.00 \mathrm{E}+00$ \\
\hline & & FHL2 & -0.15 & 0.90 & $4.59 \mathrm{E}-01$ & $9.72 \mathrm{E}-01$ & & FHL2 & 0.44 & 1.35 & $6.31 \mathrm{E}-05$ & $2.60 \mathrm{E}-02$ \\
\hline & & FLNC & 0.99 & 1.99 & $1.97 \mathrm{E}-14$ & $1.07 \mathrm{E}-04$ & & FLNC & -0.02 & 0.99 & $1.00 \mathrm{E}+00$ & $1.00 \mathrm{E}+00$ \\
\hline & & JUP & 0.19 & 1.14 & 2.97E-01 & 9.43E-01 & & JUP & -0.02 & 0.99 & $1.00 \mathrm{E}+00$ & $1.00 \mathrm{E}+00$ \\
\hline & & LDB3 & 1.44 & 2.71 & $3.54 \mathrm{E}-20$ & $9.89 \mathrm{E}-07$ & & LDB3 & 0.33 & 1.26 & $9.71 \mathrm{E}-02$ & $1.00 E+00$ \\
\hline & & MYBPC3 & 1.42 & 2.68 & $1.58 \mathrm{E}-15$ & $4.36 \mathrm{E}-05$ & & MYBPC3 & 0.09 & 1.06 & $1.00 \mathrm{E}+00$ & $1.00 \mathrm{E}+00$ \\
\hline & & MYH6 & -0.09 & 0.94 & $6.94 \mathrm{E}-01$ & 9.91E-01 & & MYH6 & -0.60 & 0.66 & 2.11E-01 & $1.00 \mathrm{E}+00$ \\
\hline & & MYH7 & 1.47 & 2.78 & 1.37E-08 & $1.01 \mathrm{E}-02$ & & MYH7 & -0.01 & 0.99 & $9.61 \mathrm{E}-07$ & $6.93 \mathrm{E}-04$ \\
\hline & & MYL1 & -0.41 & 0.75 & 6.37E-01 & $9.89 \mathrm{E}-01$ & & MYL1 & -0.35 & 0.78 & $1.00 \mathrm{E}+00$ & $1.00 \mathrm{E}+00$ \\
\hline & & MYL2 & 1.27 & 2.42 & $2.08 \mathrm{E}-05$ & $1.01 \mathrm{E}-01$ & & MYL2 & 0.03 & 1.02 & $3.91 \mathrm{E}-01$ & $1.00 \mathrm{E}+00$ \\
\hline & & MYL3 & 0.63 & 1.54 & $9.15 \mathrm{E}-04$ & $2.95 \mathrm{E}-01$ & & MYL3 & 0.07 & 1.05 & $1.00 \mathrm{E}+00$ & $1.00 \mathrm{E}+00$ \\
\hline & & MYL4 & 0.27 & 1.21 & 7.37E-02 & 7.83E-01 & & MYL4 & 0.23 & 1.17 & 9.81E-01 & $1.00 \mathrm{E}+00$ \\
\hline & & MYOM1 & 0.88 & 1.83 & $1.98 \mathrm{E}-09$ & $5.28 \mathrm{E}-03$ & & MYOM1 & 0.11 & 1.08 & $2.82 \mathrm{E}-01$ & $1.00 \mathrm{E}+00$ \\
\hline
\end{tabular}




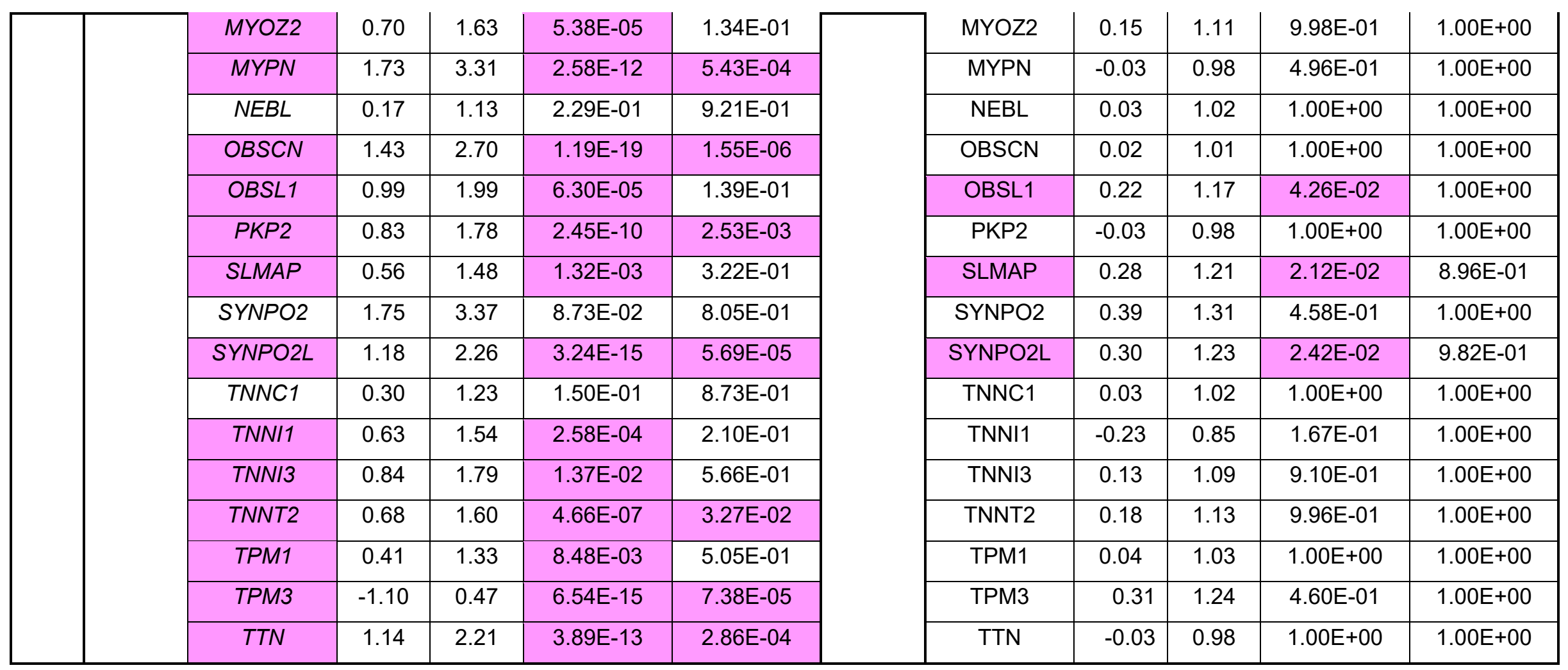

Purple indicates significantly altered genes or proteins. Abbreviation: FC, Fold change. 
Table S2. RNA-seq and mass-spectrometry analyses of sarcomere-associated proteins in 2D-cultured ACTN2hom vs. ACTN2ic hiPSC-CMs.

\begin{tabular}{|c|c|c|c|c|c|c|c|c|c|c|c|c|}
\hline $\begin{array}{l}\text { Cell } \\
\text { line }\end{array}$ & Group & RNA & $\begin{array}{l}\text { Log2 } \\
\text { ratio }\end{array}$ & FC & $P$-value & $\begin{array}{c}\text { Adjusted } \\
P \text {-value }\end{array}$ & Group & Protein & $\begin{array}{l}\text { Log2 } \\
\text { ratio }\end{array}$ & FC & $P$-value & $\begin{array}{c}\text { Adjusted } \\
P \text {-value }\end{array}$ \\
\hline \multirow{19}{*}{ 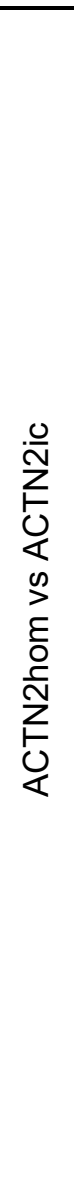 } & \multirow{19}{*}{ 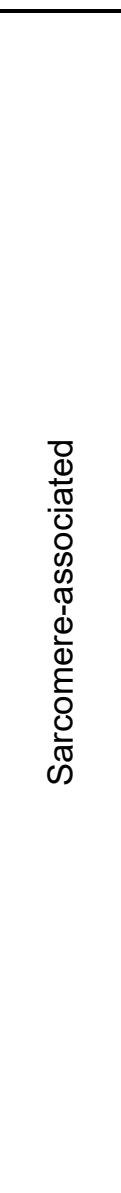 } & ACTA1 & 0.84 & 1.78 & $6.98 \mathrm{E}-02$ & $4.42 \mathrm{E}-01$ & \multirow{19}{*}{ 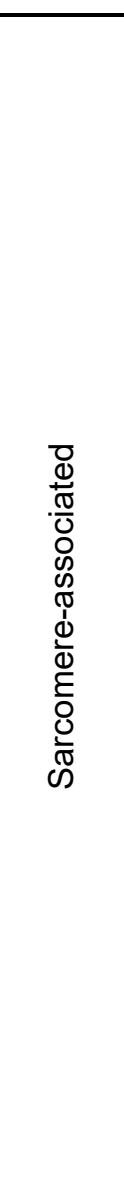 } & ACTA1 & -0.59 & 0.66 & 6.30E-06 & $2.93 \mathrm{E}-04$ \\
\hline & & ACTC1 & 0.26 & 1.20 & 2.69E-01 & $8.56 \mathrm{E}-01$ & & ACTC1 & -0.64 & 0.64 & $3.27 \mathrm{E}-03$ & $4.84 \mathrm{E}-02$ \\
\hline & & ACTN1 & -0.26 & 0.84 & $6.57 \mathrm{E}-01$ & $9.83 \mathrm{E}-01$ & & ACTN1 & 0.48 & 1.39 & $2.63 \mathrm{E}-05$ & $9.58 \mathrm{E}-04$ \\
\hline & & ACTN2 & 0.46 & 1.38 & 2.14E-01 & $8.02 \mathrm{E}-01$ & & ACTN2 & -1.63 & 0.32 & $3.02 \mathrm{E}-80$ & 2.91E-77 \\
\hline & & $D E S$ & -0.01 & 0.99 & $9.75 \mathrm{E}-01$ & 9.97E-01 & & DES & 0.31 & 1.24 & $7.03 \mathrm{E}-02$ & 3.34E-01 \\
\hline & & $D M D$ & -0.40 & 0.76 & $2.54 \mathrm{E}-01$ & $8.44 \mathrm{E}-01$ & & DMD & -0.21 & 0.87 & $2.10 \mathrm{E}-02$ & $1.70 \mathrm{E}-01$ \\
\hline & & FHL1 & -0.19 & 0.88 & 7.31E-01 & $9.87 \mathrm{E}-01$ & & FHL1 & 0.56 & 1.47 & 1.34E-02 & 1.30E-01 \\
\hline & & FHL2 & -0.44 & 0.74 & $4.49 \mathrm{E}-02$ & $3.37 \mathrm{E}-01$ & & FHL2 & 0.27 & 1.20 & $3.74 \mathrm{E}-02$ & $2.37 \mathrm{E}-01$ \\
\hline & & FLNC & 0.33 & 1.25 & $1.71 \mathrm{E}-01$ & $7.26 \mathrm{E}-01$ & & FLNC & -0.49 & 0.71 & $3.94 \mathrm{E}-21$ & $1.42 \mathrm{E}-18$ \\
\hline & & JUP & -0.06 & 0.96 & $8.18 \mathrm{E}-01$ & $9.96 \mathrm{E}-01$ & & JUP & -0.31 & 0.80 & $5.19 \mathrm{E}-06$ & 2.54E-04 \\
\hline & & $\angle D B 3$ & 0.21 & 1.15 & $6.18 \mathrm{E}-01$ & $9.80 \mathrm{E}-01$ & & LDB3 & 0.01 & 1.01 & $1.00 \mathrm{E}+00$ & $1.00 \mathrm{E}+00$ \\
\hline & & MYBPC3 & 0.35 & 1.27 & 3.94E-01 & $9.33 \mathrm{E}-01$ & & MYBPC3 & -0.82 & 0.57 & $4.61 \mathrm{E}-51$ & $3.32 \mathrm{E}-48$ \\
\hline & & MYH6 & 0.92 & 1.89 & 2.95E-02 & 2.56E-01 & & MYH6 & -0.52 & 0.70 & $3.35 \mathrm{E}-02$ & 2.23E-01 \\
\hline & & MYH7 & -0.01 & 0.99 & $9.75 \mathrm{E}-01$ & 9.97E-01 & & MYH7 & -0.89 & 0.54 & $1.23 \mathrm{E}-10$ & $1.54 \mathrm{E}-08$ \\
\hline & & $M Y L 1$ & 0.85 & 1.81 & $3.44 \mathrm{E}-01$ & 9.11E-01 & & MYL1 & -0.81 & 0.57 & $2.17 \mathrm{E}-115$ & $3.13 \mathrm{E}-112$ \\
\hline & & MYL2 & -0.03 & 0.98 & $9.49 \mathrm{E}-01$ & $9.96 \mathrm{E}-01$ & & MYL2 & -0.65 & 0.64 & $5.23 \mathrm{E}-03$ & $6.92 \mathrm{E}-02$ \\
\hline & & MYL3 & 0.03 & 1.02 & $9.11 \mathrm{E}-01$ & $9.96 \mathrm{E}-01$ & & MYL3 & -0.68 & 0.62 & $2.10 \mathrm{E}-09$ & $2.33 \mathrm{E}-07$ \\
\hline & & MYL4 & -0.32 & 0.80 & $2.06 \mathrm{E}-01$ & $7.88 \mathrm{E}-01$ & & MYL4 & -0.58 & 0.67 & 1.31E-06 & $7.15 \mathrm{E}-05$ \\
\hline & & MYOM1 & 0.06 & 1.04 & $8.56 \mathrm{E}-01$ & 9.96E-01 & & MYOM1 & -0.99 & 0.50 & $1.80 \mathrm{E}-05$ & $7.01 \mathrm{E}-04$ \\
\hline
\end{tabular}




\begin{tabular}{|c|c|c|c|c|c|c|c|c|c|}
\hline MYOZ2 & -0.07 & 0.95 & 8.09E-01 & 9.96E-01 & MYOZ2 & -1.00 & 0.50 & $5.66 \mathrm{E}-42$ & 3.26E-39 \\
\hline MYPN & 0.32 & 1.25 & 5.26E-01 & $9.72 \mathrm{E}-01$ & MYPN & -0.24 & 0.84 & $1.91 \mathrm{E}-15$ & $4.59 \mathrm{E}-13$ \\
\hline$N E B L$ & -0.14 & 0.90 & $6.14 \mathrm{E}-01$ & $9.80 \mathrm{E}-01$ & NEBL & -0.63 & 0.65 & $9.34 \mathrm{E}-21$ & $2.99 \mathrm{E}-18$ \\
\hline OBSCN & 0.15 & 1.11 & $7.25 \mathrm{E}-01$ & 9.87E-01 & OBSCN & -0.72 & 0.61 & $8.78 \mathrm{E}-22$ & $3.62 \mathrm{E}-19$ \\
\hline OBSL1 & 0.51 & 1.42 & 1.51E-01 & 6.88E-01 & OBSL1 & -0.24 & 0.85 & 2.36E-01 & $6.25 \mathrm{E}-01$ \\
\hline PKP2 & 0.13 & 1.10 & $6.45 \mathrm{E}-01$ & 9.83E-01 & PKP2 & -0.55 & 0.68 & 9.08E-05 & $2.73 E-03$ \\
\hline SLMAP & -0.34 & 0.79 & 2.04E-01 & 7.84E-01 & SLMAP & -0.21 & 0.86 & 9.36E-02 & 3.92E-01 \\
\hline SYNPO2 & 0.37 & 1.29 & $4.28 \mathrm{E}-01$ & $9.43 \mathrm{E}-01$ & SYNPO2 & -0.40 & 0.76 & $1.78 \mathrm{E}-02$ & $1.54 \mathrm{E}-01$ \\
\hline SYNPO2L & 0.02 & 1.01 & 9.59E-01 & 9.96E-01 & SYNPO2L & -0.69 & 0.62 & 3.31E-07 & 2.33E-05 \\
\hline TNNC1 & -0.09 & 0.94 & 6.90E-01 & 9.84E-01 & TNNC1 & -0.89 & 0.54 & $2.12 \mathrm{E}-08$ & 1.91E-06 \\
\hline TNNI1 & 0.44 & 1.36 & $1.17 \mathrm{E}-01$ & $6.03 E-01$ & TNNI1 & -0.87 & 0.55 & 8.09E-07 & 4.67E-05 \\
\hline TNNI3 & 0.15 & 1.11 & $5.12 \mathrm{E}-01$ & $9.70 \mathrm{E}-01$ & TNNI3 & -0.82 & 0.57 & 4.57E-05 & $1.54 \mathrm{E}-03$ \\
\hline TNNT2 & 0.22 & 1.17 & $3.50 \mathrm{E}-01$ & $9.16 \mathrm{E}-01$ & TNNT2 & -0.86 & 0.55 & $3.74 \mathrm{E}-07$ & 2.51E-05 \\
\hline TPM1 & 0.07 & 1.05 & $7.44 \mathrm{E}-01$ & 9.91E-01 & TPM1 & -0.80 & 0.57 & $9.28 \mathrm{E}-14$ & $1.78 \mathrm{E}-11$ \\
\hline TPM3 & -0.23 & 0.86 & $6.77 \mathrm{E}-01$ & $9.83 \mathrm{E}-01$ & TPM3 & -0.93 & 0.52 & $4.17 \mathrm{E}-02$ & $2.49 \mathrm{E}-01$ \\
\hline TTN & -0.14 & 0.90 & $7.64 \mathrm{E}-01$ & $9.93 \mathrm{E}-01$ & TTN & -0.83 & 0.56 & $0.00 \mathrm{E}+00$ & $3.60 \mathrm{E}-306$ \\
\hline
\end{tabular}

Purple indicates significantly altered genes or proteins. Abbreviation: FC, Fold change. 
Table S3. RNA-seq and mass-spectrometry analyses of the UPS and ALP in 2D-cultured ACTN2het vS. ACTN2ic hiPSCCMs.

\begin{tabular}{|c|c|c|c|c|c|c|c|c|c|c|c|c|}
\hline $\begin{array}{l}\text { Cell } \\
\text { line }\end{array}$ & Group & RNA & $\begin{array}{l}\text { Log2 } \\
\text { ratio }\end{array}$ & FC & $P$-value & $\begin{array}{c}\text { Adjusted } \\
P \text {-value }\end{array}$ & Group & Protein & $\begin{array}{l}\text { Log2 } \\
\text { ratio }\end{array}$ & FC & $P$-value & $\begin{array}{c}\text { Adjusted } \\
P \text {-value }\end{array}$ \\
\hline \multirow{19}{*}{ 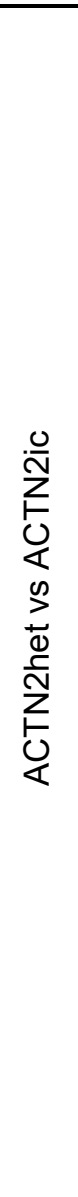 } & \multirow{19}{*}{$\begin{array}{l}0 \\
\frac{1}{\alpha} \\
0 \\
\frac{1}{\pi} \\
\infty \\
0 \\
D\end{array}$} & $B A G 3$ & 0.42 & 1.34 & 7.74E-03 & 4.95E-01 & \multirow{18}{*}{$\begin{array}{l}\frac{a}{1} \\
\frac{\pi}{\pi} \\
\frac{0}{0} \\
\frac{\pi}{\sigma} \\
0 \\
0 \\
0\end{array}$} & $\overline{A S A H 1}$ & 0.28 & 1.21 & $2.20 \mathrm{E}-01$ & $1.00 \mathrm{E}+00$ \\
\hline & & BNIP3 & 2.03 & 4.08 & 3.18E-02 & $6.81 \mathrm{E}-01$ & & BAG3 & 0.12 & 1.08 & 8.46E-01 & $1.00 \mathrm{E}+00$ \\
\hline & & DEPTOR & -3.49 & 0.09 & $2.34 \mathrm{E}-08$ & $1.21 \mathrm{E}-02$ & & CTSC & 0.42 & 1.34 & $6.17 \mathrm{E}-03$ & $4.86 \mathrm{E}-01$ \\
\hline & & ERBB2 & 0.77 & 1.70 & 7.58E-07 & 3.73E-02 & & CTSL & 0.47 & 1.39 & 9.47E-02 & $1.00 \mathrm{E}+00$ \\
\hline & & FAM98A & -0.47 & 0.72 & 8.31E-03 & $5.03 \mathrm{E}-01$ & & FAM98A & 0.47 & 1.39 & 5.95E-01 & $1.00 \mathrm{E}+00$ \\
\hline & & FYCO1 & 0.70 & 1.62 & 1.59E-08 & 1.05E-02 & & GBA & 0.22 & 1.16 & $4.51 \mathrm{E}-01$ & $1.00 \mathrm{E}+00$ \\
\hline & & $G B A$ & -0.83 & 0.56 & 7.37E-03 & 4.89E-01 & & HSPA1A & 0.06 & 1.04 & $1.00 \mathrm{E}+00$ & $1.00 \mathrm{E}+00$ \\
\hline & & HSPA1A & 0.83 & 1.78 & 3.36E-05 & 1.16E-01 & & PSMA3 & -0.01 & 0.99 & $1.00 \mathrm{E}+00$ & $1.00 \mathrm{E}+00$ \\
\hline & & KLHL13 & -1.41 & 0.38 & 7.27E-07 & $3.69 \mathrm{E}-02$ & & PSMA6 & 0.03 & 1.02 & $9.99 \mathrm{E}-01$ & $1.00 \mathrm{E}+00$ \\
\hline & & KLHL2O & -1.14 & 0.45 & $1.56 \mathrm{E}-11$ & $1.01 \mathrm{E}-03$ & & PSMB5 & 0.07 & 1.05 & 9.86E-01 & $1.00 \mathrm{E}+00$ \\
\hline & & LAMP1 & -0.63 & 0.65 & $9.37 \mathrm{E}-03$ & $5.16 \mathrm{E}-01$ & & PSMC6 & 0.06 & 1.04 & 9.86E-01 & $1.00 \mathrm{E}+00$ \\
\hline & & MDM2 & -0.58 & 0.67 & $1.64 \mathrm{E}-02$ & $5.88 \mathrm{E}-01$ & & PSMD11 & -0.01 & 0.99 & $1.00 \mathrm{E}+00$ & $1.00 \mathrm{E}+00$ \\
\hline & & MTOR & 0.51 & 1.42 & 9.71E-04 & 2.99E-01 & & PSME1 & 0.16 & 1.12 & 6.02E-01 & $1.00 \mathrm{E}+00$ \\
\hline & & PSMA1 & -0.66 & 0.63 & 3.03E-05 & 1.12E-01 & & PSME2 & 0.15 & 1.11 & 6.63E-01 & $1.00 \mathrm{E}+00$ \\
\hline & & PSMA3 & -0.68 & 0.63 & 7.40E-05 & 1.46E-01 & & TRIM54 & 0.03 & 1.02 & 9.99E-01 & $1.00 \mathrm{E}+00$ \\
\hline & & PSMA6 & -0.51 & 0.70 & $9.71 \mathrm{E}-04$ & $2.99 \mathrm{E}-01$ & & UBA1 & 0.15 & 1.11 & $8.77 \mathrm{E}-01$ & $1.00 \mathrm{E}+00$ \\
\hline & & PSMB5 & -0.62 & 0.65 & 2.28E-05 & $1.03 \mathrm{E}-01$ & & UBE2O & 0.03 & 1.02 & 9.90E-01 & $1.00 \mathrm{E}+00$ \\
\hline & & SQSTM1 & -0.42 & 0.75 & 2.83E-02 & 6.63E-01 & & UBQLN2 & 0.14 & 1.10 & $7.05 E-01$ & $1.00 \mathrm{E}+00$ \\
\hline & & STAT1 & -1.89 & 0.27 & $8.64 \mathrm{E}-32$ & $2.91 \mathrm{E}-11$ & & & & & & \\
\hline
\end{tabular}




\begin{tabular}{|l|c|c|c|c|c|}
\hline \multirow{3}{*}{} & STAT3 & 0.40 & 1.32 & $1.55 \mathrm{E}-02$ & $5.83 \mathrm{E}-01$ \\
\cline { 2 - 6 } & STX12 & -0.88 & 0.54 & $1.09 \mathrm{E}-05$ & $8.33 \mathrm{E}-02$ \\
\cline { 2 - 6 } & TRIM54 & 1.37 & 2.59 & $1.05 \mathrm{E}-12$ & $3.99 \mathrm{E}-04$ \\
\hline & TRIM63 & 0.79 & 1.73 & $3.95 \mathrm{E}-05$ & $1.22 \mathrm{E}-01$ \\
\hline & UBE2O & 0.80 & 1.74 & $4.59 \mathrm{E}-04$ & $2.47 \mathrm{E}-01$ \\
\hline & UBQLN2 & 0.50 & 1.42 & $6.26 \mathrm{E}-04$ & $2.66 \mathrm{E}-01$ \\
\hline
\end{tabular}

Purple indicates significantly altered genes or proteins. Abbreviation: FC, Fold change.

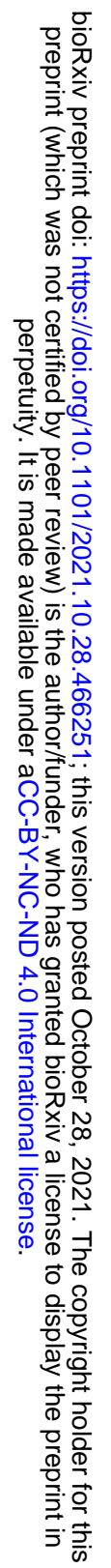


Table S4. RNA-seq and mass-spectrometry analyses of the UPS and ALP in 2D-cultured ACTN2hom vs. ACTN2ic hiPSCCMs.

\begin{tabular}{|c|c|c|c|c|c|c|c|c|c|c|c|c|}
\hline $\begin{array}{l}\text { Cell } \\
\text { line }\end{array}$ & Group & RNA & $\begin{array}{l}\text { Log2 } \\
\text { ratio }\end{array}$ & FC & $P$-value & $\begin{array}{c}\text { Adjusted } \\
P \text {-value }\end{array}$ & Group & Protein & $\begin{array}{l}\text { Log2 } \\
\text { ratio }\end{array}$ & FC & $P$-value & $\begin{array}{c}\text { Adjusted } \\
P \text {-value }\end{array}$ \\
\hline \multirow{18}{*}{ 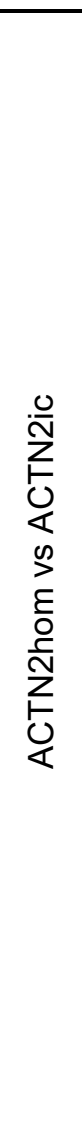 } & \multirow{8}{*}{$\begin{array}{l}0 \\
\frac{1}{<} \\
\frac{0}{0} \\
\frac{1}{0} \\
0 \\
0\end{array}$} & BNIP3 & 1.85 & 3.61 & 0.0006 & $6.16 \mathrm{E}-03$ & \multirow{18}{*}{$\begin{array}{l}0 \\
\frac{1}{\alpha} \\
0 \\
\frac{0}{\pi} \\
0 \\
0 \\
D\end{array}$} & ASAH1 & 0.89 & 1.85 & $2.29 \mathrm{E}-05$ & $8.68 \mathrm{E}-04$ \\
\hline & & $\mathrm{CTSH}$ & 1.13 & 2.18 & 0.0000 & $6.25 \mathrm{E}-05$ & & BAG3 & 0.38 & 1.30 & $2.30 \mathrm{E}-02$ & $1.79 \mathrm{E}-01$ \\
\hline & & DEPTOR & -1.74 & 0.30 & 0.0016 & 1.75E-02 & & CTSC & 0.67 & 1.59 & $1.39 \mathrm{E}-03$ & $2.61 \mathrm{E}-02$ \\
\hline & & KLHL13 & -1.35 & 0.39 & 0.0000 & 1.93E-04 & & CTSL & 1.07 & 2.10 & $2.26 \mathrm{E}-03$ & 3.76E-02 \\
\hline & & MAP1LC3A & -0.94 & 0.52 & 0.0246 & $2.23 \mathrm{E}-01$ & & FAM98A & 1.38 & 2.61 & $1.68 \mathrm{E}-02$ & $1.50 \mathrm{E}-01$ \\
\hline & & MDM2 & -0.95 & 0.52 & 0.0002 & 1.32E-03 & & GBA & 0.38 & 1.30 & $4.71 \mathrm{E}-02$ & $2.69 \mathrm{E}-01$ \\
\hline & & STAT1 & -1.06 & 0.48 & 0.0463 & $3.44 \mathrm{E}-01$ & & HSPA1A & 0.23 & 1.18 & $2.37 \mathrm{E}-03$ & $3.89 \mathrm{E}-02$ \\
\hline & & TRIM4 & -6.35 & 0.01 & 0.0000 & 4.38E-07 & & PSMA3 & 0.38 & 1.30 & 1.97E-02 & $1.62 \mathrm{E}-01$ \\
\hline & & & & & & & & PSMA6 & 0.37 & 1.29 & $6.47 \mathrm{E}-04$ & 1.47E-02 \\
\hline & & & & & & & & PSMB5 & 0.45 & 1.37 & $3.68 \mathrm{E}-02$ & $2.35 \mathrm{E}-01$ \\
\hline & & & & & & & & PSMC6 & 0.29 & 1.22 & $2.02 \mathrm{E}-03$ & $3.42 \mathrm{E}-02$ \\
\hline & & & & & & & & PSMD11 & 0.31 & 1.24 & $1.11 \mathrm{E}-03$ & $2.15 \mathrm{E}-02$ \\
\hline & & & & & & & & PSME1 & 0.46 & 1.37 & $5.36 \mathrm{E}-06$ & $2.54 \mathrm{E}-04$ \\
\hline & & & & & & & & PSME2 & 0.38 & 1.30 & $3.78 \mathrm{E}-02$ & $2.39 \mathrm{E}-01$ \\
\hline & & & & & & & & TRIM54 & 0.44 & 1.36 & $2.60 \mathrm{E}-03$ & 4.10E-02 \\
\hline & & & & & & & & UBA1 & 0.39 & 1.31 & 7.83E-07 & 4.67E-05 \\
\hline & & & & & & & & UBE2O & 0.68 & 1.60 & $2.53 \mathrm{E}-02$ & $1.88 \mathrm{E}-01$ \\
\hline & & & & & & & & UBQLN2 & 0.70 & 1.62 & 7.99E-04 & 1.70E-02 \\
\hline
\end{tabular}

Purple indicates significantly altered genes or proteins. Abbreviation: FC, Fold change. 
Table S5. RNA-seq and mass-spectrometry analyses of sarcomere-associated proteins in 3D-cultured ACTN2hom vs. ACTN2ic hiPSC-CMs.

\begin{tabular}{|c|c|c|c|c|c|c|c|c|c|c|c|c|}
\hline $\begin{array}{l}\text { Cell } \\
\text { line }\end{array}$ & Group & RNA & $\begin{array}{l}\text { Log2 } \\
\text { ratio }\end{array}$ & FC & $P$-value & $\begin{array}{c}\text { Adjusted } \\
P \text {-value }\end{array}$ & Group & Protein & $\begin{array}{l}\text { Log2 } \\
\text { ratio }\end{array}$ & FC & $P$-value & $\begin{array}{c}\text { Adjusted } \\
P \text {-value }\end{array}$ \\
\hline \multirow{19}{*}{ 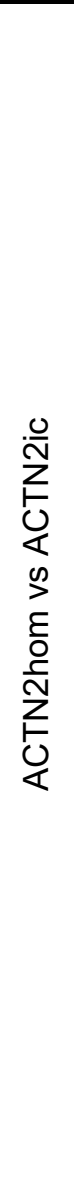 } & \multirow{19}{*}{ 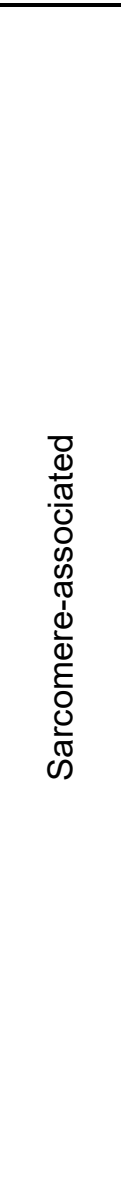 } & ACTA1 & 2.79 & 6.91 & $6.13 \mathrm{E}-05$ & $9.47 \mathrm{E}-02$ & \multirow{19}{*}{ 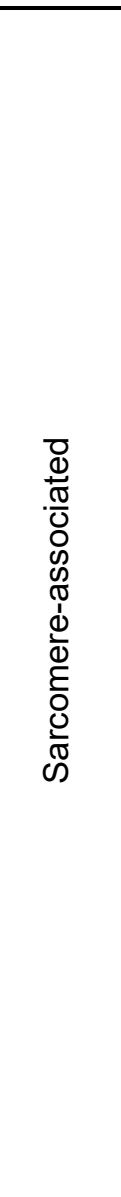 } & ACTA1 & -0.55 & 0.69 & $1.30 \mathrm{E}-04$ & $1.63 \mathrm{E}-02$ \\
\hline & & ACTC1 & 0.71 & 1.64 & $2.41 \mathrm{E}-04$ & $1.74 \mathrm{E}-01$ & & ACTC1 & -0.47 & 0.72 & $6.47 \mathrm{E}-02$ & $1.00 \mathrm{E}+00$ \\
\hline & & ACTN1 & 0.38 & 1.30 & 1.18E-01 & 9.04E-01 & & ACTN1 & 0.03 & 1.02 & $1.00 \mathrm{E}+00$ & $1.00 \mathrm{E}+00$ \\
\hline & & ACTN2 & 0.10 & 1.07 & 6.47E-01 & 9.94E-01 & & ACTN2 & -1.41 & 0.38 & $1.14 \mathrm{E}-56$ & 1.65E-53 \\
\hline & & $D E S$ & 0.61 & 1.53 & $1.41 \mathrm{E}-02$ & $6.46 \mathrm{E}-01$ & & DES & -0.42 & 0.75 & $8.26 \mathrm{E}-07$ & $1.40 \mathrm{E}-04$ \\
\hline & & $D M D$ & -0.14 & 0.91 & $5.65 \mathrm{E}-01$ & $9.91 \mathrm{E}-01$ & & DMD & -0.15 & 0.90 & $1.00 \mathrm{E}+00$ & $1.00 \mathrm{E}+00$ \\
\hline & & FHL1 & -0.04 & 0.97 & 9.49E-01 & 9.99E-01 & & FHL1 & -0.43 & 0.74 & $2.81 \mathrm{E}-01$ & $1.00 \mathrm{E}+00$ \\
\hline & & FHL2 & 0.09 & 1.06 & $7.03 \mathrm{E}-01$ & 9.95E-01 & & FHL2 & -0.14 & 0.91 & $8.59 \mathrm{E}-01$ & $1.00 \mathrm{E}+00$ \\
\hline & & FLNC & 0.70 & 1.63 & $2.72 \mathrm{E}-02$ & $7.50 \mathrm{E}-01$ & & FLNC & -0.09 & 0.94 & $1.00 \mathrm{E}+00$ & $1.00 \mathrm{E}+00$ \\
\hline & & JUP & -0.31 & 0.81 & $9.16 \mathrm{E}-02$ & 8.80E-01 & & JUP & -0.63 & 0.65 & $2.91 \mathrm{E}-12$ & 1.20E-09 \\
\hline & & LDB3 & -0.07 & 0.95 & $6.90 \mathrm{E}-01$ & $9.95 \mathrm{E}-01$ & & LDB3 & -0.44 & 0.74 & $7.13 \mathrm{E}-05$ & $1.00 \mathrm{E}-02$ \\
\hline & & MYBPC3 & 0.20 & 1.15 & $2.87 \mathrm{E}-01$ & $9.70 \mathrm{E}-01$ & & MYBPC3 & -0.94 & 0.52 & $9.00 \mathrm{E}-49$ & $8.65 \mathrm{E}-46$ \\
\hline & & MYH6 & 0.43 & 1.35 & 1.52E-01 & $9.23 \mathrm{E}-01$ & & MYH6 & -0.29 & 0.82 & $3.75 \mathrm{E}-03$ & 2.17E-01 \\
\hline & & MYH7 & 0.04 & 1.03 & 8.86E-01 & 9.97E-01 & & MYH7 & -0.95 & 0.52 & 1.16E-01 & $1.00 \mathrm{E}+00$ \\
\hline & & MYL1 & 1.11 & 2.15 & $3.21 \mathrm{E}-01$ & $9.75 \mathrm{E}-01$ & & MYL1 & -0.74 & 0.60 & 7.06E-94 & 2.04E-90 \\
\hline & & MYL2 & -0.18 & 0.88 & $5.62 \mathrm{E}-01$ & $9.90 \mathrm{E}-01$ & & MYL2 & -0.84 & 0.56 & $1.55 \mathrm{E}-02$ & $5.40 \mathrm{E}-01$ \\
\hline & & MYL3 & -0.35 & 0.78 & $1.18 \mathrm{E}-01$ & $9.04 \mathrm{E}-01$ & & MYL3 & -0.69 & 0.62 & $1.54 \mathrm{E}-08$ & $4.92 \mathrm{E}-06$ \\
\hline & & MYL4 & -0.29 & 0.82 & $1.69 \mathrm{E}-01$ & 9.36E-01 & & MYL4 & -0.56 & 0.68 & 1.14E-07 & 2.52E-05 \\
\hline & & MYOM1 & 0.28 & 1.21 & 1.79E-01 & $9.38 \mathrm{E}-01$ & & MYOM1 & -1.01 & 0.50 & $5.87 \mathrm{E}-04$ & $5.46 \mathrm{E}-02$ \\
\hline
\end{tabular}




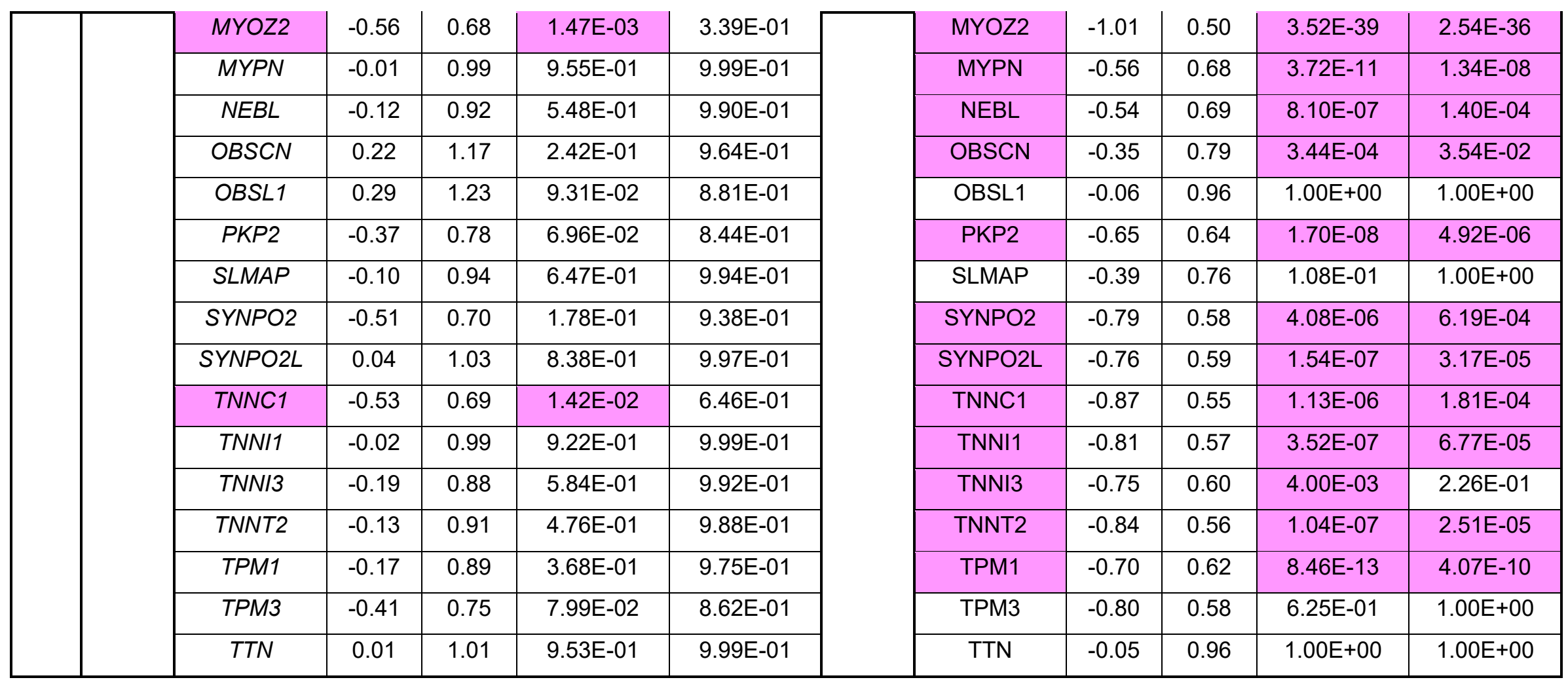

Purple indicates significantly altered genes or proteins. Abbreviation: FC, Fold change. 
Table S6. Acronyms and names of genes evaluated with the nanoString nCounter ${ }^{\circledR}$ Elements technology.

\begin{tabular}{|l|l|l|}
\hline Gene & Acronym & $\begin{array}{l}\text { Accession } \\
\text { (NCBI) }\end{array}$ \\
\hline Alpha-Actinin 2 & ACTN2 & NM_001103.2 \\
\hline LIM Domain Binding 3 & LDB3 & NM_001080116.1 \\
\hline Myozenin 2 & MYOZ2 & NM_016599.4 \\
\hline Myopalladin & MYPN & NM_032578.2 \\
\hline Titin & TTN & NM_133432.1 \\
\hline Titin-cap & TCAP & NM_003673.3 \\
\hline Vinculin & VCL & NM_014000.2 \\
\hline Desmin & DES & NM_001927.3 \\
\hline Nebulin & NEBL & NM_001173484.1 \\
\hline Obscurin & OBSCN & NM_001098623.2 \\
\hline Actin alpha 1, skeletal muscle & ACTA1 & NM_001100.3 \\
\hline Actin Alpha 2, Smooth Muscle & ACTA2 & NM_001613.1 \\
\hline actin alpha cardiac muscle 1 & ACTC1 & NM_005159.4 \\
\hline Cofilin 1 & CFL1 & NM_005507.2 \\
\hline Filamin C & FLNC & NM_001127487.1 \\
\hline Nexilin & NEXN & NM_144573.3 \\
\hline Tropomyosin 1 & TPM1 & NM_000366.5 \\
\hline Myosin heavy chain 6 & MYH6 & NM_002471.3 \\
\hline Myosin heavy chain 7 & MYH7 & NM_000257.2 \\
\hline Myosin Regulatory Light Chain 2 & MYL2 & NM_000432.3 \\
\hline Myosin Regulatory Light Chain 3 & MYL3 & NM_000258.2 \\
\hline Myosin Regulatory Light Chain 4 & MYL4 & NM_002476.2 \\
\hline Myosin Regulatory Light Chain 7 & MYL7 & NM_021223.2 \\
\hline Cardiac myosin binding protein C & MYBPC3 & NM_000256.3 \\
\hline ATP Binding Cassette Subfamily F Member 1 & ABCF1 & NM_001090.2 \\
\hline Clathrin Heavy Chain & CLTC & NM_004859.2 \\
\hline Glyceraldehyde 3-phosphate dehydrogenase & GAPDH & NM_002046.3 \\
\hline Tubulin Beta Class I & TUBB & NM_178014.3 \\
\hline
\end{tabular}


Table S7. LC-MS/MS parameter (data dependent mode, spectral library).

\begin{tabular}{|c|c|}
\hline $\begin{array}{l}\text { Data dependent analyses } \\
\text { (DDA) }\end{array}$ & \\
\hline $\begin{array}{l}\text { Reversed phase liquid } \\
\text { chromatography }\end{array}$ & Ultimate 3000 RSLC (Thermo Scientific) \\
\hline Trap column & $\begin{array}{l}75 \mu \mathrm{m} \text { inner diameter, packed with } 3 \mu \mathrm{m} \text { C18 particles } \\
\text { (Acclaim PepMap100, Thermo Scientific) }\end{array}$ \\
\hline Analytical column & $\begin{array}{l}\text { Accucore }^{\mathrm{TM}} 150-\mathrm{C} 18,25 \mathrm{~cm} \times 75 \mu \mathrm{m}, 2.6 \mu \mathrm{m} \mathrm{C} 18,150 \\
\AA \text { (Thermo Scientific) }\end{array}$ \\
\hline Flow rate & $300 \mathrm{nl} / \mathrm{min}$ \\
\hline Column oven temperature & $40^{\circ} \mathrm{C}$ \\
\hline Buffer system & $\begin{array}{l}\text { Binary buffer system consisting of } 0.1 \% \text { acetic acid in } \\
\text { HPLC-grade water (buffer A) and } 100 \% \text { ACN in } 0.1 \% \\
\text { acetic acid (buffer B) }\end{array}$ \\
\hline Gradient & $\begin{array}{l}\text { Gradient of buffer B: } 2 \min 2 \% \text { to } 5 \%, 10 \min 5 \%, 120 \\
\min 5 \% \text { to } 25 \%, 5 \min 25 \% \text { to } 40 \%, 2 \min 40 \% \text { to } 90 \% \text {, } \\
5 \min 90 \%, 3 \min 90 \% \text { to } 2 \%, 10 \min 2 \%\end{array}$ \\
\hline Mass spectrometer & Q Exactive HFx \\
\hline Operation mode & Data-dependent \\
\hline Electrospray & Nanospray Flex Ion Source \\
\hline \multicolumn{2}{|l|}{ Full MS } \\
\hline MS scan resolution & 60,000 \\
\hline AGC target & $3.00 \mathrm{E}+06$ \\
\hline $\begin{array}{l}\text { Maximum ion injection time } \\
\text { for the MS scan }\end{array}$ & $45 \mathrm{~ms}$ \\
\hline Scan range & 350 to $1650 \mathrm{~m} / \mathrm{z}$ \\
\hline Spectra data type & Profile \\
\hline \multicolumn{2}{|l|}{$d d-M S 2$} \\
\hline Resolution & 15,000 \\
\hline MS/MS AGC target & $1.00 \mathrm{E}+05$ \\
\hline $\begin{array}{l}\text { Maximum ion injection time } \\
\text { for the MS/MS scans }\end{array}$ & $22 \mathrm{~ms}$ \\
\hline Spectra data type & Profile \\
\hline
\end{tabular}




\begin{tabular}{|l|l|}
\hline Selection for MS/MS & $\begin{array}{l}12 \text { most abundant isotope patterns with charge } \geq 2 \\
\text { from the survey scan }\end{array}$ \\
\hline Isolation window & $1,3 \mathrm{~m} / \mathrm{z}$ \\
\hline Fixed first mass & $100 \mathrm{~m} / \mathrm{z}$ \\
\hline Dissociation mode & $\mathrm{HCD}$ \\
\hline Normalized collision energy & $27 \%$ \\
\hline Dynamic exclusion & $45 \mathrm{~s}$ \\
\hline Charge exclusion & $1,>6$ \\
\hline
\end{tabular}


Table S8. LC-MS/MS parameter (data independent mode; quantitative data).

\begin{tabular}{|c|c|}
\hline $\begin{array}{l}\text { Data independent } \\
\text { analyses (DIA) }\end{array}$ & \\
\hline $\begin{array}{l}\text { Reversed phase liquid } \\
\text { chromatography }\end{array}$ & Ultimate 3000 RSLC (Thermo Scientific) \\
\hline Trap column & $\begin{array}{l}75 \mu \mathrm{m} \text { inner diameter, packed with } 3 \mu \mathrm{m} \text { C18 particles } \\
\text { (Acclaim PepMap100, Thermo Scientific) }\end{array}$ \\
\hline Analytical column & $\begin{array}{l}\text { Accucore }^{\mathrm{TM}} 150-\mathrm{C} 18,25 \mathrm{~cm} \times 75 \mu \mathrm{m}, 2.6 \mu \mathrm{m} \mathrm{C} 18,150 \\
\AA \text { (Thermo Scientific) }\end{array}$ \\
\hline Flow rate & $300 \mathrm{nl} / \mathrm{min}$ \\
\hline Column oven temperature & $40^{\circ} \mathrm{C}$ \\
\hline Buffer system & $\begin{array}{l}\text { Binary buffer system consisting of } 0.1 \% \text { acetic acid in } \\
\text { HPLC-grade water (buffer A) and } 100 \% \text { ACN in } 0.1 \% \\
\text { acetic acid (buffer B) }\end{array}$ \\
\hline Gradient & $\begin{array}{l}\text { Dradient of buffer B: } 2 \min 22 \% \text { to } 5 \%, 8 \min 5 \%, 120 \\
\min 5 \% \text { to } 25 \%, 5 \min 25 \text { to } 40 \%, 2 \min 40 \% \text { to } 90 \%, 5 \\
\min 90 \%, 3 \min 90 \% \text { to } 2 \%, 10 \min 2 \%\end{array}$ \\
\hline Mass spectrometer & Q Exactive HFx \\
\hline Operation mode & Data-independent \\
\hline Electrospray & Nanospray Flex Ion Source \\
\hline Full MS & \\
\hline MS scan resolution & 120,000 \\
\hline AGC target & $3.00 \mathrm{E}+06$ \\
\hline $\begin{array}{l}\text { Maximum ion injection time } \\
\text { for the MS scan }\end{array}$ & $60 \mathrm{~ms}$ \\
\hline Scan range & 350 to $1200 \mathrm{~m} / \mathrm{z}$ \\
\hline Spectra data type & Profile \\
\hline DIA MS2 & \\
\hline Resolution & 30,000 \\
\hline MS/MS AGC target & $3.00 \mathrm{E}+06$ \\
\hline $\begin{array}{l}\text { Maximum ion injection time } \\
\text { for the MS/MS scans }\end{array}$ & Auto \\
\hline Spectra data type & Profile \\
\hline
\end{tabular}


bioRxiv preprint doi: https://doi.org/10.1101/2021.10.28.466251; this version posted October 28, 2021. The copyright holder for this preprint (which was not certified by peer review) is the author/funder, who has granted bioRxiv a license to display the preprint in perpetuity. It is made available under aCC-BY-NC-ND 4.0 International license.

\begin{tabular}{|l|l|}
\hline selection for MS/MS & 1 \\
\hline Isolation window & 70 windows $\mathrm{m} / \mathrm{z} 10,11 \mathrm{~m} / \mathrm{z}$ \\
\hline Fixed first mass & 200 \\
\hline Dissociation mode & Higher energy collisional dissociation (HCD) \\
\hline Normalized collision energy & $27.5 \%$ \\
\hline Dissociation mode & HCD \\
\hline
\end{tabular}




\section{Movie legends}

Movie 1. Contracting ACTN2het hiPSC-CMs transduced with WT ACTN2 HaloTag. Widefield fluorescence microscopy of contracting ACTN2ic hiPSC-CMs that were transduced with AAV6-TNNT2-WT-ACTN2-HaloTag and stained for imaging with TMR-ligand to visualize sarcomeres.

Movie 2. Contracting ACTN2het hiPSC-CMs transduced with Mut ACTN2 HaloTag. Widefield fluorescence microscopy of contracting ACTN2ic hiPSC-CMs that were transduced with AAV6-TNNT2-Mut-ACTN2-HaloTag and stained for imaging with TMR-ligand to visualize sarcomeres.

Movie 3. Contracting ACTN2ic EHTs. Widefield video microscopy of contracting ACTN2ic EHTs that were paced at $1 \mathrm{~Hz}$ to analyze functional parameters independent of varying baseline frequencies.

Movie 4. Contracting ACTN2hom EHTs. Widefield video microscopy of contracting ACTN2hom EHTs that were paced at $1 \mathrm{~Hz}$ to analyze functional parameters independent of varying baseline frequencies. 


\section{Data Set legends}

Data Set I. MS data of 2D ACTN2het hiPSC-CMs analyzed with IPA. Significantly altered proteins were submitted to an unsupervised analysis of ACTN2het in relation to ACTN2ic hiPSC-CMs. Fisher's exact test, unadjusted p-value $<0.05$.

Data Set II. RNA-seq data of 2D ACTN2het hiPSC-CMs analyzed with IPA. Significantly altered protein-coding genes were submitted to an unsupervised analysis of ACTN2het in relation to ACTN2ic hiPSC-CMs. Fisher's exact test, unadjusted $p$-value $<0.05$.

Data Set III. MS data of 2D ACTN2hom hiPSC-CMs analyzed with IPA. Significantly altered proteins were submitted to an unsupervised analysis of ACTN2hom in relation to ACTN2ic hiPSC-CMs. Fisher's exact test, unadjusted pvalue $<0.05$.

Data Set IV. RNA-seq data of 2D ACTN2hom hiPSC-CMs analyzed with IPA. Significantly altered protein-coding genes were submitted to an unsupervised analysis of ACTN2hom in relation to ACTN2ic hiPSC-CMs. Fisher's exact test, unadjusted $p$-value $<0.05$. 